\title{
EXAMINING THE ENVIROSCHOOLS PROGRAMME WITHIN THE GREATER WELLINGTON REGION: A MIXED METHODS APPROACH
}

Ria Kate Goble

A 120 point thesis submitted to Victoria University of Wellington in partial fulfilment of requirements for the degree of Master of Environmental Studies

School of Geography, Environment and Earth Sciences

Victoria University of Wellington 



\begin{abstract}
This study focused on the Enviroschools organisation, a provider of education for sustainability in Aotearoa New Zealand. This research used a mixed-methods approach, involving seven schools in the Wellington region. Study one incorporated qualitative methods and gained insight into how the Enviroschools programme works in schools through interviewing teachers. Specifically, this study examined: 1) How the Enviroschools programme is implemented in different schools, 2) How action competence (a key component of the Enviroschools programme) is encouraged in students, and 3) Identified the challenges and benefits that teachers faced when implementing the programme.
\end{abstract}

The second study used a quantitative approach and aimed to identify if variables from the Theory of Planned Behaviour could predict children's behaviour intentions. Study two: 1) Explored whether the Theory of Planned Behaviour could predict children's gardening and waste behaviour intentions, 2) Investigated whether environmental concern could explain behaviour intentions, and 3) Explored whether sociodemographic variables helped explain behaviour intentions.

The results of study one highlighted the different ways in which teachers implemented the Enviroschools programme; this varied from being fully integrated throughout their teaching to offering extra-curricular environmental activities. The challenges and benefits included a lack of support, positive impacts on the community, and the influence of school culture.

The quantitative survey $(n=155)$ found that the Theory of Planned Behaviour variables could predict both Living Landscapes and Zero Waste behaviour intentions. However, environmental concern or socio-demographics did not add to explaining behaviour intentions.

These study findings may benefit the Enviroschools organisation and policy makers who want to improve education for sustainability in New Zealand and know which variables to target to increase children's engagement in waste and gardening behaviours. 


\section{Acknowledgements}

This study would not have been possible without the help of the Enviroschools organisation, the schools, teachers and students involved in this research. Thank you for support throughout this research process.

Thank you to Dr. Wokje Abrahamse, for being a wonderful supervisor. I am forever grateful for your guidance, patience, and expertise throughout my thesis, especially with helping me to master SPSS - thank you.

This thesis would not have happened without the love and support from all my friends and family. To Mum and Dad, for fostering in me a strong desire to care for the natural environment, to Andi, for being such an inspiring person, and to Brianna for pushing me to strive for more. To Dacia, thank you for your feedback, for proofreading my thesis and supporting me during this research process. A huge thank you to Sky, for your proofreading skills, support, and humour throughout my research. To Chantal, Joey, Leo, Nicola, Rachel, Bryn, and Alyssa, thank you for challenging me, providing delicious baking and making the past two years bearable.

Last but not least, thank you to my lovely Cameron. Thank you for putting up with my late nights and stress. Your constant love, support, and reassurance got me through the past year and I will forever be grateful. 


\section{Table of Contents}

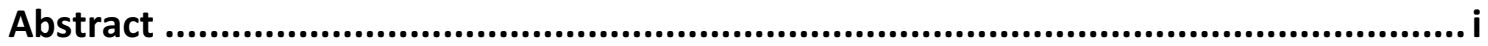

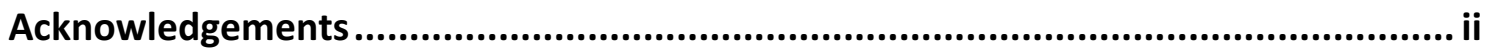

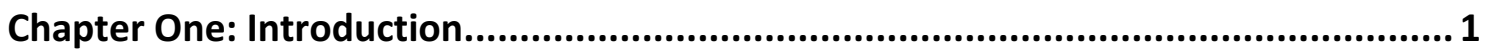

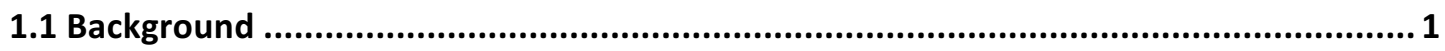

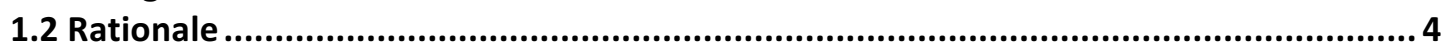

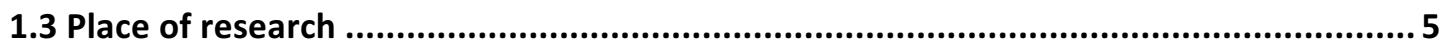

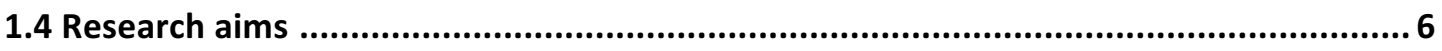

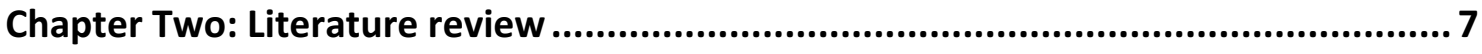

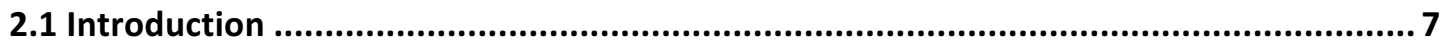

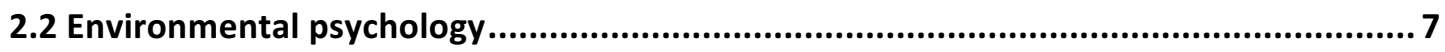

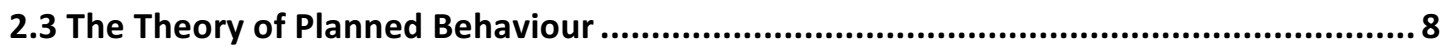

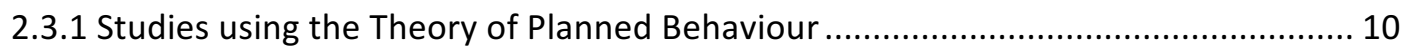

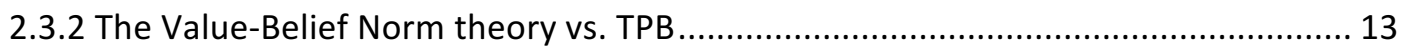

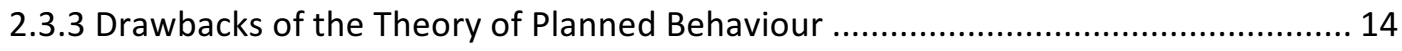

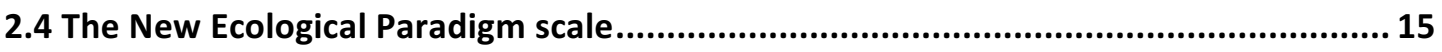

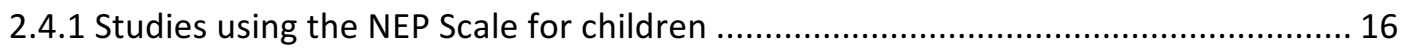

2.5 Environmental Education/ Education for Sustainability ........................................ 19

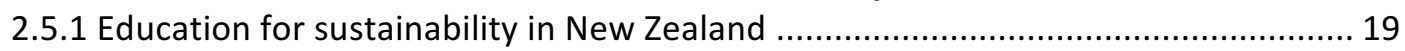

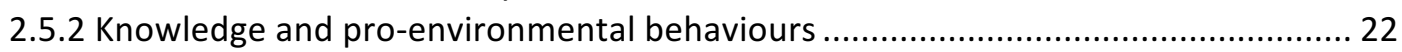

2.5.3 Studies examining knowledge and pro-environmental behaviour ............................. 24

2.6 Action competence in education for sustainability................................................... 28

2.7 Teacher's perceptions of Education for Sustainability ............................................ 29

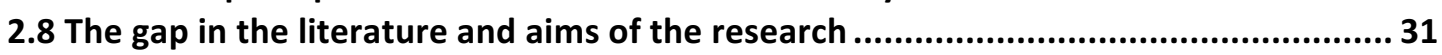

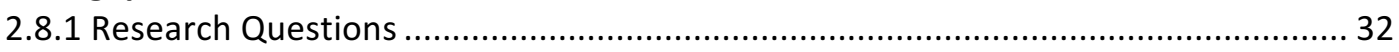

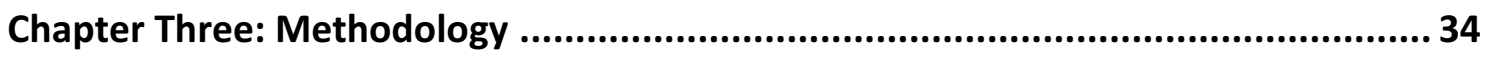

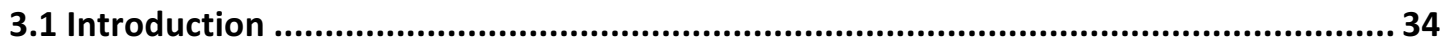

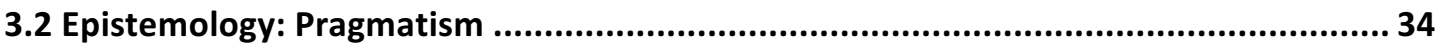

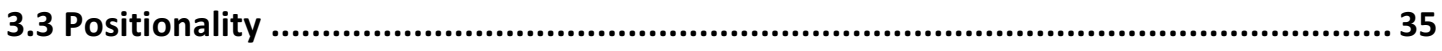

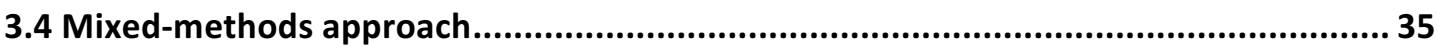

3.5 Study one (qualitative): the implementation and experience of the Enviroschools programme from teachers' perspectives ............................................................................ 36

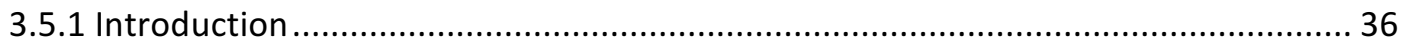

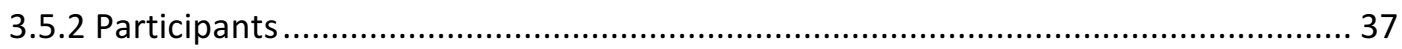

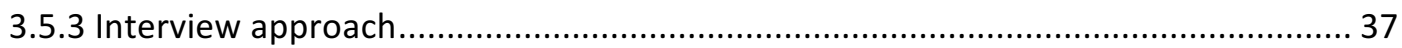

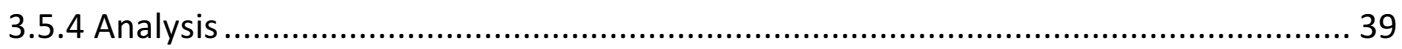

3.6 Study two: Using the TPB, NEP Scale and socio-demographics to explain behaviour intentions in children ........................................................................................................ 41

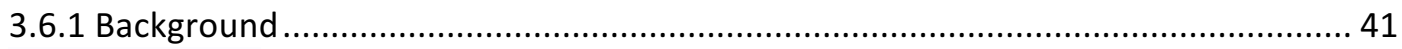

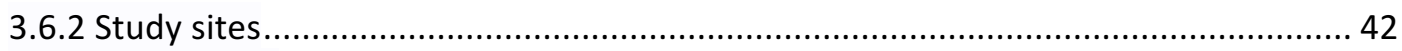

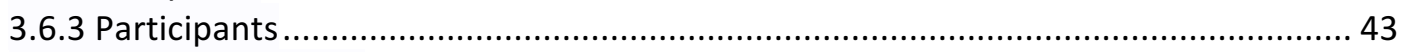

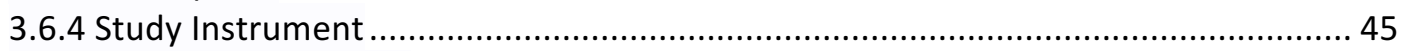

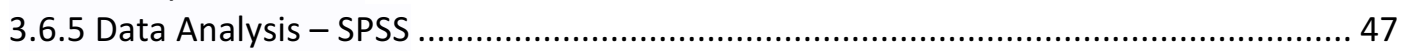

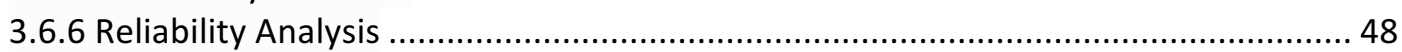

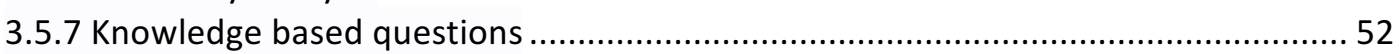

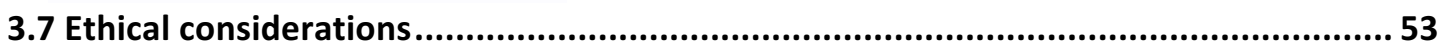

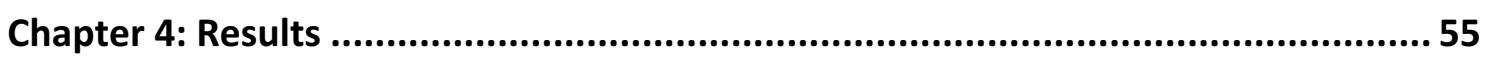




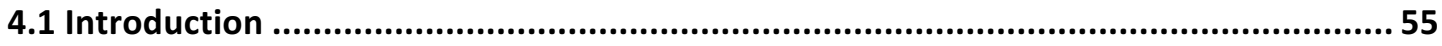

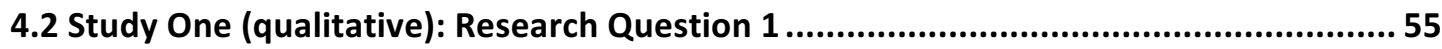

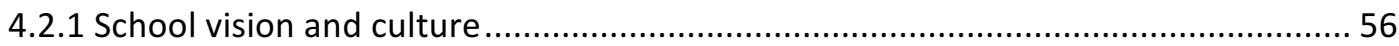

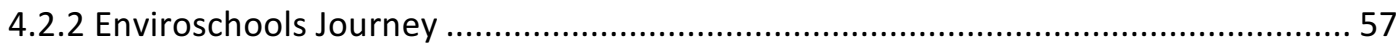

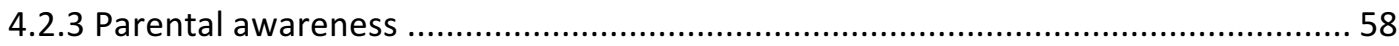

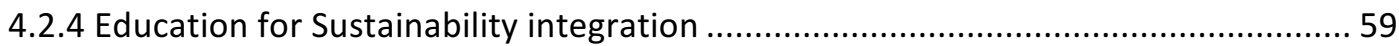

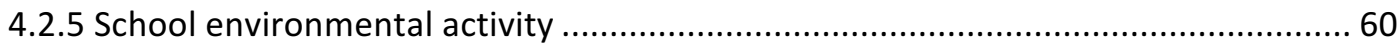

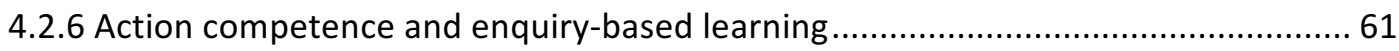

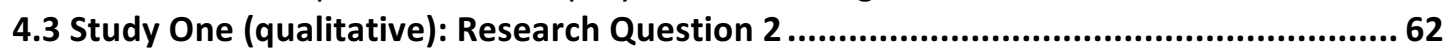

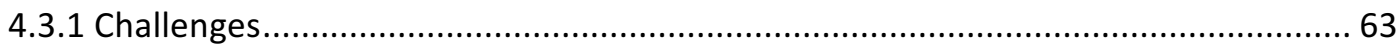

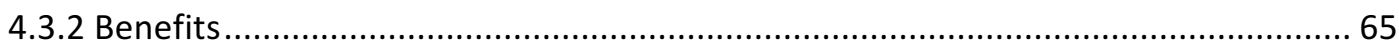

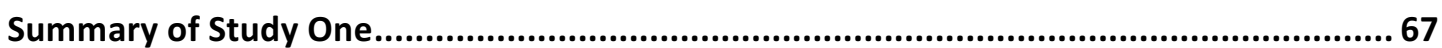

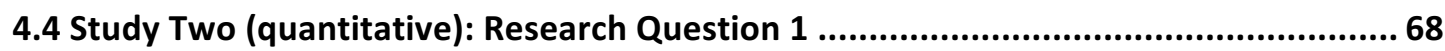

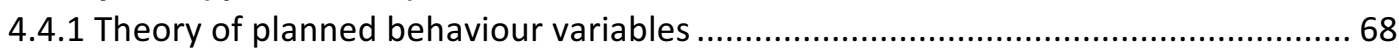

4.4.2 New Ecological Paradigm Scale versus behaviour intentions ................................... 70

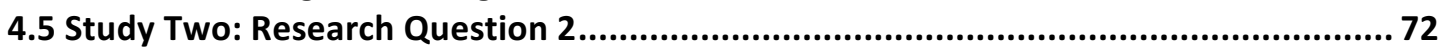

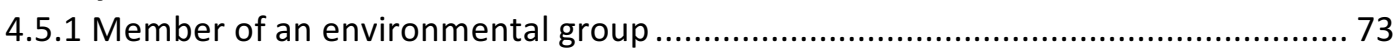

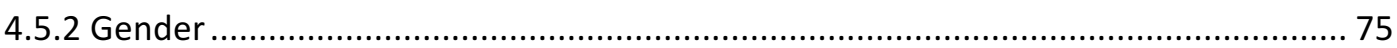

4.5.3 Age

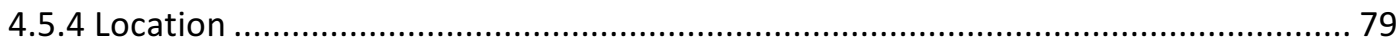

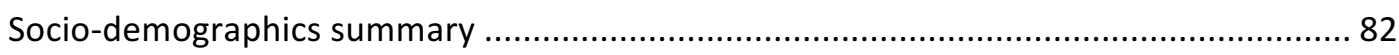

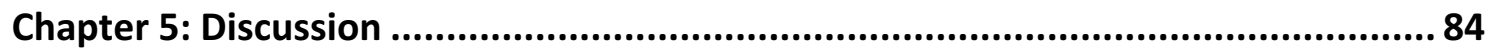

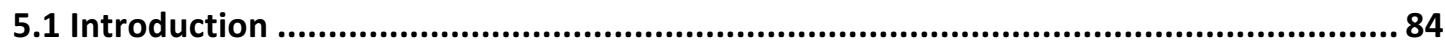

5.2 Study One: Implementation and experience of the Enviroschools programme from

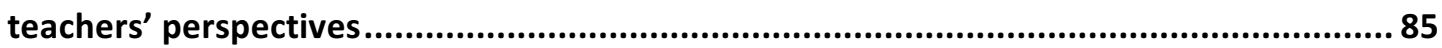

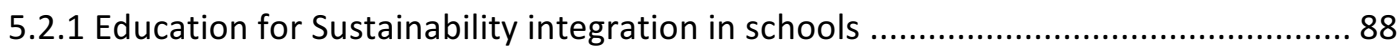

5.3 Study Two: Using the TPB to explain behaviour intentions .......................................92

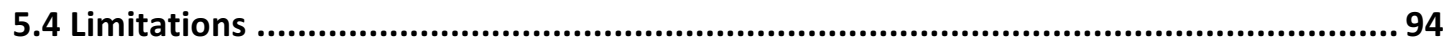

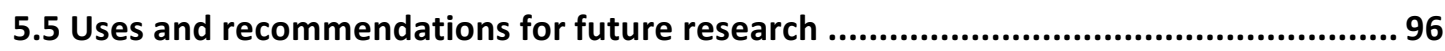

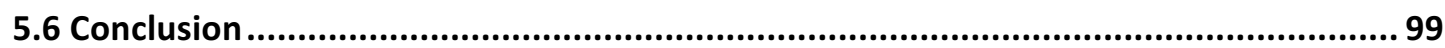

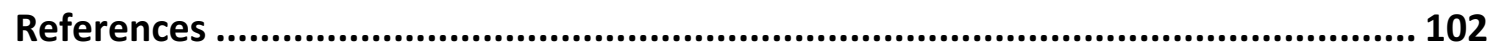

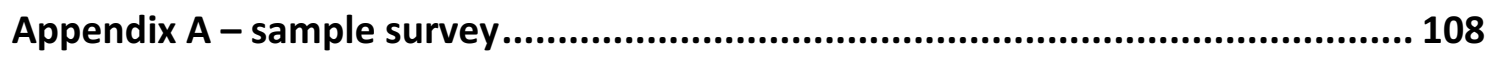

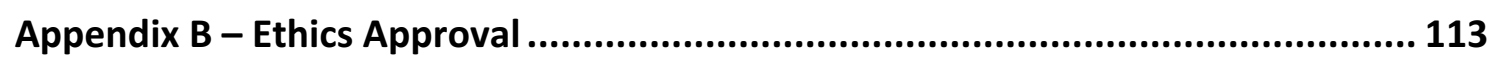

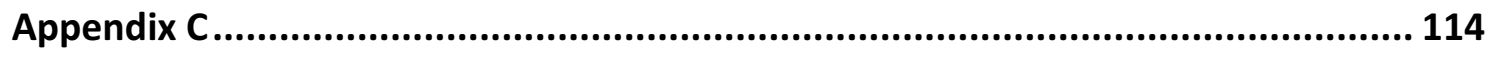

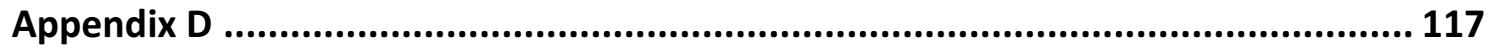




\section{List of Figures}

Figure 1: The Theory of Planned Behaviour

Figure 2: Map of the schools used in the research (Google, 2018)

Figure 3: Mind-map of the key themes and sub-themes relating to Research Question 1

Figure 4: Mind-map of themes relating to RQ1 and RQ2

Figure 5: A comparison of the TPB Living Landscapes variables with members of an environmental group

Figure 6: Comparison of TPB waste variables with members of an Environmental group

Figure 7: Comparison of TPB Living Landscapes variables with gender .......................76

Figure 8: Comparison of the TPB Waste variables with gender ..................................77

Figure 9: Comparison of the TPB Living Landscape variables with age ........................78

Figure 10: Comparison of the TPB Waste variables with age....................................79

Figure 11: Comparison of the TPB Living Landscape variables with location.................81

Figure 12: Comparison of the TPB Waste variables and Location .................................82

\section{List of Tables}

Table 1: The semi-structured questions used to interview lead Enviroschools teachers

Table 2: The six steps for conducting a thematic analysis (table adapted from Braun \&

Clarke (2006:87))

Table 3: Characteristics of the schools involved in the research

Table 4: Socio-demographic characteristics of the study sample

Table 5: Summary of the mean, standard deviation and Cronbach's alpha of the NEP

Scale

Table 6: Mean scores, standard deviations and Cronbach's alpha for TPB waste constructs.

Table 7: Mean and standard deviations for TPB Living Landscapes constructs

Table 8: Responses to the environmental knowledge questions (the correct answers are bolded)

Table 9: The results of a Pearson's correlation and regression test for the TPB with Living Landscapes behaviour intentions....

Table 10: The results of a Pearson's correlation and regression test for the TPB with waste behaviour intentions.

Table 11: Socio-demographics characteristics and Living Landscapes behaviour intentions

Table 12: Socio-demographics characteristics and waste behaviour intentions 


\section{List of Abbreviations}

CHEAKS - Children's Environmental Attitude and Knowledge Scale

DOC - Department of Conservation

$\mathrm{EE}-$ Environmental Education

EfS - Environmental for Sustainability

HiPIC - The Hierarchical Personality Inventory for Children

IPCC - Intergovernmental Panel on Climate Change

MfE - Ministry for the Environment

MOE - Ministry of Education

NEP - New Ecological Paradigm

NGO - Non-governmental organisation

PBC - Perceived Behavioural Control

PCE - Parliamentary Commissioner for the Environment

TPB - Theory of Planned Behaviour

VBN - Value-Belief-Norm theory 


\section{Chapter One: Introduction}

\subsection{Background}

Climate change is an immense and complex environmental issue the negative impacts of which are becoming increasingly evident. Scientists are urging governments around the world to keep rising global temperatures below $2^{\circ} \mathrm{C}$, in order to minimise the adverse effects of climate change (IPCC, 2015). New Zealand is predicted to experience a range of effects, including changes in rainfall patterns and an increase in flooding and heatwaves, some of which have already resulted in economic losses for the country (Reisinger et al., 2014). To keep below this $2^{\circ} \mathrm{C}$ threshold governments and individuals need to take action. Some of solutions proposed include creating more green spaces in urban areas to counter rising temperatures, improving building regulations to avoid infrastructure being affected by floods, and rezoning coastal areas to prepare for the impacts of sea level rise (Reisinger et al., 2014).

The majority of solutions recommended by the Intergovernmental Panel on Climate Change (IPCC) require regulation to be created by local or central government (Reisinger et al., 2014). van Aalst, Cannon, and Burton (2008) highlight a potential issue with adopting IPCC's recommended solutions as climate scenarios provided in the report do not incorporate local climate variation, which will influence how the impacts of climate change on specific regions are predicted. The authors argue that involving the community in the science and decision making surrounding climate change adaptation is much more effective than top-down, government policy approaches. Urwin and Jordan (2008) take a different stance, arguing that neither top-down or bottom-up provide a comprehensive approach to implementing adaptation policies for climate change. They argue that the most successful method is a combination of both approaches so that a range of perspectives can be used to shape and integrate effective climate policy. Despite the differing conclusions, both of these studies emphasise the importance of involving a bottom-up or community lead approach when tackling the impacts of climate change. 
Children play an important part in community-based adaption methods as they often have a better understanding of the science surrounding the causes and implications of climate change gained through education (Reid et al., 2009). The inclusion of children in the climate change decision-making process is important as they face the current and future impacts of climate change. Education is one way children can gain knowledge, further individual awareness, and subsequently increase their pro-environmental behaviours. Education for sustainability (EfS) aims to educate people about the natural environment and the impact that humans have on it, by focusing on the interconnectedness of human equality and quality of the environment (Parliamentary Commissioner for the Environment, 2004; Tilbury, Stevenson, Fien, \& Schreuder, 2002). The process of EfS intends to incorporate social aspects of environmental issues (such as food security through climate change induced poverty) with the processes behind the environmental issues themselves (Tilbury et al., 2002). This form of education can be used to create behaviour change at both individual and community levels, which enables children to contribute to community-based adaptation (Vaughan, Gack, Solorazano, \& Ray, 2003).

In the New Zealand context, EfS is incorporated into the subject of science but is not a compulsory component of the school curriculum, meaning schools are not obligated to teach children about sustainability or environmental issues (Ministry of Education, 2007). This gap in education policy provided an opportunity for a range of independent environmental education programmes to arise. The Enviroschools organisation has been identified in the literature as one of the leading grass-roots organisations in implementing education for sustainability at a community level in New Zealand (Eames, Cowie, \& Bolstad, 2008). Enviroschools is a nationwide programme that provides EfS resources and guidance to early childhood centres, primary schools, and secondary schools (Eames et al., 2008; Eames, Roberts, Cooper, \& Hipkins, 2010). The Enviroschools organisation is governed by the following principles: Sustainable communities, Learning for sustainability, Genuine student participation, Māori perspectives, and Respect for the diversity of people and cultures (Eames et al., 2010). The regional facilitators of the programme provide schools with support and guidance throughout their Enviroschools journey. Schools can choose a number of theme areas to incorporate within their school and Enviroschools facilitators provide the resources 
for the teachers to implement. The themes that are offered are Living Landscapes (promoting gardening and understanding of ecosystems), Zero Waste (reducing waste), Water of Life (developing an understanding of the water cycle), Energy (promoting energy conservation behaviours), and Ecological building (looking at ways to sustainably create structures) (Enviroschools, 2017a).

One of the tools that the Enviroschools organisation emphasises using in the implementation of their programme is the idea of 'action competence', achieved through the action learning cycle (Toimata Foundation, 2017a). The action learning cycle was designed to complement learning that is enquiry-based. There are four different parts of the cycle, with the first being for students to identify the current situation. The second stage is to explore the alternatives to the situation. The third and fourth stages are to take action, and then reflect on the change that was made (Toimata Foundation, 2017a). The present study examines how the action learning cycle/action competence works in practice in schools signed up to the Enviroschools programme.

A 2010 report prepared for the Ministry of Education examined the history of the Enviroschools Foundation and how it aligns with the National Guidelines for Education for Sustainability developed in 2007 (Eames et al., 2010). The report concluded that Enviroschools' five guiding principles closely align with the guidelines that the government set out in the national curriculum, therefore indicating that it is an effective form of EfS (Eames et al., 2010). However, the Enviroschools programme is voluntary for schools to sign up to, thus limiting the accessibility of education for sustainability in New Zealand.

It is important that children are taught EfS in a way that encourages them to take action to protect the environment (Jensen, 2002). A potential issue that EfS faces is that teachers may be targeting the same motivating factors, such as subjective norms (what others are doing), to change behaviours and not tailoring motivators to specific behaviours. One way to identify these motivators is to utilise methods from environmental psychology to determine the effect that education is having on behaviours and/or to examine the key influencers on pro-environmental behaviours. The Theory of Planned Behaviour (TPB) is one theory researchers can use to examine 
how well subjective norms, perceived behavioural control (what people perceive as limiting their behaviour), and attitudes can predict intentions for environmental behaviours (Ajzen, 1991). The present study examines if the TPB can effectively predict the behaviour intentions of children involved in the Enviroschools programme.

\subsection{Rationale}

The New Zealand government appears to be hesitant to promote the importance of EfS through the national curriculum (Ministry of Education, 2007). The findings produced through this study address the gaps in New Zealand literature concerning teachers' perceptions of EfS - specifically the Enviroschools programme and how it can be improved. The study also examines whether the TPB can predict children's behaviour intentions. The rationale behind this study is recognised by two key factors. Firstly, the findings of this research will benefit the Enviroschools organisation by providing information about areas their programme can improve, where they are doing well, and which factors influence children's waste and gardening behaviour intentions. Secondly, this research will help New Zealand education policy makers to understand how teachers perceive the Enviroschools programme, where it could use more support, and how to better shape policy to give teachers more time and resources to spend on EfS.

While the Enviroschools organisation provides schools with a range of resources to incorporate into their teaching, there has been no comprehensive qualitative research looking into how these resources are used when implementing the programme. The Enviroschools programme puts emphasis on helping children to act pro-environmentally through encouraging action competence "and become catalysts for change within their families, and within the wider New Zealand community" (Enviroschools, 2014, p. 1). However, it appears the organisation lacks New Zealand specific references using the TPB to examine which factors to target when addressing children's environmental behaviours.

Additionally, New Zealand education policy makes the assumption that children will adopt pro-environmental behaviours through information provision (Ministry for the Environment, 1998). Few studies demonstrate knowledge directly leading to long-term 
behaviour change (Alp, Ertepinar, Tekkaya, \& Yilmaz, 2006; Boyes \& Stanisstreet, 2012; M. Stern, Powell, \& Ardoin, 2008). However, some researchers argue that teaching students in a way that allows them to take action will encourage them to adopt proenvironmental behaviours (Jensen \& Schnack, 2006). This study aimed to gain insight into this postulation by examining how the Enviroschools programme is taught in schools and whether it encourages children to take independent or collective environmental action.

The quantitative research identifies key factors within the TPB that have the most influence over children's behaviour intentions relating to waste reduction and gardening. Policy makers can incorporate these findings into the curriculum to enable EfS teaching to be tailored in a way that encourages pro-environmental behaviour formulation. The results from this research can be used to support including the community and children in policy decisions relating to environmental issues. From this, the government can see the value that educating children about the environment has on society as a whole.

Overall, this research is expected to contribute to the international literature on the TPB by offering research done with children, using a variable measuring environmental concern, in a New Zealand context. The qualitative research will advance knowledge about how EfS is implemented in practice versus how it is intended to be applied in theory.

\subsection{Place of research}

The Greater Wellington region was chosen as the location for the present study for several reasons. A key factor was the range of schools that are part of the Enviroschools programme in this region, which according the Enviroschools website is 113 earlychildhood, primary and secondary schools (Enviroschools, 2018). The geography of the region also meant that schools were located in a variation of urban and rural areas, which allowed for diversity in participants. This region was also chosen due to its proximity to Victoria University of Wellington. Being close to the study sites allowed the researcher to develop relationships with each of the schools. 


\subsection{Research aims}

The overarching research question for the present study was: what is the role of education for sustainability in New Zealand primary schools, and how can the TPB offer a greater understanding into what motivates waste and gardening behaviour intentions of primary school students?

To answer this overarching research question, the present study aimed to gain insight into how the Enviroschools programme works in schools, by interviewing the lead teacher/s involved in implementing the programme at these schools. The interviews also intended to provide insight into the perceived impact that teachers thought the programme had on their students and any challenges that the teachers faced when implementing the programme. This thesis chose the most popular of the Enviroschools themes, Zero Waste and Living Landscapes, to examine whether the TPB could predict behaviour intentions of children whose schools who had signed up to the Enviroschools programme. Socio-demographics and environmental concern were also measured against behaviour intentions to identify any relationships between the variables. 


\section{Chapter Two: Literature review}

\subsection{Introduction}

This chapter focuses on literature surrounding environmental psychology and education for sustainability. Studies looking at how the Theory of Planned Behaviour is portrayed in literature are examined, with particular reference to the use of the theory with children. The New Ecological Paradigm scale is then examined as a potential variable for measuring environmental concern in children. The analysis then examines the history of EfS and how it has been used in a New Zealand context, as well as the relationship between knowledge and pro-environmental behaviour. Lastly, this chapter explores studies looking at teacher's perceptions of teaching EfS. The gap in the literature is then explained along with aims of the research and the subsequent research questions.

\subsection{Environmental psychology}

Environmental psychology forms the basis of this study and so it is important to explore how it is portrayed in current literature. The field of environmental psychology is defined as a "discipline that studies the interplay between individuals and their built and natural environment" (Steg, van den Berg, \& de Groot, 2012, p. 2). The history of this field dates back to the 1940s and 50s when psychology first began to focus on the built environment (such as architecture) in the post-war time and looked at ways that these environments could best support their inhabitants (Gifford, 2014; Steg et al., 2012). In the late 1960s, the field of environmental psychology started to grow as people increased their awareness about environmental issues. This led to a push for researchers to study the effect that humans were having on the physical environment and how this affected people's well-being and health (Gifford, 2014; Steg et al., 2012). This research increased in the $21^{\text {st }}$ Century as environmental psychologists began to look at how to reverse environmental impacts through changing people's behaviour and ensuring their well-being or quality of life was not affected (Osbaldiston \& Schott, 2012; Steg et al., 2012). Academics argue that applying an environmental psychology approach to 
research helps provide long-term solutions to environmental issues as it focuses on changing peoples' behaviours to be more pro-environmental (Steg \& Vlek, 2009).

Today, environmental psychology is characterised by four aspects: interactions between humans and the environment, interdisciplinary collaboration, a focus on solving problems, and using a diverse range of methods to carry out research (Steg et al., 2012). The 'interactive approach' looks at how human behaviour is influenced by the environment and vice versa (Steg et al., 2012). Interdisciplinary collaboration refers to how environmental psychology can work with and compliment other disciplines of research such as environmental science. The last two characterisations highlight that environmental psychology is solution driven, and finally, using a range of methods to do this and measure if they are successful (Steg \& Vlek, 2009).

\subsection{The Theory of Planned Behaviour}

To evaluate whether a behaviour change intervention has been successful, the TPB is one of several methods used to analyse the social behaviours of people (Ajzen, 1991). This theory was created as an improvement to the previously used Theory of Reasoned Action by including the variable of 'perceived behaviour control' (Ajzen, 1991; Armitage \& Conner, 2001). Typically, when using the TPB, four different components are measured: 'attitudes', 'subjective norms', 'perceived behavioural control', and 'behaviour intention' (Ajzen, 1991, 2011; Armitage \& Conner, 2001; Bamberg, Ajzen, \& Schmidt, 2003). Figure 1 below illustrates how the TPB variables interlink and lead to behavioural intentions and the subsequent behaviour. 


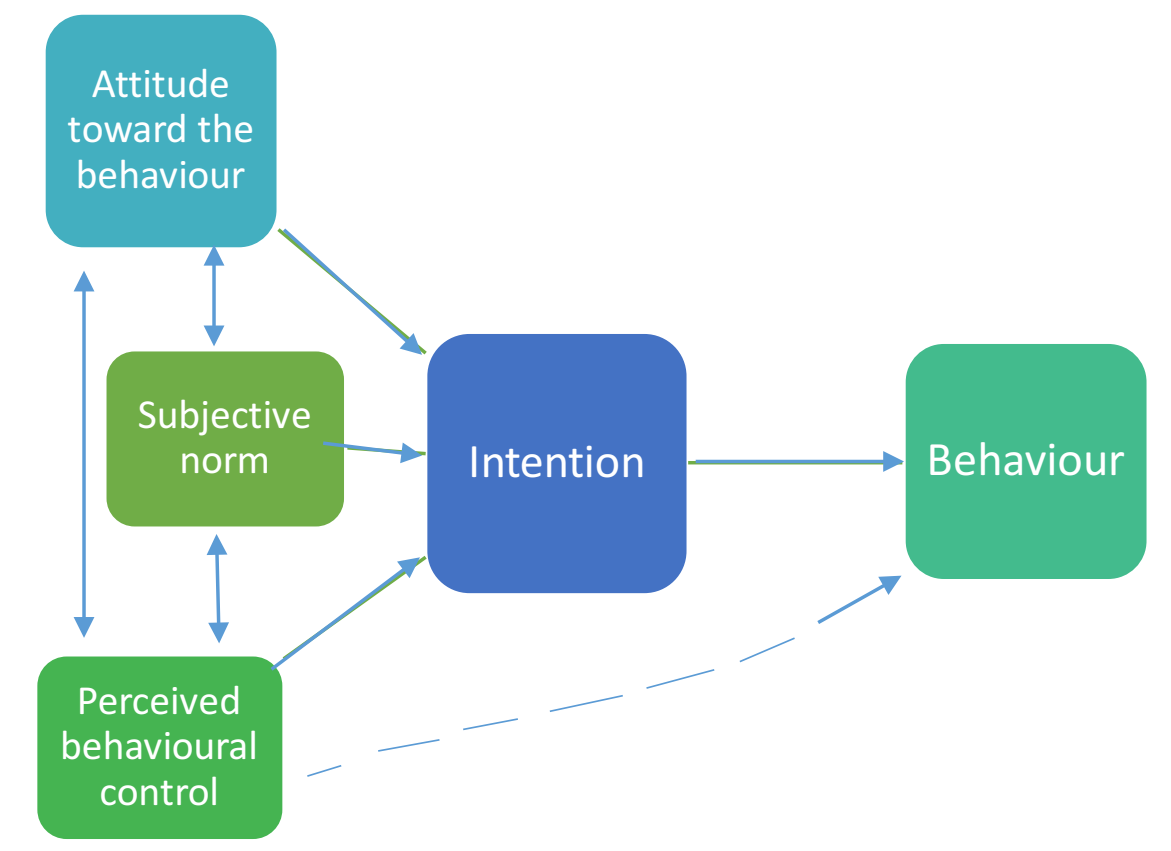

Figure 1: The Theory of Planned Behaviour

Ajzen (1991) explains that the 'attitude toward the behaviour' variable looks at whether a person views the desired behaviour in a positive or negative way. 'Subjective norms' evaluate if a person is influenced by the perception of surrounding social pressures for them to perform a particular behaviour. 'Perceived behavioural control' (PBC) refers to a person's perception of how much control they have over performing a behaviour (i.e. whether it will be easy or difficult to achieve). PBC is one of the key variables in this theory as it can have a strong influence over whether a person actually performs a behaviour. All three of these TPB variables cumulatively influence a person's intention to perform a behaviour, which then influence actual behaviours.

Energy conservation behaviours in adults can be used to illustrate how each of the TPB variables influences behaviour intention. An example of a subjective norm would be for a person to believe that those who are important to them would want them to perform conservations behaviours, such as using a clothes line instead of a dryer (Gotch \& Hall, 2004; Kaiser, Hübner, \& Bogner, 2005). Attitudes towards the behaviour would be measured by seeing if the thought of performing conservation behaviours is viewed positively or negatively. To measure these attitudes a statement such as "Refraining from using a clothes dryer is... (good/bad)" would be used (Kaiser et al., 2005, p. 2155). An example of a perceived behavioural control would be if a person perceives air-drying 
their clothes as not practical due to a lack of space. Lastly, an example of a behaviour intention for conservation behaviour would be for a person to state they intend to avoid using their clothes dryer within the next week.

\subsubsection{Studies using the Theory of Planned Behaviour}

Within the TPB literature there have been some studies using the TPB with children although not all of them had an environmental component. A study done by Murtagh and colleagues (2012), applied the TPB to a group of 126 children in Scotland aged eight and nine years old. The authors examined active travel to school, using the variable of 'habit' to investigate children's routines around taking the bus, the car and walking. The TPB variables (behaviour intention, attitude, perceived behavioural control and subjective norms) were put into a questionnaire format, responded to statements on a four-point Likert scale ( $1=$ strongly disagree, $4=$ strongly agree). The questionnaire addressed the TPB variables using statements for measuring attitudes such as "Walking to school every day would be fun" or perceived behaviour control with "I could walk to school every day if I wanted to" (Murtagh et al., 2012, p. 4). To measure actual behaviour, commuting steps of students were counted using an accelerometer.

The results of Murtagh and colleagues' (2012) study showed that the TPB accounted for $41 \%$ of the variance in the children's intention to walk to school and $10 \%$ of the variance in objectively measured behaviour. When looking at each of the TPB variables, perceived behaviour control independently predicted children's intentions to walk to school. This indicated that children who had felt they had more control over walking to school were more likely to do it. The results also found that children's behaviour intentions could predict their actual behaviour, showing that students with stronger intentions were more likely to use active travel to get to school. Both 'subjective norms' and 'attitudes' were not independent predictors of behaviour intentions but perceived behaviour control was. However, 'perceived behavioural control' did not predict actual behaviour. The researchers noted that a potential reason why 'subjective norms' did not independently predict behaviour intentions was that many children might not have been allowed to walk to school, based on the notion that it would be unsafe. Therefore, even if it were common amongst their peers, they would be unable to walk to school; 
indicating perhaps why perceived behavioural control has a stronger effect. It was also found that habits surrounding walking, catching the bus, and taking the car were stronger predictors of behaviour intention and actual behaviour than the TPB variables.

While some studies evaluate how well the TPB can predict behaviour intentions, there have been studies that use the TPB to measure the effectiveness of an intervention. Gratton, Povey, and Clark-Carter (2007) use the TPB to compare a motivational intervention with a volitional intervention, both of which had the goal of encouraging children to eat more fruit and vegetables. The motivational intervention looked at encouraging students to examine ways they could overcome their lack of motivation to eat fruit and vegetable. The volitional intervention looked at encouraging children's intentions to implement a plan to eat fruit and vegetables. The study consisted of 198 students aged between 11 and 16. Two questionnaires were involved in the research one given before the intervention and one given after. The questionnaire included the four TPB variables, asking questions such as "For me to eat five portions of fruit and vegetables a day for the next seven days would be...very un-pleasant - very pleasant" (scored from one to seven) which is reflective of attitudes towards eating fruit and vegetables (Gratton et al., 2007, p. 643). Students completed a seven-day food diary, which enabled researchers to gauge how many fruit and vegetables were being consumed.

Students were subsequently divided randomly into three different groups and received either the volitional intervention $(N=103)$, the motivational intervention $(N=52)$ or were part of a control group $(N=43)$. Those students in the volitional intervention group were asked to write down their intentions of eating fruit and vegetables for a seven-day period - noting where, when, and how they would be consumed. The motivational intervention group of students were given an activity sheet with information about the benefits of eating fruit and vegetables. It also asked students about their positive and negative beliefs towards eating fruit and vegetables along with stating ways of how their negative beliefs could be overcome. The control group were tasked with writing their intentions for how, when and where they would complete their homework in the next week. 
The results of Gratton, Povey and Clark-Carter's (2007) study showed that both types of intervention were successful in getting children to eat more fruit and vegetables. The volitional intervention had a significant, positive impact on all of the TPB variables except for 'attitudes'. This indicated that planning when and where students would eat their fruit and vegetables did not significantly affect their attitudes towards eating fruit and vegetables. The findings from the motivational intervention were different. This intervention only had a significant impact on the 'attitudes' variable of the TPB, showing that learning about the benefits of eating fruit and vegetables can positively influence attitudes towards the behaviour, but not any of the other TPB variables. Overall, this research shows that different interventions affect different factors of the TPB. If one wanted to influence the attitudes towards eating healthy then it would more effective to use a motivational intervention, but if one wanted to influence any of the other TPB variables then it would be better to use a volitional intervention.

One of the few studies using the TPB with children in New Zealand was conducted by Hewitt and Stephens (2007) with 261 children aged 10 to 13, and their parents using two questionnaires. The first questionnaire was completed by the children and used the TPB to ask them about their behavioural beliefs, attitudes, subjective norms, behaviour intentions, perceived behavioural control, and actual behaviour around healthy eating. The second questionnaire was completed by parents/caregivers and investigated their perceived influence and responsibility over what their child ate, concern about their child's weight, and any restrictions they put in place. The results suggested that children's behaviour intentions could be predicted by their beliefs and attitudes towards the behaviour, their perceived behavioural control, and subjective norms. An interesting finding with the children was the differing results between genders. Girls' attitudes towards healthy eating were more positive than boys, which correlated to girls showing higher intentions to eat healthier as well as higher consumption of healthy food. This study is one of the few that uses the TPB as a framework to examine factors related to food choices of children in New Zealand, therefore similar methods and wording were used in the present study. 


\subsubsection{The Value-Belief Norm theory vs. TPB}

The Value-Belief-Norm (VBN) theory is another theory used to predict proenvironmental behaviour. This model measures five variables believed to influence a person's behaviour: personal values, environmental worldview, awareness of consequences, acknowledgment of responsibility to self-beliefs, and personal norms (Chan, 1996; Kaiser et al., 2005; P. C. Stern, Dietz, Abel, Guagnano, \& Kalof, 1999). Personal values look at how a person acts if their values are under threat (P. C. Stern et al., 1999). To measure a person's view of the environment, the New Ecological Paradigm scale is used (this scale is discussed in more depth later on in the chapter) (P. C. Stern et al., 1999). Awareness of consequences refers to whether a person is aware of the treats that environmental issues have to people and the natural environment (P. C. Stern et al., 1999). Acknowledgement of responsibility to self-beliefs looks at whether a person acknowledges that the actions they take can help reduce the consequences of an environmental condition (P. C. Stern et al., 1999). Lastly the personal norms variable examines whether a person feels obligated to perform a behaviour because of their selfexpectations (P. C. Stern et al., 1999). The VBN theory differs to the TPB due to its inclusion of variables examining a person's altruistic considerations - whether a person acts out of self-interest or not (Kaiser et al., 2005).

A study done by Kaiser et al. (2005) compares the TPB with the VBN model to see which framework best explained conservation behaviour. The study involved 468 students from a German university answering a questionnaire that included the four components of the TPB (subjective norms, attitudes, perceived behavioural control, and behaviour intentions) and four measures from the VBN theory: 'self-ascription of responsibility', 'awareness of consequences', 'personal norms' and 'ecological worldview'. The results of this study showed that when looking at the TPB, 'attitudes', 'subjective norms' and 'perceived behaviour control' accounted for $76 \%$ of the students' behaviour intentions, and explained $95 \%$ of variance in conservation behaviour. In contrast, using the VBN model 'personal norms' were the strongest independent predictor, explaining $64 \%$ of behaviour variance. This shows that the TPB is better at explaining the variance in conservation behaviour than the VBN is. However, the authors do note that their results may have been biased due to participants responding to questions in a way they thought 
would please the researchers. The findings from the study by Kaiser and colleagues (2005) is supported by research by Aguilar-Luzón, García-Martínez, Calvo-Salguero, and Salinas (2012), who compare the VBN model with the TPB in relation to the recycling behaviour of Spanish housewives, and by Lopez-Mosquera and Sanchez (2012) which compares the two models when predicting people's willingness to pay for nature conservation. As the TPB was shown to explain more of the behaviour variance in these studies, this model will be explored further as a measure for the present study.

\subsubsection{Drawbacks of the Theory of Planned Behaviour}

Despite the popular use of the TPB in literature and its effectiveness at explaining variance in behaviour, researchers have reported several drawbacks of using this theory. One of the issues is that most of the TPB studies rely on people self-reporting their behaviour intentions, attitudes, perceived control and subjective norms (Armitage \& Conner, 2001). This suggests that answers may be given in a way that participants think the researchers want and therefore may not be a true representation of their actual behaviours. Examining behaviour intentions is also limiting, as it is not a measure of actual behaviour (Ajzen, 2011). However, the addition of perceived behaviour control into the TPB eliminates some of this risk by looking at factors that will encourage or inhibit a person performing the desired behaviour (Armitage \& Conner, 2001).

Another issue with the TPB is it does not include variables that examine environmental concern or beliefs (Ajzen, 2011; De Groot \& Steg, 2007). If a variable looking at environmental concern were included it would give insight into how this variable influences pro-environmental behaviours (De Groot \& Steg, 2007). However, the creator of the TPB, Icek Ajzen, argues that environmental concern is covered in the TPB through its effect on a person's perception of behavioural control (De Groot \& Steg, 2007). There have been a few studies that use the TPB to examine the relationship between environmental concern and behaviour (De Groot \& Steg, 2007). These studies found that environmental concern was directly related to attitudes towards a behaviour but there was no direct relationship between environmental concern and behaviour intention (De Groot \& Steg, 2007). Due to the small number of studies looking at environmental concern alongside TPB, the present included a measure of environmental concern in its 
methods, to investigate whether it influences behaviour intentions. Including environmental concern in the TPB allows the research to examine the impact that concern has on attitudes, perceived behavioural control, and subjective norms. The present study also applies the TPB to children, as there is a paucity of New Zealand studies using this theory to examine children's behaviour intentions, as shown in section 2.3.1 Studies using the Theory of Planned Behaviour.

\subsection{The New Ecological Paradigm scale}

One way to measure environmental concern is through the New Ecological Paradigm (NEP) scale. This scale was created by Dunlap and colleagues in 1978, and later revised in 2000 (Boeve-de Pauw, Donche, \& Van Petegem, 2011). The NEP scale is used to measure environmental worldviews, placing people on a scale ranging from anthropocentric (a low score) to ecological (a high score) (Manoli, Johnson, \& Dunlap, 2007). Those on the anthropocentric end of the scale believe that "man is central to existence and above nature" (Boeve-de Pauw et al., 2011, p. 110). Those on the ecological end of the scale take the position of man being a part of nature (Boeve-de Pauw et al., 2011). The key idea behind the creation of the NEP scale was that nature's value beyond human use was being compromised by modern society's processes such as the exploitation of fossil fuels (Manoli et al., 2007).

The original scale consists of 15 statements and is one of the most popular methods used to measure environmental concern (Hawcroft \& Milfont, 2010; Manoli et al., 2007). Within the 15 questions, there are five different dimensions, the first being limits to growth', the idea that human society can only grow to a certain point before reaching capacity. The second dimension is 'anti-anthropocentrism', a concept against the idea that "nature exists primarily for human use and has no inherent value of its own" (Dunlap, Van Liere, Mertig, \& Jones, 2000, p. 431). The third dimension is the 'fragility of nature's balance', the idea that the balance of nature can be easily upset by human activities (Dunlap et al., 2000). The fourth dimensions is the 'rejection of human exemptionalism', which rejects the idea that humans are exempt from nature and its constraints (Dunlap et al., 2000). Lastly, the fifth dimension is the 'belief in eco-crisis', 
which focuses on the likelihood of an environmental or ecological catastrophe happening, such as global warming (Dunlap et al., 2000; Manoli et al., 2007).

Despite the NEP scale's popularity in environmental research, it was not until 2007 that Manoli and colleagues introduced a version applicable for children, created over a threeyear timeframe. The first stage involved interviewing 30 children about their understanding of the wording of the 15 statements in the NEP scale (Manoli et al., 2007). A pilot study was then completed using the revised 15 statements on 54 children in the fifth-grade. In the second year, Manoli and colleagues surveyed 672 students in the fourth, fifth and sixth grade (aged 9-12), and included a 'do not understand' option to the statements in order to stop children answering randomly if they did not understand what the statement was saying. The statements answered with 'do not understand' were removed from the scale, reducing it to 10 items. This revised scale included three questions about the rights of nature, four questions on the eco-crisis and three questions about human exemptionalism (the idea that humans are exempt from the laws of nature). Manoli and colleagues (2007) concluded that their adapted, 10 item NEP scale could be used with children aged 10-12 years old. However, they noted that their scale needed to be tested with children from differing backgrounds and locations in order to make it more reliable (Manoli et al., 2007).

\subsubsection{Studies using the NEP Scale for children}

Since the NEP scale for children was formed, several researchers have tested its validity with children across the world. A study done in Spain examines whether the inclusion of an Environmental Education (EE) programme in various summer camps impacts on children's attitudes and behaviours towards the environment (Collado, Staats, \& Corraliza, 2013). A total of 397 children going on different summer camps in Spain completed a survey before they went and filled in another survey after the camps had finished. One of the variables in the survey was children's environmental concerns, which was measured by the NEP Scale for Children. Four different summer camps were examined, the first was a Catholic camp for girls based in a natural area with no EE activities, and the second was the same except for boys. The third was an outdoors camp for boys and girls that included EE activities, such as being taught how to recycle at 
home, and how to conserve water and energy. The last was a camp based in an urban area for boys and girls and had no EE activities included in the programme. The results showed that being exposed to nature and the outdoors through the summer camps allowed children to develop a connection towards nature and increased their ecological beliefs. The researchers also found that exposure to nature through the camp promoted ecological beliefs found in the NEP, although this was not influenced by whether EE activities had been included in the camp.

A qualitative study performed in the Netherlands used the NEP scale for children with 59 students aged 10 to 12 (Kopnina, 2011). Kopnina (2011) used focus groups to see how well the students understood the 10 items in the scale created by Manoli and colleagues. The issues that arose from the focus groups were the contested definitions of words such as 'modern lifestyle' and 'nature'. The author concludes that how children score on the NEP scale (whether they are anthropogenic or ecological) can depend on a person's background and culture. For example, a child's parents may have a strong influence over how they perceive items in the NEP scale. For example, students may have different ideas about what a modern lifestyle looks like, depending on what they have been taught or what they have seen through the media. One way to avoid this is to include factors that look at the influence others have on a child's worldviews (Kopnina, 2011). Using the TPB can help to overcome this as it looks at how behaviour intentions are influenced by others such as children's peers, families, and teachers.

A study done in Belgium by Boeve-de Pauw et al. (2011) explored the relationship between the environmental worldviews and personality traits of 957 adolescents, aged between 14 and 16. The authors used a version of the NEP Scale for children consisting of 15 items, based on one of the models proposed by Manoli and colleagues in 2005 (before they produced their revised 2007 scale). This scale contained eight items examining children's ecological views, and seven items that looked at children's anthropocentric worldviews. To measure the five main personalities of the children (extraversion, benevolence, conscientiousness, emotional stability, and imagination), the hierarchical personality inventory for children (HiPIC) was used. For the NEP scale, the Cronbach's alpha was $\alpha=0.71$, showing that the items in this scale were reliable. The HiPIC scale also had alpha levels above $\alpha=0.7$ for each of the five personality types 
showing that these variables were also reliable. The results showed that the females within the study had a stronger environmental worldview than males did. The relationship between environmental worldview and personality showed that those who had the personality types of conscientiousness and benevolence (kindness) displayed a more eco-centric worldview, compared to those adolescents who had dominant and quickly irritated personalities. However, the authors do note that these results should be interpreted with caution as none of the correlations between personality traits and NEP scale were over $\mathrm{p}=0.28$ showing a weak relationship, and personality only accounted for $0.7 \%$ of explained variance in the participants' environmental worldview.

A study done by Karpudewan and Keong (2013), used Manoli and colleague's revised 10 item NEP scale for children to look at environmental concern in Malaysian school children. Their study involved 348 12-year-olds, from four schools in Penang and four in Perak. Each child was asked to what extent they agreed or disagreed with the ten NEP statements, on a scale of 1 (strongly disagree) to 5 (strongly agree). The use of the NEP scale in this context had a reliability of $\alpha=0.66$ using Cronbach's alpha, showing that it was a reliable variable. The mean score for the NEP scale across all children was 3.66 with mean scores of 3.72 and 3.61 for boys and girls respectively, indicating no significant difference between the two groups. This shows that using the five-point scale, students had an ecological worldview, showing concern for the environment. The authors conclude that the children in their study showed high levels of environmental concern, meaning that they would be more likely to be "environmentally responsible citizens" in the future (Karpudewan \& Keong, 2013, p. 5).

These studies show that the NEP Scale has been successfully used with children in a range of settings. When Manoli and colleagues (2007) created the NEP scale for children they noted that the scale needed to be used in different countries and cultures to ensure its validity. By using the NEP scale in the present study, it offers results on how well the scale works with New Zealand children. Using the NEP Scale for children with the Theory of Planned Behaviour in the present study provides the theory with an environmental concern dimension to see if it can predict behaviour intentions. Kopnina's (2011) study also highlights that there needs to be an aspect within the scale that examines the impact that others have on environmental worldview. By using the TPB, the present 
study examines whether there is a relationship between subjective norms and environmental worldview. Boeve-de Pauw et al. (2011) conclude that personality does not significantly contribute to explaining children's environmental worldview, which suggests that other factors better explained the variance. The present study attempts to fill this gap by examining whether the TPB variables can explain the variance in the NEP scale for children.

\subsection{Environmental Education/ Education for Sustainability}

Evans and Gill (1996) describe environmental education as a way of learning that offers a "long term solution to environmental problems" (Evans \& Gill, 1996, p. 1). 'Environmental education' was a popular term used in education until the 1970's when it was replaced with the term 'Education for Sustainability' (EfS) (Parliamentary Commissioner for the Environment, 2004). EfS was argued to be more encompassing of issues, as it focussed more on how humans impact the environment as well as teaching individuals about issues such as human rights and social justice (Parliamentary Commissioner for the Environment, 2004; Tilbury et al., 2002). EfS can be taught in a number of ways, including having lessons in the outdoors, getting students to complete independent research about an environmental issue, or through experiences such as nature camps (Kemmis \& Mutton, 2012). Education has often been used as a way to increase people's awareness about environmental issues and how to solve them (Rickinson, 2001).

\subsubsection{Education for sustainability in New Zealand}

To date, EfS has not had a large role in New Zealand's education system. In 1998, the Ministry for the Environment (MfE) released a national strategy for environmental education (Ministry for the Environment, 1998). This document provided an overview of what EfS means in New Zealand, the Government's interests in promoting environmental education, their actions and priorities surrounding environmental education, and the roles that other organisations have, such as local government. The implementation of this strategy was guided by five objectives: raising awareness, 
participation, changing attitudes/values, knowledge, and skills. The strategy highlights how to link EfS together with the formal education programme. It is argued that promoting learning about the environment in schools will help children to solve environmental problems and manage resources sustainably in the future. Through the promotion of environmental education, MfE aimed to provide New Zealanders with "the knowledge, skills, attitudes and values that result in sound environmental behaviour" (Ministry for the Environment, 1998, p. 15). The strategy also emphasised that providing people with environmental knowledge based on research will help people to understand environmental policies and how they are implemented.

The Parliamentary Commissioner for the Environment (PCE) evaluated environmental education in New Zealand in the years leading up to 2004. The report entitled, See Change: Learning and education for sustainability, explores what was happening with EfS during the time it was being written (Parliamentary Commissioner for the Environment, 2004). The report notes that education in schools relating to sustainability, "has had a slow and rocky start within New Zealand" (Parliamentary Commissioner for the Environment, 2004, p. 73). In the period prior to 2004 EfS remained a non-mandatory part of the curriculum, receiving less support than compulsory learning areas, therefore relying on enthusiastic teachers to incorporate sustainability into their teaching. Another concern the report highlights is that EfS often fails to makes connections between the environment and issues relating to society, the economy, and culture. This is an issue because the environment should be viewed as a holistic system linking with every part of society, rather than in isolation.

After exploring the role of EfS in New Zealand, the report makes a number of recommendations for improvement. In terms of the central government, the PCE recommended promoting education relating to sustainability and the environment to foster New Zealand's sustainable development (Parliamentary Commissioner for the Environment, 2004). In primary and secondary schools, the PCE recommended that children should not only address solutions to environmental problems, such as recycling, but also be taught about the root causes for these problems (Parliamentary Commissioner for the Environment, 2004). The PCE also highlights the importance of supporting EfS initiatives, such as Enviroschools (an organisation explained in the 
introduction chapter) or Sustainable Coastlines, so that teachers can adequately implement this form of education in their schools.

The 2004 report was reviewed by the PCE in 2007 to see if any of the recommendations to the Government had been implemented. Making EfS "a priority at central government level", had been "partly accepted and implemented" (Parliamentary Commissioner for the Environment, 2007, p. 7). The 2007 evaluation mentions how sustainability and environmental outcomes were included in the statements of intent for the Ministry for the Environment (MFE), Department of Conservation (DOC), and Ministry of Education (MOE). Education initiatives were suggested as a way of meeting these objectives. An example of progress is shown through "better coordination of funding and resource effort for Education for Sustainability" which was attained by the Enviroschools Foundation as well as other committees (Parliamentary Commissioner for the Environment, 2004, p. 13).

In terms of primary and secondary schools, the Government had acknowledged that there needed to be a stronger presence of EfS, but by 2007 no action had been taken to implement this (Parliamentary Commissioner for the Environment, 2007). At the time the evaluation report was written, the final version of the New Zealand Curriculum was still being drafted and came out later the same year making it difficult for the PCE to evaluate how the government had included EfS (Ministry of Education, 2007; Parliamentary Commissioner for the Environment, 2007). Another action area for primary and secondary schools was to provide the Enviroschools Foundation with more support (Parliamentary Commissioner for the Environment, 2007). This action was accepted and implemented. In the period 2006-2010, $\$ 4.26$ million dollars was allocated to the Enviroschools Foundation to provide services that would support and offer development to teachers involved in EfS (Parliamentary Commissioner for the Environment, 2007). The MOE and Enviroschools agreed on a number of objectives which included incorporating conservation, biodiversity, and Māori cultural perspectives into their framework (Parliamentary Commissioner for the Environment, 2007). 
The MOE released the revised version of the New Zealand Curriculum in 2007 (Ministry of Education, 2007). Within this curriculum one of the core values was for young people to use their knowledge to create a sustainable future for their society, culture, economy, and environment (Ministry of Education, 2007). The curriculum also placed emphasis on encouraging students to value ecological sustainability and the natural environment (Ministry of Education, 2007). The environment and/or sustainability are mentioned in the subjects of science and social sciences. However, science is only a compulsory subject until year 10, with the topic 'Nature of Science' being the only strand that is required to be taught (Ministry of Education, 2007). Nature of Science is a broad topic that encompasses the basics of science, including how scientific investigations are carried out, and how to communicate scientific knowledge to everyday people. The other strands that can be incorporated into the Nature of Science include: the Living World, Planet Earth and Beyond, the Physical World, and the Material World (Ministry of Education, 2007). The subject of science should include these four strands somewhere between the years 1 to 10 . However, EfS is not emphasised in this topic and is stated as an option that schools can adopt for pupils in years 11 to 13 but is not required for those in primary school education (Ministry of Education, 2007). The New Zealand curriculum is an example of a missed opportunity to use a top-down approach to make EfS compulsory in schools and therefore encourage climate change adaptation.

\subsubsection{Knowledge and pro-environmental behaviours}

To create a societal change, environmental psychologists acknowledge the need to first understand and then change people's motivations and thoughts about behaviours benefiting the environment. Environmental psychology is widely used to promote and understand people's pro-environmental behaviours, which are defined as "behaviour that consciously seeks to minimise the negative impact of one's actions on the natural and built world" (Kollmuss \& Agyeman, 2002, p. 240; Steg \& Vlek, 2009). Research looking at the various strategies used to promote pro-environmental behaviour has concluded that people's behaviours can be changed through various techniques (Schultz, 2014). Some techniques work better than others, such as using prompts to remind people to perform the desired behaviours (Schultz, 2014). However, the results 
can vary and are not uniform across behaviour changing techniques showing that methods should be tailored to the target group or individual.

Schultz (2014) argues that the behavioural change tool used should depend on the person's perceived barriers and benefits to adopting the behaviour. He defines benefits as a "person's beliefs about the positive outcomes associated with the behaviour" and barriers as "anything that reduces the probability of engaging in the target behaviour" (Schultz, 2014, p. 109). Schultz argues that education, as a tool to create proenvironmental behaviours should be used in a situation when there are high benefits and low barriers. When using education to change behaviour, a person must already be motivated to make those changes and the behaviour must have low barriers for people to be able to perform it (Schultz, 2014). These barriers can be linked to 'perceived behavioural control' as this is what people see as limiting them from performing a behaviour. For example, a study by Townrow, Laurence, Blythe, Long, and Harré (2016) examined the potential for litter reduction in a school, encouraged through an incentive of taking money from a donation to a conservation fund for an endangered dolphin species for every piece of litter picked up. A perceived benefit of this behaviour for the students was the potential to save rubbish from going into the ocean and harming these dolphins, as well as the money saved from picking up litter. A perceived barrier would be the effort involved for the students to find and pick the rubbish. In this example, the benefits could be seen as outweighing the barriers, meaning that students were more likely to perform the behaviour. Therefore, information provision was an appropriate behaviour modifying technique to use in this context.

Despite this advice, increasing a person's knowledge about environmental issues remains a popular method of attempting to create behaviour change. Most information campaigns are based on the idea that environmental knowledge will lead to increased environmental awareness, resulting in pro-environmental behaviour (Kollmuss \& Agyeman, 2002). Several environmental non-governmental organisations (NGOs) and government departments rely on the assumption that an increase in knowledge will have a direct impact on a person's behaviour (Kollmuss \& Agyeman, 2002). However, this is not always the case and this supposed gap between awareness and behaviour has been explained by several reasons (Alp et al., 2006). One of these is the difference 
between direct and indirect experiences of knowledge on behaviour. It is argued direct experiences in the environment that reinforce knowledge are more likely to lead to people adopting pro-environmental behaviours (Kollmuss \& Agyeman, 2002). Jensen (2002) offers support for this reason by arguing that the environmental knowledge traditionally taught in schools is not action oriented. This means the knowledge is not taught in a way that actively involves students or that makes it relevant to their lives or school. One way to overcome this is to use an action-oriented approach to teaching EfS, which is discussed later in this chapter.

Another factor influencing behaviour change is the effect of others. Gifford (2014) argues that social norms can have a large influence over people's behaviours. For example, if a child sees their parents recycling then they are more likely to do so themselves when they are older as it would have become a habit (Gifford, 2014). Researchers argue that a person's culture, religion and family traditions can influence their attitudes and subsequent environmental behaviours (Gifford \& Nilsson, 2014; Kollmuss \& Agyeman, 2002). Some cultures may place more emphasis on the importance of caring for the environment than others do, meaning that people may be acting pro-environmentally because of their religious beliefs rather than out of respect for the environment (Kollmuss \& Agyeman, 2002).

\subsubsection{Studies examining knowledge and pro-environmental behaviour}

Studies looking at the relationship between knowledge provision and proenvironmental behaviours have shown mixed results. Rickinson (2001) conducted a meta-analysis, examining the evidence that studies found in relation to environmental education for young people. When looking at students' environmental behaviours he concluded that the studies highlighted three main points. The first was that after receiving education, students reported performing pro-environmental behaviours. However, he does note that most of the studies measured behaviour by self-reporting, meaning that the results may not reflect actual behaviour. The second point Rickinson concluded, was that students were more likely to perform behaviours that did not require a lot of effort, rather than ones that did. He gave an example of students being more likely to practise conservation behaviours such as turning off lights when they 
leave a room, rather than reducing the amount of waste they produce by not purchasing products containing a lot of packaging. The last point Rickinson highlights is that a range of factors influenced the behaviours of students. He notes that one of the main influencers was a child's schooling. The studies he reviewed showed that those children who knew or learned a lot about the environment through their schools, were more likely to engage in pro-environmental behaviours such as recycling, highlighting the importance of having education about the environment in schools. Therefore, the present study focuses on two different behaviours taught through the Enviroschools programme, waste reduction and gardening, as waste behaviours may be seen as being easier to perform than gardening.

An earlier meta-analysis done by Zelezny (1999) compares studies published from 1971 to 1996 to examine whether educational interventions are more effective at changing environmental behaviours when done in a traditional classroom setting or in nontraditional settings, such as children being taught while on a camp. Zelezny's analysis found that all interventions done in a classroom reported an improvement in children's pro-environmental behaviours, compared to $44 \%$ in the non-traditional settings, showing that interventions were more effective when done in a classroom. She summarises these relationships by stating that interventions in the form of education, can change environmental behaviours. Zelezny indicated that non-traditional settings were less effective than the classroom because they often had adults participating and were short-term programmes, compared to those in a school setting. Zelezny concludes that education may change behaviours in children but not adults because children were more influenced by the interventions, allowing them to easily adopt pro-environmental behaviours. However, the author does note that the studies she reviewed were not all of the same quality, with some using self-reported behaviours instead of measuring actual behaviour, which may have influenced the consistency of the findings.

As shown by both of the meta-analyses mentioned above, there have been a number of overseas studies examining the relationship between knowledge provision and proenvironmental behaviours in young people. Looking at these studies in more detail, it is clear that researchers arrive at a range of conclusions about the effectiveness of using knowledge to change behaviours. A study by Alp et al. (2006) with 1,977 school children 
in Turkey, ranging from age 11 to 17 , examined the relationship between knowledge and behaviour. The authors used the Children's Environmental Attitude and Knowledge Scale (CHEAKS) (Leeming \& Dwyer, 1995) to measure environmental knowledge and a subscale of the CHEAKS model to measure attitudes, behaviour intentions and selfreported behaviours across the age groups, after they had received education about the environment. Their results indicated that environmental knowledge increased with age but attitudes towards the environment declined with age. It was also found that a combination of knowledge, age, and gender explained 7\% of variance in children's behaviour intentions. The authors concluded that behaviours could be predicted by intentions, gender, and age showing that through behaviour intentions, knowledge has an indirect impact on pro-environmental behaviour.

Based on the results of Alp et al. (2006) study, it is clear that there are a range of other factors influencing behaviour when looking at information provision. Difference in location is one of these factors and is examined in the study by Barraza and Walford (2002). Their study compares environmental education in Mexican and English primary schools, looking at the difference in environmental knowledge, attitudes and perceptions of environmental issues in children. The results suggested that both British and Mexican children showed high levels of environmental concern. The children from the two countries differed in their understanding of environmental terms, such as 'pollution' and 'ozone layer'. Overall, it was shown that children from England were more familiar with the environmental terms than the children from Mexico.

The authors also noted a difference in the way the children were taught about the environment in the two countries. In Mexico, most of the teachers used a top-down approach to teaching about the environment, where their lessons were based in the classroom and used a textbook. This differed to teachers in England, who incorporated practical activities into their teaching and the learning was more directed by students. The authors conclude their study by highlighting the impact that location has on children's attitudes and perceptions of environmental issues. For instance, the Mexican children in the study showed a greater fear of snakes and spiders than the English children did. The authors thought this might have been because the diversity of animals found in Mexico meant they were perceived with more danger. Where a child is from 
and their background will influence what they know and how they perceive environmental issues. The present study looks at the influence of location on a smaller scale by comparing the TPB variables of students who live in rural areas with those who live in a city or town.

A study done by Chan (1996), examines the relationship between attitudes towards the environment and pro-environmental behaviours amongst 992 high school students in Hong Kong. The students in the study were given a questionnaire that measured attitude, behaviour intentions and where they received most of their information about the environment. The survey had an internal reliability of $\alpha=0.80$, showing that the variables used were reliable. The study found that the students held positive attitudes towards the environment, which correlated to a strong, positive relationship with willingness to participate in pro-environmental behaviours. The media and school were the main sources of environmental knowledge, showing the influence that schools can have when providing their students with environmental education. When looking at the influence of socio-demographic factors on behaviours, Chan noted that female students were more likely to have positive environmental attitudes and therefore were more willing to act to protect the environment.

Studies have also been completed looking at the influence that children have on their parents and teachers because of receiving EfS. A study done by Grodzinska-Jurczak, Bartosiewicz, Twardowska, and Ballantyne (2003) examined how a solid waste education programme designed for primary school students indirectly impacted on teachers and parents. Their study involved 284 Polish primary school students aged from 11 to 13 , using a survey that examined their knowledge, attitudes and behavioural intentions before and after the education programme. The teachers and parents of these children also took a survey after the programme was completed. The results found that the students showed an increase in knowledge about waste after the programme had finished. Parents reported that their children would often talk about the issues that they had been learning about at home and would suggest changes that they could make at home. Despite this, the researchers found no evidence to link the increase in knowledge with changes in behaviour at home, showing that there was no clear relationship between education provision and behaviour change. 


\subsection{Action competence in education for sustainability}

Action competence has become a large part of contemporary EfS. Action competence is defined as a type of education which "involves the capacity to analyse society and everyday life critically in order to understand the sources of environmental problems, and to find and work for solutions to problems at both the individual and societal level" (Chawla \& Cushing, 2007, p. 447). Jensen and Schnack (2006) argue that promoting action competence in environmental education is vital to create behaviour change. The term 'action' differs from 'behaviour' because it relies on a person acting intentionally and not on what others are doing (Jensen \& Schnack, 2006). Behaviours are argued to be influenced by peer pressure and/or the media and are not reliant on a person making a conscious decision whereas action competence does (Chan, 1996; Jensen \& Schnack, 2006). The concept of action competence has become important in environmental education for several reasons. Firstly, traditional environmental education has had a dominant focus on the science behind environmental problems and is not linked back to the impact on people or society (Jensen \& Schnack, 2006). Incorporating action competence into education aims to change this by encouraging students to think about the causes and effects of environmental issues. Another key reason for focusing on action competence is the lack of behaviour change that results from traditional behaviour-modifying teaching. Jensen and Schnack (2006) note that the traditional (non-action competence) education system lacks practical aspects within environmental education in schools and criticise that the simulations teachers use in their EfS teaching are not authentic enough.

Jensen (2002) puts forward a model that illustrates the different dimensions of actionoriented knowledge. The first dimension addresses knowledge about the effects and extent of environmental issues. The second dimension addresses knowledge about the root causes of existing environmental issues. The third dimension looks at informing students on how they can change situations using a range of strategies. The last dimension is about giving people knowledge about alternative ways of doing things and allowing them to envision a positive future for themselves and their society. Jensen then goes on to argue that traditional education tends to be based around scientific evidence and therefore only covers the first dimension of the model - what the environmental 
problems are. He argues that despite many traditional education activities being handson, and considered by some as 'action taking', they too are oriented around the science and do not address the root causes or offer potential solutions to the environmental problem.

The types of actions that can be taken for the environment come in two different forms: direct and indirect (Jensen \& Schnack, 2006). Direct actions can be defined as "actions which directly contribute to solving the environmental problem that is being worked on" (Jensen \& Schnack, 2006, p. 479). An example of a direct action would be for a child to sort their rubbish into recycling or to take shorter showers in order to conserve water (Jensen \& Schnack, 2006). Indirect actions are defined as "actions whose purpose is to influence others to do something to contribute to solving the environmental problem in question" (Jensen \& Schnack, 2006, p. 479). An example of an indirect action would be for a child to write to a politician regarding an environmental problem. The two types of actions are closely related as indirect actions often lead to direct actions. There is also the argument that collective actions are more effective than private actions (Chawla \& Cushing, 2007). Compared with acting as an individual (private actions), collective competence and action allows young people to feel empowered and that their actions will make a difference (Chawla \& Cushing, 2007). As action competence is one of the key ideas behind the Enviroschools programme, the present research examined the types of action (direct vs. indirect, private vs. collective) teachers were encouraging in their students. Therefore, the concept of 'action competence' was chosen to be included in the present study.

\subsection{Teacher's perceptions of Education for Sustainability}

Several studies were found in the literature that looked at how teachers perceive the EfS that they were teaching to students. A study done by Spiropoulou, Antonakaki, Kontaxaki, and Bouras (2007) used a survey to gain insight into how Greek primary school teachers perceived environmental issues and education about sustainability. 188 teachers were given the questionnaire, which investigated their socio-demographics, their ideas about sustainability, classification of the importance of environmental problems, their attitudes towards sustainable development, and their experience of 
implementing environmental programmes in their schools. The results showed that the primary school teachers often misunderstood the meaning of 'sustainability'. Their definitions of sustainability tended to focus mainly on local environmental issues, and largely ignored issues that had a bigger impact, such as climate change. When asked to differentiate between renewable and non-renewable energy sources, many of the teachers were confused about which sources were renewable. Despite the concern that the teachers felt for environmental problems, they believed that technology would be able to solve a lot of it. They also did not implement programmes about the environment in their schools because they felt uncomfortable about the approaches that were needed to teach them about environmental problems. The authors put this last finding down to the fact that many of these teachers had little knowledge about the environment or how to teach students about it due to not being taught about this topic through their prior studies or training programmes.

An earlier qualitative study done by Robertson and Krugly-Smolska (1997) looked at the beliefs that teachers held about environmental education. The purpose of their study was to see how teachers implemented their school's environmental programmes and if it reflected what the EfS literature suggested doing. The researchers asked the teachers about their beliefs about the environment, whether they thought these beliefs were represented in the environmental programmes they taught, and factors that they thought contributed to their beliefs being incorporated into their programmes. The interviews showed that the main motivators for the teachers to be involved in environmental education was their personal concern for the environment. The interviews also showed that teaching methods did not match what was recommended in the literature surrounding EfS. Teachers noted several reasons why it was difficult to implement environmental programmes in their school. One of these was the lack of resources teachers received in terms of time, support and ability to take students out of their school for field trips. Teachers also felt confused about what they were supposed to be teaching due to the conflicting ideas that came from the resources for EfS.

The teachers in the study by Robertson and Krugly-Smolska (1997) noted that the activities they undertook with the classes were not focused on big environmental issues such as climate change because it was easier for them to tackle smaller issues like 
recycling and composting. They also felt that they were unable to talk about environmental issues that were too controversial, as they did not want to face backlash from their students' parents. The teachers also mentioned that a lot of the teaching that went on in their environmental education programmes relied on students participating willingly. The researchers noted how students' lack of willingness to participate in proenvironmental behaviours was not addressed in the literature surrounding sustainability education. The teachers in the study saw environmental education as a way to change social behaviours, rather than as a science, because none of the teachers considered themselves as being 'science-educated'. The teachers involved in this study also felt that there was insufficient training in environmental education and provision of teaching material, as teachers had to make their own set of resources. Similar issues relating to teachers' lack of time and understanding of topics when teaching about sustainable development was found in a study by Summers, Corney, and Childs (2003). The researchers conclude their study by stating the need to fill the gap between education theory and what is occurring in schools (Robertson \& Krugly-Smolska, 1997; Summers et al., 2003). The present study attempts to fill this gap by comparing the concept of action competence emphasised in the Enviroschools programme with what was happening in the classroom.

\subsection{The gap in the literature and aims of the research}

Based on the evidence found throughout this literature review, there is a lack of research looking into EfS programmes and the subsequent behaviour intentions of children in New Zealand. The Enviroschools organisation was identified as being one of the key providers of EfS in New Zealand and therefore the present research examined this organisation as a case study.

The literature review highlighted a lack of research looking into how teachers viewed the environmental programmes in New Zealand schools, and what they perceived the challenges and benefits to be. In addition, the use of action competence in New Zealand schools has not been examined in detail. To fill this gap, the present study was able to gain insight into how the Enviroschools programme works in schools in the Greater 
Wellington region, by interviewing the lead Enviroschools teacher/s in seven schools. The schools involved in the research were Eastern Hutt School, Paparangi School, Ridgway School, South End School, St Patrick's School, South Featherston School, and Thorndon School. The interviews allowed the researcher to develop an understanding of the impact that teachers thought the programme had on their students and any challenges that the teachers faced when implementing the programme

When looking at the methods applied in previous New Zealand research with children in EfS programmes, none of them had used the TPB. This study therefore applies the TPB to children involved in the Enviroschools programme to see if the variables within the theory can effectively predict behaviour intentions. This study involved the primary schools mentioned above, surveying children to measure the TPB variables. Two behaviours types were looked at - Living Landscapes/gardening and Zero Waste behaviours, as they are both themes of the Enviroschools programme - these are explained in more detail in the methodology chapter.

The combination of quantitative and qualitative methods gave insight into which of the TPB variables should be targeted in relation to encouraging Zero Waste and Living Landscapes behaviours in schools. The interviews were able to give insight into how the programme is being taught in schools and suggest potential areas for improvement.

\subsubsection{Research Questions}

To address the aims of the present study, the following research questions were asked:

Study one (qualitative): The implementation and experience of the Enviroschools programme from teachers' perspectives

1. How is the Enviroschools programme incorporated into participating primary schools in the Wellington region? How is action competence in students encouraged in the Enviroschools programme?

2. What do teachers perceive as the challenges and benefits of the Enviroschools programme? 
Study two (quantitative): Using the TPB, NEP, and socio-demographics to explain behaviour intentions

1. How well can the Theory of Planned Behaviour predict children's behaviour intentions? Can environmental concern add to the explanation of behaviour intentions?

2. How do socio-demographic characteristics affect behaviour intentions and each of the TPB variables? 


\section{Chapter Three: Methodology}

\subsection{Introduction}

This chapter provides an overview of the methods used for each of the studies in this research. To begin, the chapter outlines the epistemology used for the research (pragmatism), the positionality of the researcher and the merits of taking a mixedmethods approach. The methods of the qualitative study are then given, providing information on the recruitment of participants, structure of the interview, and how participants' responses were analysed. The chapter then goes on to discuss the methods used for the quantitative study. This section details the study sites, participant recruitment, the survey used, and how the resulting data was analysed using SPSS. The chapter concludes with outlining the steps taken to ensure that the research complied with the University's ethical guidelines.

\subsection{Epistemology: Pragmatism}

The epistemology used for the present research was pragmatism. Pragmatism is one of the most popular epistemologies used in mixed-methods research because it can be applied to both qualitative and quantitative research, incorporating both theory and observation (Johnson, Onwuegbuzie, \& Turner, 2007; Morgan, 2016). Pragmatism represents both qualitative and quantitative approaches by agreeing that there is both a single 'real' world and that people hold their own views of what the world is like (Morgan, 2016). This epistemology was chosen for the present study due to the ability to apply it to mixed-methods research. The Theory of Planned Behaviour (used as the quantitative aspect of the research) encompasses the pragmatic idea that there is there can be a solid answer to a research question, provided through a statistical analysis. The interviews (the qualitative aspect) used in the present study also take a pragmatic approach as they acknowledge that people may have different experiences of the Enviroschools programme, and these may not match the results of the quantitative survey. 


\subsection{Positionality}

It is impossible for a researcher to be objective in their research due to their views, background and prior knowledge surrounding a topic (Dowling, 2010). A person's positionality can influence the way that questions are framed and are answered (Bourke, 2014). I was aware of my positionality when conducting this research, especially when doing the interviews with teachers, as they were interactions that required personal resources (such as hope and optimism) to communicate with interviewees. Therefore, when forming both the interview and survey questions, I considered the fact that I am an environmentalist, and that both the primary and secondary schools I attended as a child/teenager were part of the Enviroschools programme. These influences may have caused the questions to be worded in a way that encouraged the respondent to answer pro-environmentally, creating experimenter bias. This was mitigated in the survey by using reliable scales and questions that previous researchers had created. The interview questions were worded in an unbiased way that did not encourage the answers to be pro-environmental.

\subsection{Mixed-methods approach}

Mixed methodology is the one of the three most popular methodologies, combining the other two approaches - qualitative and quantitative research (Creswell, 2014; Johnson et al., 2007). One of the key rationales behind this approach is the ability to learn more about the research topic as a whole through the use of different research techniques (Punch, 2013). Independently, qualitative and quantitative research have several strengths and weaknesses, but through combining the two, a researcher can obtain the strengths from both and avoid any weaknesses (Punch, 2013). For example, a mixed methods approach can combine the ability to examine relationships between variables gained through quantitative research, with the ability to develop an understanding of the context and local perceptions of a research topic (Punch, 2013).

Mixed methodology can be one of three types: qualitative mixed, pure mixed or quantitative mixed (Johnson et al., 2007). Qualitative dominant mixed methods have a strong emphasis in qualitative research compared to quantitative, despite both being 
included in the research. Quantitative dominant mixed methods are the opposite, where a person's research is mostly quantitative but the researcher feels that including a qualitative element will add to the research (Johnson et al., 2007). Pure mixed research is when both qualitative and quantitative methods are given equal status in the research process (Johnson et al., 2007).

A mixed methodology was used in the present study to gain a better understanding of the Enviroschools programme as a whole. The research was split into studies, with one being qualitative, and one being quantitative. Study one used qualitative research methods, in the form of interviews, to gain insight into teachers' perceptions of the Enviroschools programme and to provide context for the quantitative survey. Study two used quantitative research methods through the distribution and analysis of questionnaires. This was done to test the effectiveness of the TPB at explaining behaviour intentions, as well as other factors, described later in this chapter. The methods used in this study were pure mixed as the survey and interviews had equal importance in the study.

\subsection{Study one (qualitative): the implementation and experience of the Enviroschools programme from teachers' perspectives}

\subsubsection{Introduction}

Qualitative methods, in the form of semi-structured interviews, were used in this research to give insight into how the Enviroschools programme worked in schools, and how environmental education was integrated throughout the school. From this, the types of activities that each school participated in were able to be examined alongside survey responses for each behaviour (Living Landscapes and Zero Waste). The idea of 'action competence' was also explored in the interviews to see how it was encouraged in students. 
The following research questions were asked:

1. How is the Enviroschools programme incorporated into participating primary schools in the Wellington region? How is action competence in students encouraged in the Enviroschools programme?

2. What do teachers perceive as the challenges and benefits of the Enviroschools programme?

\subsubsection{Participants}

Participants for the interviews were selected based on recommendations from the Enviroschools facilitator for the school or from other teachers at their school. This technique of selecting participants is often referred to as 'snowball sampling' as participants are suggested to the researcher by people who know other people (Bradshaw \& Stratford, 2010). The participants selected were lead Enviroschools teacher/s at each school, resulting in seven interviews (usually one teacher per school). These teachers were recruited via email and a face-to-face interview time was arranged. The interviews were done at the teacher's school, usually in their lunch break or at a time that suited them. Interviews were recorded using an audio recorder, and lasted around 20 minutes. Once finished, a koha (gift) was given to them for their time. All of the interviews were done individually, with the exception of one school where two teachers were being interviewed at the same time. In total, eight teachers from seven schools were interviewed.

\subsubsection{Interview approach}

Semi-structured interviews were chosen so that the topics discussed could be explored to gain a greater understanding of the interviewee's experiences and perceptions (Barriball \& While, 1994; Grossoehme, 2014). Semi-structured interviews allow for the interviewer to have a set of questions that guide the interview but do not restrict them in what they can ask (Dunn, 2010). This approach limits the amount of bias that occurs by having pre-formed questions and also allows for consistency across all interviews (Dunn, 2010). Semi-structured interview questions were used in the present study to enable the conversation to venture into topics that may not have come up otherwise. The interviews used in the present study had questions based around two topics: The 
Enviroschools programme and action competence. The interview questions used are given in Table 1 below.

\section{Table 1: The semi-structured questions used to interview lead Enviroschools teachers}

\section{The Enviroschools programme}

1. How long has your school been involved in the Enviroschools programme?

2. Which of the theme areas has your school adopted? (Living Landscapes, Zero Waste, Water of Life, Energy and Ecological Building, and Sustainability) Tell me about these themes and how they're introduced to students. How do you incorporate these themes into your school and into your teaching? What are some of the challenges of implementing the chosen themes in your school?

3. How do the Enviroschools facilitators support you and your school?

\section{Action competence}

4. The Enviroschools organisation emphasises the idea of using 'action competence' when implementing their programme. What does the term 'action competence' mean to you?

5. Can you think of some examples of how you incorporated action competence into your Enviroschools teaching?

Were the students involved in deciding what to do?

What effect did this have on the students (e.g. did it encourage children to adopt pro-environmental behaviours)?

6. How do you know if/when a child is 'action-competent'?

After the first two interviews were conducted, it became clear that teachers were unsure about the meaning of the term 'action competence', making it difficult for them to answer the questions on the topic. However, they were able to answer some of the questions after a definition of action competence was given to them. This meant that many of the interviews had a stronger focus on the Enviroschools programme and how it was implemented in their school, rather than on action competence. 
The interviews were conducted over a period of three months (August to early November) and were transcribed after each interview. The transcriptions were sent out to participants so that they could comment on any changes they would like to make or anything they wanted to be removed. One participant made a small change and another replied saying that no changes needed to be made to their transcript. The other participants did not respond.

\subsubsection{Analysis}

A thematic analysis was used to examine the interviews. The purpose of this approach was to analyse the interview data for themes and patterns within it (Braun \& Clarke, 2006). A thematic analysis offers a rich description of the data set, giving an extensive overview of what was discussed and the different themes that came up. A theoretical, semantic thematic analysis is most appropriate for this research as this approach argues the themes generated are specific to the research questions and are created on the surface level of what the participant said, rather than reading deeper into what was said (Braun \& Clarke, 2006). According to Braun and Clarke (2006) there are six different phases a researcher should go through when conducting a thematic analysis. These are summarised in Table 2 below. The first steps involve making sure the researcher is familiar with their data and noting down any initial codes. The researcher then puts these codes into groups that form potential themes, which are then revised and defined in preparation for writing up the results. This same process was done with the interviews done with the teachers. The NVivo software was used to assist the collation of data and to establish a coherent map of the themes and how they linked together. 
Table 2: The six steps for conducting a thematic analysis (table adapted from Braun \& Clarke (2006:87))

\begin{tabular}{|c|l|}
\hline Phase & Description of the process \\
\hline 1. Familiarising yourself with your data & $\begin{array}{l}\text { Transcribing data, reading and re-reading } \\
\text { the data, noting down initial ideas. }\end{array}$ \\
\hline 2. Generating initial codes & $\begin{array}{l}\text { Coding interesting features of data across } \\
\text { the data set and collating data relevant to } \\
\text { each code. }\end{array}$ \\
\hline 3. Searching for themes & $\begin{array}{l}\text { Collating codes into potential themes, } \\
\text { gathering data relevant to each potential } \\
\text { theme. }\end{array}$ \\
\hline 4. Reviewing themes & $\begin{array}{l}\text { Checking if the themes work in relation to } \\
\text { the coded extracts and the entire data set, } \\
\text { generating a thematic 'map' of the analysis. }\end{array}$ \\
\hline 6. Producing the report & $\begin{array}{l}\text { Ongoing analysis to refine the specifics of } \\
\text { each theme, generating clear definitions } \\
\text { and names for each theme. }\end{array}$ \\
\hline & $\begin{array}{l}\text { The final opportunity for analysis. Selection } \\
\text { of vivid, compelling extract examples, final } \\
\text { analysis of selected extracts, relating back of } \\
\text { the analysis to the research question and } \\
\text { literature, producing a scholarly report of } \\
\text { the analysis. }\end{array}$ \\
\hline &
\end{tabular}




\subsection{Study two: Using the TPB, NEP Scale and socio-demographics to explain behaviour intentions in children}

Research Questions:

1. How well can the Theory of Planned Behaviour predict children's behaviour intentions? Can environmental concern add to the explanation of behaviour intentions?

2. How do socio-demographic characteristics affect behaviour intentions and each of the TPB variables?

\subsubsection{Background}

As mentioned in the introduction, the Enviroschools Foundation is a not-for-profit education organisation in Aotearoa New Zealand, that aims to tackle environmental issues via children and their communities (Enviroschools, 2017a). The Enviroschools Foundation exists across New Zealand, with new schools regularly being added to their programme (Enviroschools, 2017a). Within the Enviroschools programme, schools can choose to adopt from the following theme areas: Living Landscapes, Zero Waste, Water of Life, Energy and Ecological Building, and Sustainability. Enviroschools facilitators provide schools with the support and resources to implement these themes.

For the purpose of this research, the decision was made to focus on two of the themes: Living Landscapes and Zero Waste. These two themes were chosen for several reasons. In the 2013 Enviroschools and Te Aho Tū Roa Wellington Region Snapshot report (2013), 93\% of the schools involved in the Enviroschools programme in the Wellington region incorporated the Living Landscapes theme into their schools by growing food (fruit and vegetables), and $80 \%$ were using it to increase biodiversity. In terms of Zero Waste, in the same report it was stated that over $93 \%$ of schools were implementing methods to reduce the amount of waste going to landfill (Enviroschools Wellington, 2013). Based on these statistics, Living Landscapes and Zero Waste were the two themes used in the survey as schools were more likely to have adopted them, rather than other themes that had participation rates of around 40\% in 2013 (Enviroschools Wellington, 2013). Choosing these two themes also meant that the survey could be narrowed down to two behaviours, namely waste and gardening (Living Landscapes), allowing the research to 
be more focused and reducing the potential time taken for participants to respond to the survey.

The theme of Living Landscapes focuses on the planting of trees, and fruits and vegetables at schools (Enviroschools, 2017b). The resources provided by Enviroschools aim to give children an understanding of their natural environment and the skills to "assess the health of the landscape and envisage alternative ways that it could be" (Enviroschools, 2017b, p. 140) Schools involved in this theme often planted native trees around their schools and in their local communities (Enviroschools Wellington, 2013).

The Zero Waste theme looks at the issue of waste in schools and in students' homes (Toimata Foundation, 2017b). Resources provided to schools focused on achieving Zero Waste through the introduction of composting, recycling, and moving away from single use items, such as plastic (Toimata Foundation, 2017b). Schools are encouraged to help their students think of the bigger picture when it comes to rubbish, in terms of where it ends up and how it affects the environment. There are a number of activities that teachers can choose from to use with their students, such as doing a waste audit or looking at where their waste end up (Toimata Foundation, 2017b).

\subsubsection{Study sites}

The Wellington region was chosen as the study location due to its proximity to Victoria University, the ability to compare a diverse range of students from rural and urban areas, and the researcher's connections with an Enviroschools facilitator from the Wairarapa. Schools were initially chosen based on the length of time they had been part of the Enviroschools programme, with some being selected based on their duration (some long, some short). However, there was a low uptake rate from the first group of schools, due to having prior commitments. Therefore, the scope was widened to include all schools who were actively involved in the Enviroschools programme. Contacts for schools were accessed through various Enviroschools facilitators throughout the region and through the schools' websites. The area that each school was located in, schools' decile and number of students who completed the survey is summarised in Table 3 below. 
Table 3: Characteristics of the schools involved in the research

\begin{tabular}{|l|l|l|l|l|}
\hline Location & School & Decile & $\mathbf{\%}$ & N \\
\hline Wellington City & Thorndon School & 10 & 20 & 31 \\
\cline { 2 - 5 } & Ridgway School & 9 & 15.5 & 24 \\
\hline \multirow{2}{*}{ Johnsonville } & Paparangi School & 9 & 5.2 & 8 \\
\hline Lower Hutt & Eastern Hutt School & 9 & 20.6 & 32 \\
\hline Wairarapa & South End School & 6 & 9.7 & 15 \\
\cline { 2 - 5 } & St Patrick's School & 6 & 27.1 & 42 \\
\cline { 2 - 4 } & South Featherston School & 6 & 1.9 & 3 \\
\hline Totals & $\mathbf{7}$ & & $\mathbf{1 0 0 \%}$ & $\mathbf{1 5 5}$ \\
\hline
\end{tabular}

The schools were spread across the Greater Wellington region, with the majority being centred around Wellington City. Figure 2 below shows the area of the Greater Wellington region that the eight schools (including the pilot school) were located.
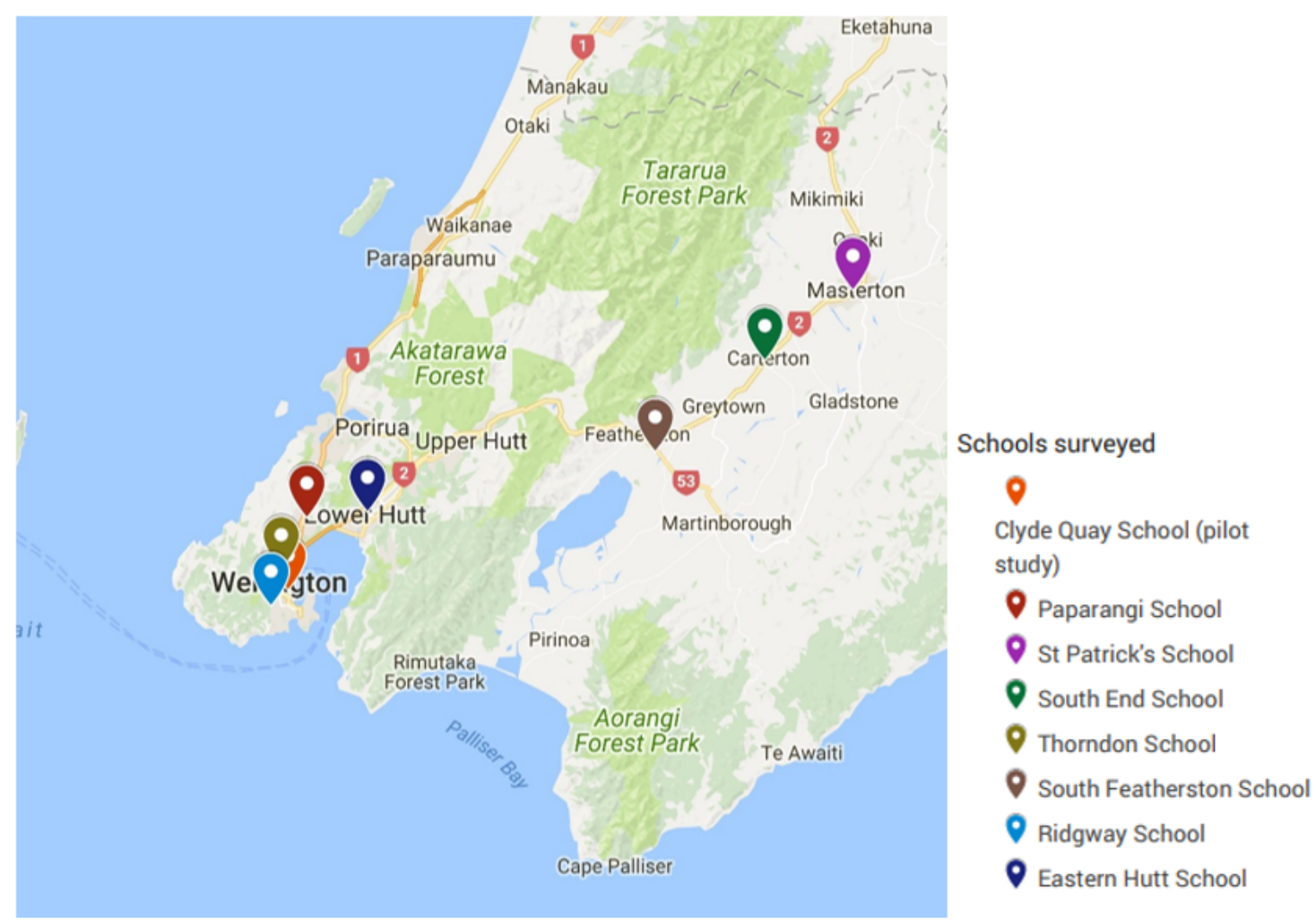

Figure 2: Map of the schools used in the research (Google, 2018)

\subsubsection{Participants}

The participants in the quantitative study comprised of primary school students, who were from schools in the Greater Wellington region involved in the Enviroschools programme. Schools were contacted directly via email or through their local 
Enviroschools facilitator. Children in the sample were chosen based on whether they returned their parental consent forms and were aged 9 to 13. The NEP Scale for children used in the survey, was created for children between the ages of 10 and 12 (Manoli et al., 2007), therefore, the same age range was used for this research. Based on how the schooling system in New Zealand works, children could not be excluded from the study based on their age. However, certain year groups could be excluded from the research, meaning that the survey was given to students in years $5,6,7$ and 8 , accounting for children aged 9 to 13.

Participants were asked to provide their age, gender, school year, whether they were a member of an environmental organisation, whether they lived in a rural or urban area and their proximity to an outdoor area. To summarise the socio-demographic data, descriptive statistics were used through a frequency analysis. The summaries of these are shown in Table 4 below.

Table 4: Socio-demographic characteristics of the study sample

\begin{tabular}{|c|c|c|c|}
\hline Variable & Measure & $\%$ & $\mathbf{N}$ \\
\hline \multirow[t]{3}{*}{ Gender } & Male & 47.7 & 74 \\
\hline & Female & 51.6 & 80 \\
\hline & Gender diverse & 0.6 & 1 \\
\hline \multirow[t]{5}{*}{ Age } & 9 & 24.5 & 38 \\
\hline & 10 & 49 & 76 \\
\hline & 11 & 15.5 & 24 \\
\hline & 12 & 8.4 & 13 \\
\hline & 13 & 1.3 & 2 \\
\hline \multirow[t]{2}{*}{ Proximity to nature } & Lives close to outdoor area & 82.5 & 127 \\
\hline & $\begin{array}{l}\text { Does not live close to outdoor } \\
\text { area }\end{array}$ & 17.5 & 27 \\
\hline \multirow[t]{4}{*}{ Location } & Lives in city & 40 & 62 \\
\hline & Lives in town & 42.6 & 66 \\
\hline & Lives in rural area & 11 & 17 \\
\hline & Other & 6.5 & 10 \\
\hline \multirow{2}{*}{$\begin{array}{l}\text { Member of an } \\
\text { environmental } \\
\text { group }\end{array}$} & Yes & 25.3 & 39 \\
\hline & No & 74.7 & 115 \\
\hline
\end{tabular}


The socio-demographic figures in table 1 show that there were slightly more females who participated in the survey than males and gender diverse children. Nearly half of the children were aged 10 when the survey was done, with many also being aged 9 and 11. Over $80 \%$ of students reported that they lived close to an outdoor area, and the majority of students reported living in a town or a city. When asked about whether they belonged to an environmental organisation, over $74 \%$ of students said that they did not.

\subsubsection{Study Instrument}

\section{Pilot study}

A pilot study was done in June 2017, with nine members of the enviro-group at Clyde Quay Primary School, located in Wellington City. The pilot had the purpose of ensuring children in the study's age range could understand the survey questions, that the format of the survey was easy for them to follow and to gauge how long it would take for the survey to be completed. In response to feedback from the pilot, several changes were made. Firstly, it was clear that the layout of the survey needed changing as several students missed every second page of the survey, by failing to notice that the pages were double sided. Another issue was that the majority of the children in the pilot did not know what the laws of nature were, relating to the statement, "People must still obey the laws of nature". This question is part of the NEP Scale for Children, which makes it difficult to remove from the survey, as its inclusion would contribute to the reliability of the scale. Therefore, it was decided to include a definition of the 'Laws of nature' to help children understand and answer the question. A further issue that was highlighted in the pilot study was surrounding the parental consent forms. Several of the students had not returned their consent forms, highlighting a potential issue that may have been faced when getting parental consent from schools in the final study. As a result of this issue arising in the pilot, teachers from schools participating in the final study were given regular reminders about the importance of getting their students to return their signed consent forms. After piloting the survey, it was estimated that children would take 15 minutes on average to complete the survey. 


\section{Survey design}

The survey was primarily based on existing research and surveys using the TPB, with some contributions from Enviroschools facilitators regarding types and wording of questions. Due to the students in the pilot study not answering both sides of the pages, the final survey was designed in a booklet format, with clear page numbers so that children would not miss any questions. The survey consisted of 61 items, with 52 of these being on a five-point Likert-scale, six being answered with either true, false, or I don't know, and three being multiple choice answers. The Likert-scale questions were chosen because this method had been previously used in studies relating to the TPB and the NEP Scale (Murtagh et al., 2012).

All ten NEP items from the scale for children were included in this survey, with a definition of the Laws of Nature included ("Laws of Nature can be defined as natural events that humans may not have control over e.g. earthquakes and storms"). The survey began with a summary of the study's purpose, followed by a statement signalling their consent, as required by the University's Human Ethics Committee. This was followed with several socio-demographic questions, asking students about their age, school year, school name and gender. A copy of the survey can be found in Appendix A - sample survey.

\section{Distribution and Collection}

After consent was given for each school, information sheets for parents and students, and a parental consent form were given to the schools either to distribute electronically or as paper copies. Depending on prior commitments, schools had 1 to 2 weeks to encourage their students to return their parental consent form. The researcher then delivered the paper surveys to each school, where schools had the option of the researcher being present while the surveys were done or to do it independently.

If the researcher was not present, the responsible teachers distributed the surveys to those students who had returned their signed consent forms. If the researcher was present, the same was done but with both the researcher and teacher present. Students were given instructions to fill out their survey independently, without the help of their 
peers. However, students could ask either the researcher or the teacher for clarification relating to survey questions.

The researcher collected the completed surveys and consent forms from each school, making sure to talk to the responsible teacher to ensure there were no issues. The data from each of the surveys was entered into Microsoft Excel and the surveys and consent forms were placed in a locked filing cabinet in the researcher's office. These surveys will remain in a locked cabinet until 1 year after the research has concluded, where they will be destroyed as per the Human Ethics Committee application.

\subsubsection{Data Analysis - SPSS}

The data gathered from the survey was analysed using IBM's Statistical Package for Social Sciences (SPSS) version 23. SPSS was used in the present study because it is one of the most popular statistical programmes used within social sciences, thus giving it credibility (Bryman \& Cramer, 2011). All of the survey items, excluding eight, were coded using a Likert Scale where 1= Strongly Agree to 5 = Strongly Disagree. Therefore, a lower score on an item, correlated to a higher level of agreement. Any missing data was excluded from the final analysis and $p>.05$ was set as the significance level. Ten composite variables were created.

The reliability of each variable was measured using Cronbach's alpha coefficients. An Cronbach's alpha coefficient that was $\alpha=0.60$ or higher was considered sufficient for this study, with the idea that the higher the alpha score, the more reliable each variable was (Streiner, 2003). Only one of the variables was reported as having a lower reliability, the NEP scale. Despite this, it was still included in the final analysis to examine if environmental concern influences behaviour intentions as this variable was a key component of the overarching research question. The figures from the reliability analysis are displayed later in this chapter.

Correlation tests were used to examine the relationships between the different TPB variables, as well as TPB variables against behaviour intentions, socio-demographics factors, and other variables of interest. The findings from these are discussed in the 
results chapter.

\subsubsection{Reliability Analysis}

\section{New Ecological Paradigm scale for children}

The students' environmental/ecological worldview was measured using a version of the NEP Scale which was adapted for children (Manoli et al., 2007). The 10 NEP items used in this research remained the same as those used by Manoli and colleagues (2007). The item "People must still obey the laws of nature" was changed to include a definition of 'Laws of Nature' as 'natural events that humans may not have control over e.g. earthquakes and storms'. This definition was included because of the pilot study revealing that students were unsure about what this statement meant.

The NEP scale consists of two dimensions, where a lower score correlates to an anthropocentric worldview and a higher score correlates to an ecological worldview (Manoli et al., 2007). Four of the items in the NEP scale were reverse coded due to the wording, which ensured participants were actually reading each statement. The following four items were reverse coded so that $1=$ Strongly Disagree to $5=$ Strongly Agree:

1. "Nature is strong enough to handle the bad effects of our modern lifestyle"

2. "People will someday know enough about how nature works to be able to control it"

3. "People are supposed to rule over the rest of nature"

4. "People are clever enough to keep from ruining the earth"

The overall reliability of the NEP scale was $\alpha=0.51$, which makes the scale below the 0.60 Cronbach's threshold. However, the results from this scale are still used in the research analysis but will be interpreted with caution due to the low reliability of the scale. The NEP has been a reliable scale in other research (Karpudewan \& Keong, 2013) and its inclusion in the present study is important so the relationship between environmental concern and behaviour intentions can be examined. Table 5 below summarises the mean and standard deviation for the scale as a whole and for each of the individual statements. A lower mean score indicates a more anthropocentric worldview. As shown by the overall mean score for the NEP scale, children showed a 
more anthropocentric worldview, showing that they had the view that "nature exists primarily for human use" (Dunlap, 2008, p. 6).

Table 5: Summary of the mean, standard deviation and Cronbach's alpha of the NEP Scale

\begin{tabular}{|c|c|c|}
\hline & Item & $\mathbf{M} \pm \mathbf{S D}$ \\
\hline & NEP Scale $(\alpha=0.51, n=152)$ & $1.97 \pm 0.38$ \\
\hline 1 & Plants and animals have as much right as people to live & $1.31 \pm 0.66$ \\
\hline 2 & People must still obey the laws of nature & $1.75 \pm 0.79$ \\
\hline $3 *$ & People are supposed to rule over the rest of nature & $1.99 \pm 1.01$ \\
\hline 4 & There are too many (or almost too many) people on earth & $2.99 \pm 1.00$ \\
\hline 5 & When people mess with nature it has bad results & $2 \pm 0.84$ \\
\hline 6 & People are treating nature badly & $2.01 \pm 0.90$ \\
\hline 7 & $\begin{array}{l}\text { If things don't change, we will have a big disaster in the } \\
\text { environment soon }\end{array}$ & $1.88 \pm 0.87$ \\
\hline 8* & People are clever enough to keep from ruining the Earth & $\begin{array}{l}3.30 \\
\pm 1.12\end{array}$ \\
\hline $9 *$ & $\begin{array}{l}\text { Nature is strong enough to handle the bad effects of our modern } \\
\text { lifestyle }\end{array}$ & $\begin{array}{l}2.47 \\
\pm 0.94\end{array}$ \\
\hline $10 *$ & $\begin{array}{l}\text { People will someday know enough about how nature works to be } \\
\text { able to control it }\end{array}$ & $\begin{array}{l}3.22 \pm \\
0.97\end{array}$ \\
\hline
\end{tabular}

\section{Theory of planned behaviour measures}

The TPB used in this study focused on two behaviours, Zero Waste and Living Landscapes. Each behaviour was split into four variables: 'perceived behaviour control', 'attitudes towards the behaviour', 'subjective norms', and 'behaviour intentions'. The wording for the perceived behaviour control and subjective norms questions were adapted from a study by Murtagh et al. (2012) where they used the TPB to look at children's active transport behaviours. The wording for the statements of the attitude variable were primarily based on the CHEAK Scale created by Leeming and Dwyer (1995). Lastly, the statements for the behaviour intentions variable were adapted from wording of survey questions created by Leeming and Dwyer (1995) and Legault and Pelletier (2000).

\section{Zero Waste - Theory of Planned Behaviour constructs}

When doing the reliability analysis, the TPB variables were split into the two themes: Zero Waste and Living Landscapes. The Cronbach's alpha for Zero Waste attitudes was 
$\alpha=0.77$, Zero Waste norms $\alpha=0.71$, Zero Waste perceived behavioural control $\alpha=0.74$, and Zero Waste behaviour intentions were $\alpha=0.69$. Table 6 below shows the mean, standard deviation, and explained variance for each item. A lower score correlated to children having a higher level of agreement with each statement.

Table 6: Mean scores, standard deviations and Cronbach's alpha for TPB waste constructs

\begin{tabular}{|c|c|c|}
\hline & Item & $M \pm S D$ \\
\hline \multicolumn{2}{|r|}{ Construct: Zero Waste attitudes ( $\alpha=0.77, n=151)$} & $2.40 \pm 0.70$ \\
\hline 1 & It makes me happy when people recycle used bottles, cans and paper & $1.70 \pm 0.83$ \\
\hline 2 & Recycling used bottles, cans and paper is important to me & $2.10 \pm 0.95$ \\
\hline 3 & $\begin{array}{l}\text { Reducing the amount of waste going to a rubbish dump is important } \\
\text { to me }\end{array}$ & $2.27 \pm 1.04$ \\
\hline 4 & $\begin{array}{l}\text { I get upset if my parents don't use re-useable containers in my } \\
\text { lunchbox }\end{array}$ & $2.87 \pm 1.08$ \\
\hline 5 & I enjoy picking up rubbish around school & $2.95 \pm 1.15$ \\
\hline 6 & I get upset when people throw away things that could be recycled & $2.53 \pm 1.07$ \\
\hline \multicolumn{2}{|r|}{ Construct: Zero Waste PBC $(\alpha=0.74, n=153)$} & $2.14 \pm 0.81$ \\
\hline 7 & $\begin{array}{l}\text { I live in a place where I can separate things at home for recycling if I } \\
\text { wanted to }\end{array}$ & $1.79 \pm 0.80$ \\
\hline 8 & $\begin{array}{l}\text { I could ask my parents for re-useable containers in my lunchbox if I } \\
\text { wanted to }\end{array}$ & $1.56 \pm 0.76$ \\
\hline 9 & I could separate things at home for recycling if I wanted to & $1.76 \pm 0.81$ \\
\hline 10 & $\begin{array}{l}\text { I live in a place where it is easy for my parents to get re-useable } \\
\text { containers for my lunchbox }\end{array}$ & $1.84 \pm 0.90$ \\
\hline 11 & I have the time to separate things at home for recycling if I wanted to & $2.24 \pm 1.02$ \\
\hline 12 & Asking my parents for re-useable containers in my lunchbox is easy & $1.67 \pm 0.88$ \\
\hline \multicolumn{2}{|r|}{ Construct: Zero Waste norms $(\alpha=0.71, n=152)$} & $2.54 \pm 0.67$ \\
\hline $13^{*}$ & $\begin{array}{l}\text { My parents want me to have plastic rubbish (e.g. glad wrap) in my } \\
\text { lunchbox }\end{array}$ & $2.36 \pm 1.18$ \\
\hline 14 & My parents would like me to separate things at home for recycling & $2.38 \pm 0.93$ \\
\hline 15 & My friends want me to separate things at home for recycling & $3.32 \pm 1.06$ \\
\hline 16 & My teachers would like me to separate things at school for recycling & $1.99 \pm 1.00$ \\
\hline 17 & $\begin{array}{l}\text { My teachers want me to have a waste free lunchbox (e.g. no glad } \\
\text { wrap) }\end{array}$ & $2.04 \pm 1.07$ \\
\hline 18 & $\begin{array}{l}\text { My friends want me to have a waste free lunch box (e.g. no glad } \\
\text { wrap) }\end{array}$ & $3.15 \pm 1.00$ \\
\hline \multicolumn{2}{|r|}{ Construct: Zero Waste behaviour intentions ( $\alpha=0.69, n=155)$} & $2.14 \pm 0.81$ \\
\hline 19 & In the next week, I will separate things at home for recycling & $2.19 \pm 0.95$ \\
\hline 20 & $\begin{array}{l}\text { In the next week, I will ask my parents for re-useable containers in my } \\
\text { lunchbox }\end{array}$ & $2.34 \pm 1.15$ \\
\hline 21 & $\begin{array}{l}\text { In the next week, I will tell someone to pick up their rubbish if they } \\
\text { drop it }\end{array}$ & $1.88 \pm 0.97$ \\
\hline
\end{tabular}


The Cronbach's alpha for the four different TPB variables within the Living Landscapes construct were as follows: Living Landscapes norms $\alpha=0.77$, Living Landscapes attitudes $\alpha=0.82$, Living Landscapes perceived behaviour control $\alpha=0.81$ and, Living Landscapes behaviour intentions $\alpha=0.63$. One of the perceived behavioural control items, "Putting my food scraps in the compost is easy (if you don't have a compost, don't circle anything)", was removed from the perceived behavioural control variable, as many participants did not answer it due to not have a compost bin. The mean, standard deviation, and explained variance for each of the items are shown in Table 7 below, where a lower mean score indicates a higher level of agreement.

Table 7: Mean and standard deviations for TPB Living Landscapes constructs

\begin{tabular}{|c|c|c|}
\hline & Item & $\mathbf{M} \pm \mathbf{S D}$ \\
\hline \multicolumn{2}{|r|}{ Construct: Living Landscapes attitudes ( $\alpha=0.82, n=149$ ) } & $2.12 \pm 0.76$ \\
\hline 1 & Planting trees and vegetables is important to me & $2.07 \pm 1.00$ \\
\hline 2 & Planting trees and vegetables is fun & $2.02 \pm 1.05$ \\
\hline 3 & I enjoy eating fruit and vegetables that I have grown myself & $1.81 \pm 0.98$ \\
\hline 4 & Putting food scraps in the compost is important to me & $2.32 \pm 1.09$ \\
\hline 5 & It is good to stop food scraps from going into the rubbish & $1.95 \pm 1.03$ \\
\hline 6 & I enjoy composting my food scraps & $2.58 \pm 1.09$ \\
\hline \multicolumn{2}{|r|}{ Construct: Living Landscapes PBC $(\alpha=0.81, n=152)$} & $1.89 \pm 0.82$ \\
\hline 7 & $\begin{array}{l}\text { I live in a place where I can help my parents to grow fruit or vegetables } \\
\text { in my garden if I wanted to }\end{array}$ & $1.78 \pm 1.05$ \\
\hline 8 & $\begin{array}{l}\text { I live in a place where I can put my food scraps in a compost bin if I } \\
\text { wanted to }\end{array}$ & $2.21 \pm 1.23$ \\
\hline 9 & $\begin{array}{l}\text { I have the time to help my parents to grow fruit or vegetables in my } \\
\text { garden if I wanted to }\end{array}$ & $2.06 \pm 1.18$ \\
\hline 10 & I could put my food scraps in a compost bin if I wanted to & $1.80 \pm 1.00$ \\
\hline 11 & $\begin{array}{l}\text { I could help my parents grow fruit or vegetables in my garden if I } \\
\text { wanted to }\end{array}$ & $1.60 \pm 0.91$ \\
\hline \multicolumn{2}{|r|}{ Construct: Living Landscapes norms ( $\alpha=0.77, n=152)$} & $2.30 \pm 0.67$ \\
\hline 12 & My family would like me to put my food scraps in a compost bin & $2.08 \pm 1.01$ \\
\hline 13 & My teachers want me to put my food scraps in a compost bin & $1.89 \pm 0.94$ \\
\hline 14 & My friends want me to put my food scraps in a compost bin & $2.94 \pm 1.01$ \\
\hline 15 & My friends want me to help plant trees and vegetables at school & $2.93 \pm 1.10$ \\
\hline 16 & My teachers want me to help plant trees and vegetables at school & $2.19 \pm 0.97$ \\
\hline 17 & My parents like it when I help them plant trees and vegetables & $1.75 \pm 0.87$ \\
\hline \multicolumn{2}{|r|}{ Construct: Living Landscapes behaviour intentions ( $\alpha=0.63, n=154)$} & $2.24 \pm 0.83$ \\
\hline 18 & In the next week, I will put my food scraps in a compost bin & $1.97 \pm 1.09$ \\
\hline 19 & In the next month, I will help my parents plant trees or vegetables & $2.18 \pm 1.12$ \\
\hline 20 & In the next month, I will help plant trees in the community & $2.57 \pm 1.10$ \\
\hline
\end{tabular}




\subsubsection{Knowledge based questions}

The survey asked students six knowledge-based questions, three for each behaviour theme - Zero Waste and Living Landscapes. The students were given a statement, to which there was one correct answer. The students could choose from 'True', 'False', or 'I don't know'. A score was then given for each of the answers where 1= True, 2= False, and 3=I don't know, with only the ' 1 's being included in the final score. One of the six items was reverse coded, so that the correct answer would correlate to 1 . The statements for this section were based on the information provided in the Enviroschools' Zero Waste and Living Landscapes resources. As indicated in Table 8 below, the mean score for the knowledge-based questions was $4.38 \pm 1.30(n=155)$, showing that on average students got approximately four of the six questions correct. Table 8 shows a summary of these responses.

Table 8: Responses to the environmental knowledge questions (the correct answers are bolded)

\begin{tabular}{|c|c|c|c|c|c|}
\hline & Item & $\begin{array}{l}\% \\
\text { Responded } \\
\text { 'True' }\end{array}$ & $\begin{array}{l}\% \\
\text { Responded } \\
\text { 'False' }\end{array}$ & $\begin{array}{l}\text { \% Responded } \\
\text { 'I Don't Know' }\end{array}$ & $\begin{array}{l}\% \\
\text { Missing }\end{array}$ \\
\hline \multicolumn{6}{|c|}{ Construct: Environmental knowledge $(4.38 \pm 1.30, n=155)$} \\
\hline 1 & $\begin{array}{l}\text { If I live in a house with no } \\
\text { backyard, I can grow } \\
\text { vegetables in a pot }\end{array}$ & 76.1 & 17.4 & 6.5 & \\
\hline 2 & $\begin{array}{l}\text { Trees breathe in what we } \\
\text { humans breathe out }\end{array}$ & 72.3 & 7.1 & 20.6 & \\
\hline 3 & $\begin{array}{l}\text { Glass bottles can be put in } \\
\text { a recycling bin }\end{array}$ & 61.9 & 23.9 & 14.2 & \\
\hline $4^{*}$ & $\begin{array}{l}\text { Putting compost (after it } \\
\text { has decomposed) on the } \\
\text { vegetable garden doesn't } \\
\text { help the vegetables to } \\
\text { grow }\end{array}$ & 8.4 & 68.4 & 23.2 & \\
\hline 5 & $\begin{array}{l}\text { Recycling turns waste and } \\
\text { used materials (e.g. plastic) } \\
\text { into new products }\end{array}$ & 88.4 & 3.9 & 7.7 & \\
\hline 6 & $\begin{array}{l}\text { Plastic bottles can take } \\
\text { hundreds of years to } \\
\text { decompose }\end{array}$ & 71 & 6.5 & 21.3 & 1.3 \\
\hline
\end{tabular}


The answers to the knowledge questions showed that overall students were knowledgeable about both the living landscape and the Zero Waste themes. The question that had the lowest score of correct answers was question 3, which asked students about whether glass could be recycled. The question that had the highest number of correct answers was question 5, which asked about the what recycling does to used products.

\subsection{Ethical considerations}

For ethical reasons it was important this research complied with the human ethical guidelines set out by Victoria University of Wellington. The Ethics Committee granted ethics approval on 26 May 2017 (ethics approval number 24521, Appendix B - Ethics Approval).

For the qualitative part of the research, the Ethics committee required two documents to be given to participants; these were the Participant Information sheet, and the Participant Consent Form. In the information sheets, participants were informed about the nature and length of the interviews. They were told that their names would not be used in the final report and that the interview would be recorded. Participants had the choice to receive a summary and the transcription of their interview, as well as a copy of the final report. Participants had a month after their interview to withdraw from the research and the transcribed interviews were sent to each person for comment. None of the participants chose to opt out of the research and only a few minor changes were made to the transcriptions. Copies of the interviewee's consent form and information sheet can be found in Appendix C.

For the quantitative section, the Ethics Committee required six documents to be sent to each school, where three of these documents were to be sent home and signed by parents before the research was to be conducted. The six documents were: 1) Information sheet for parent/legal guardian; 2) Information sheet for participant; 3) Consent form for parent; 4) Information sheet for teachers/principal; 5) Consent form for principal; and 6) Consent form for teachers (Appendix D). Participants' names were not collected throughout this process and the students gave their consent by agreeing 
to complete the survey ("I am happy to participate in this research as shown by completing this survey"). Once the surveys had been completed, students were unable to withdraw from the research due to being unable to link a survey back to a specific respondent because of the anonymity of the survey.

All 155 of the participants were informed about the research (through the student information sheet - Appendix DAppendix D) and understood it was optional to complete the survey. No participant chose to opt out of the study. 


\section{Chapter 4: Results}

\subsection{Introduction}

This chapter examines the results of the two studies looking at the qualitative and quantitative aspects of the Enviroschools programme. The results of the thematic analysis done on the semi-structured interviews are examined to answer the research questions from the first study. The statistical analysis of the second study is then discussed, looking at the relationships between the TPB constructs and several other variables. To give equal representation to all of the results, the chapter is broken into sections, covering each study and its respective research questions.

\subsection{Study One (qualitative): Research Question 1}

How is the Enviroschools programme incorporated into participating primary schools in the Wellington region? How is action competence in students encouraged in the Enviroschools programme?

The answers given by the participants regarding the Enviroschools programme and its integration were put into key themes, using the software program NVivo, presented in Figure 3. The darker green bubble shows the overarching theme, which then flows into the themes that come from school vision (the overarching theme), shown in yellow. The bubbles in light green are the sub-themes for the themes of 'School environmental activity' and 'Enquiry-based learning'. The following section will go into each of these themes, using quotes from the interviews to illustrate ideas that arose. 


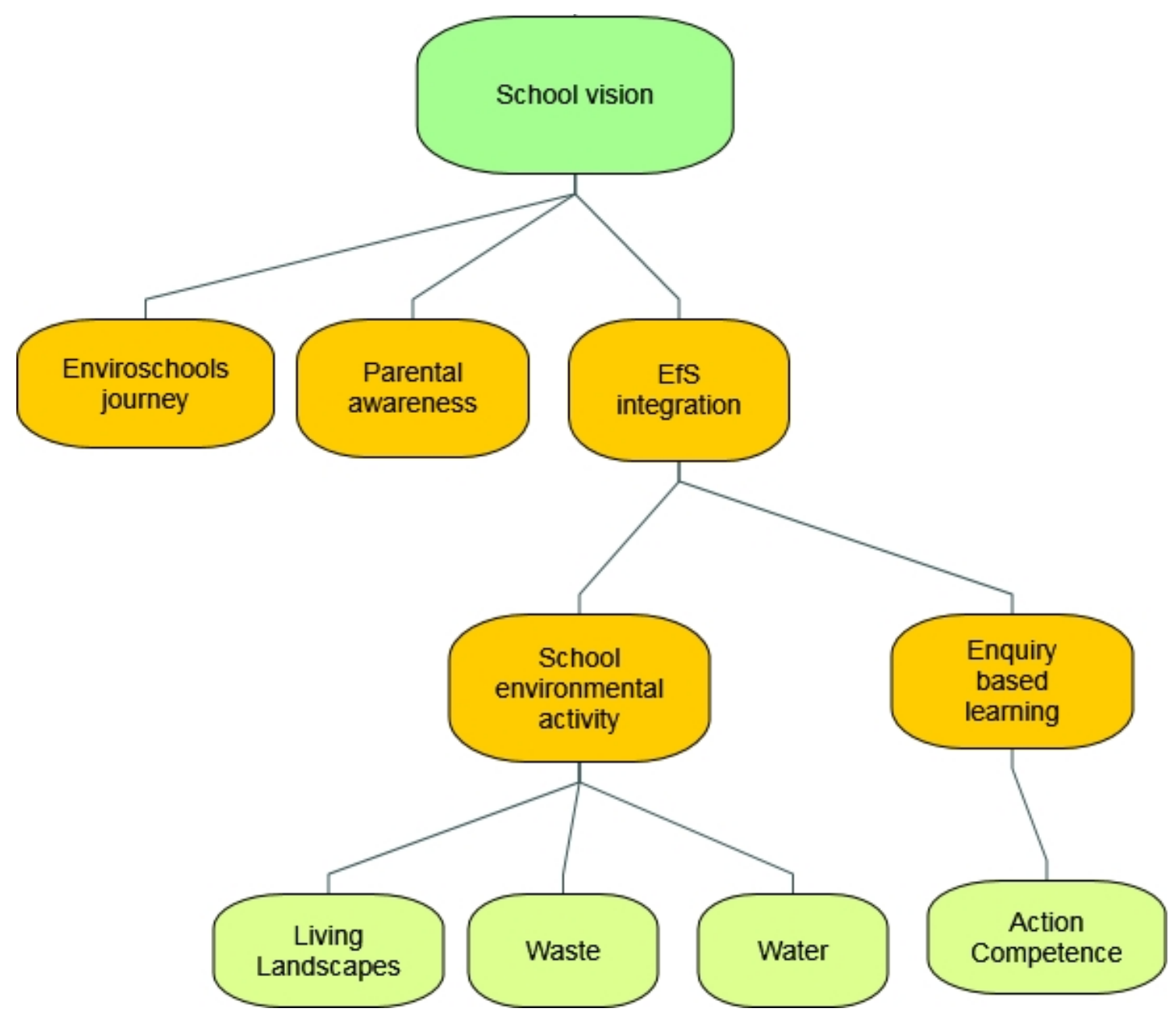

Figure 3: Mind-map of the key themes and sub-themes relating to Research Question 1

\subsubsection{School vision and culture}

When the teachers were interviewed, a strong theme that emerged was the school's vision and identity. This theme incorporates the idea that the decisions made by schools are influenced by their future goals, as well as the culture that has been created by the school community. Vision and culture played a large part in how the Enviroschools programme was implemented at each school, linking strongly to why they joined the programme in the first place. Several schools felt that their culture already aligned with the Enviroschools programme, and that they did not need to make many changes when they joined the programme.

“'Cause people are saying, "What's Enviroschools?" Well it's actually what we're doing, you know?" 
This quote illustrates that the Enviroschools programme and school identity aligned so closely at this school that it was easier to encourage teachers to continue what they were already doing rather than introduce new concepts to them.

Schools who took an integrated approach to this programme often had clear goals for their environmental journey. They felt that being an Enviroschool had become part of their culture and therefore wanted the whole school to be involved in environmental activities and understand why they were important.

"... for us it's about educating these guys to the point that they know why we do things at the school, the way we do them and how they can positively impact the environment by themselves and how they can educate others."

Some schools saw that being an Enviroschool had become a reason for parents to enrol their children there: "... you think this is why you enrol your child at this school because you want that enviro message there." Others saw that displaying the environmental message that they had created through the Enviroschools programme helped to promote their school - "We wanna be the best school in the Wairarapa. We want people to come to our school and see what we're doing."

\subsubsection{Enviroschools Journey}

The theme 'Enviroschools journey' refers to the different paths that schools take when they become an Enviroschool. The school's vision and culture had a strong influence on their decision to become an Enviroschool (their Enviroschools journey) and the resources and support that teachers used. The interviews revealed that participating schools had been part of the Enviroschools programme for a varying length of time, ranging from two to more than ten years.

The interviewees found that the length of time a school had been part of the programme did not necessarily correlate to higher levels of integration or use of Enviroschools resources. The participants took varied approaches as to how they used the resources provided to them by the Enviroschools programme. For example, one school sent any 
new staff on an Enviroschools course so they could gain an understanding of how the programme works.

"Any new people that come in, they're going to one of the um, what do you call those courses? The Enviro courses, introductory course, discussing and finding out about all the guiding principles and how it works..."

Another school did not have a strong reliance on the Enviroschools resources because the lead teacher had previously been an Enviroschools facilitator herself.

A teacher from Thorndon School mentioned the value and potential that the Enviroschool resources provide, illustrated by the following quote “... I think Enviroschools; you know provides amazing resources for us to be able to you know, action in the classroom, support the learning in the classroom."

The Enviroschools journey that schools took depended a lot on how they utilised the resources provided to them by the organisation, with some schools applying them more thoroughly than others.

\subsubsection{Parental awareness}

An underlying theme for incorporating the Enviroschools programme into schools was the level of parental awareness and involvement. The parental awareness theme showed the impacts that children had on their families as well as the impacts that parents had on their children and the school. Teachers mentioned how parents had commented on the changes that they had made at home because of their children learning about environmental issues.

“... we've noticed a change in the way the lunches are packed [...] also I think it being an Enviroschool gives those families with a real passion for it... They often step up; their kids step up, yeah. It's not just the once then, it's something that they continually do. Yeah, as a family and at school." 
One school had a strong group of parents who were driving a number of environmental activities such as a bike track and helping to organise a walking school bus.

"Yeah I think they're influencing each other but you know the parents, the bike track would not happen without a couple of very, very proactive parents."

Teachers also noted a lack of parental awareness about environmental issues such as waste, which makes it difficult for changes to be made at home - "... talking to other schools it's always you know, some parents are more aware and others are not."

\subsubsection{Education for Sustainability integration}

The key to successfully incorporating the Enviroschools programme into schools often relies on how well EfS is integrated into the school's curriculum. Through the interviews, it became clear that schools had varying levels of EfS integration. A lot of this depended on how other staff perceived the Enviroschools programme, as many saw it as an extra activity on top of their usual teaching:

“... it's [Enviroschools] an extra, and that's one thing we've been talking about, as a green-gold school, is it's done, but it's done alongside things. Whereas - and that's the next step, is actually having it seamlessly throughout things."

Some teachers had the programme integrated seamlessly throughout their teaching. In the following example, teachers from Ridgway School had to note down which Enviroschools principle they were incorporating into their teaching when they did their lesson plans - "... in our planning format we have a box that says, "What Enviroschools principle are you covering?"”"

Some participants felt that they lacked support from their fellow staff.

“... they [Enviroschools] sent us through like a whole fantastic pack of information, so I shared that with the staff and said, "look at what we can do and 
this is great, and who's with me? Who's with me?!" And um, that didn't happen. So I didn't have enough people to have the impact that l'd hoped."

Others noted that they felt very supported by their respective Enviroschools facilitators:

“... one thing that I must say that has been part of the key to us keeping going and our some of our successes is that we've had one constant ES facilitator, all the way through, [...] rather than swapping and changing. Now she's been fantastic, just her quiet sort of way of leading us through and having her every year for 10 years has been great."

\subsubsection{School environmental activity}

Linking all of the above themes together is the environmental activities that schools undertook. These activities are grouped into three main sub-themes: Zero Waste, Living Landscapes and water. Zero Waste included different methods that schools used to reduce their waste. This included composting, recycling, and waste free lunches. One school had become so motivated to have Zero Waste that they had removed the rubbish bins from around their schools. This meant any waste children had in their lunches was taken home so their parents could see the amount of waste that was being produced each day.

“... we're now Zero Waste so we have a pig bucket, coz the next-door neighbour has chooks and pigs. So all the kids put all their food waste into there and then the neighbour comes and collects it every night and feeds it to her pigs and chooks. So we don't have any rubbish bins outside now."

Living Landscapes involved schools having various types of gardens around their schools:

“... you know we've moved to lots of gardens outside all the classrooms, we've, we're working on a food forest up over there"; "Yep, Living Landscapes. We've created a bush area and a garden area." 
Water activities involved educating students about water pollution and keeping toxic substances out of drains:

"... so we do the water cycle and each team and each class do that all differently. So the seniors and the middles do more of like a focus on the community, so the Hutt River. The juniors will do more of like a general water cycle and the weather, and keep it quite in the school community or the school environment."

Schools were also involved in other environmental activities such as having solar panels and pest control. Each school's environmental activities were seen as the final stage of how the Enviroschools programme is incorporated into each school.

\subsubsection{Action competence and enquiry-based learning}

The theme of 'action competence' comes from enquiry-based learning (discussed later in this chapter), which is a branch of EfS integration within the thematic mind-map. When participants were asked for a definition of action competence, one of the components of the Enviroschools programme, a number of them were unsure what the term meant. Those who did know, defined action competence as:

"What actions do the children take from what you're teaching them" or as "they're [the students] actively involved in the learning and also the doing and are part of the whole planning of it."

These responses link closely to how action competence is defined in the literature where students would lead the action that they were taking without external factors, such as peers influencing their actions (Jensen \& Schnack, 2006). The teachers who were unsure of a definition were given one, which allowed them to think of some examples where action competence was used in their teaching or in the school. An example of action competence given by one teacher was when students were shown videos of the impact of plastic on the ocean. The teacher noted that even though the children were not told by their teacher to tell their parents about it, because of this exercise: 
"The kids all went home and talked to their parents. We had a lot of parents saying things like "Oh my gosh, we were at the supermarket and my child said, “No, you're not allowed a plastic bag!"[...]That happened because that really impacted them [the students]."

A key theme that came out of the interviews was that most of the schools used enquirybased learning to get students to take action on their ideas. When teachers were describing how they encouraged action competence, they often referred to enquirybased learning, as a type of teaching where students took ownership of their learning through completing inquiries into certain topics (Chu, Tse, \& Chow, 2011). Enquirybased learning is not specifically a result of the Enviroschools programme, but as one teacher noted: "it's kind of like the Enviroschools principles but they're being reflected a lot in the actual enquiry curriculum." The inquiries that schools and teachers do are led by students and often involve environmental activities. South Featherston School did a student directed enquiry where they investigated ideas students had about what they could do within the Enviroschools programme.

"The kids came up with bird feeders, which they found pros and cons of bird feeders. The kids, they took on some pretty big things. They wanted to beautify the school and make a, sort of a gecko garden over in the corner of the school."

It was later noted that several of these ideas were not completed due to lack of resources and consent, but the experience allowed the children to feel as if their ideas mattered.

\subsection{Study One (qualitative): Research Question 2}

What do teachers perceive as the challenges and benefits of the Enviroschools programme?

As shown in Figure 4, the challenges and benefits teachers experience due to the Enviroschools programme link in with the rest of the themes examined in Research Question One, specifically as a result of the 'EfS integration' theme. To answer this 
research question, the challenges and benefits were broken down into two sub-themes: internal, where the challenge/benefit is centred around the school and the students, and external, where the benefits/challenges occur outside of the immediate school environment. These two themes are portrayed in Figure 4 by the yellow bubbles. Within the internal and external themes, there were several sub-themes, indicated in the mindmap by the light green bubbles. The challenges and benefits of the Enviroschools programme are discussed below, using quotes from the teachers to illustrate key ideas and opinions.

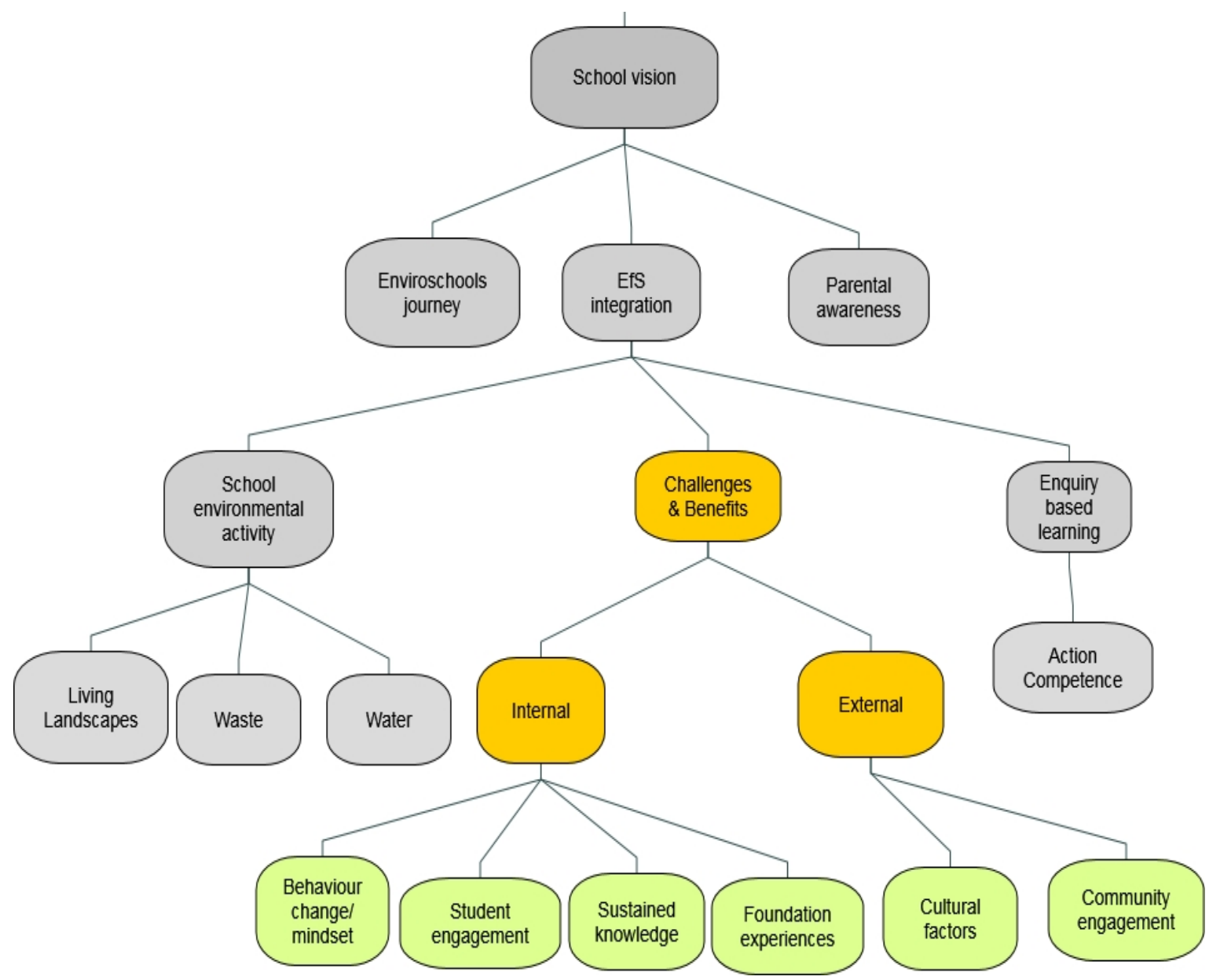

Figure 4: Mind-map of themes relating to $R Q 1$ and $R Q 2$

\subsubsection{Challenges}

Teachers listed a number of challenges that they faced implementing the Enviroschools programme in their school. One of the internal challenges included changing the mindset of both students and teachers so that they were more open to how the Enviroschools programme worked in their school. Some of the teachers mentioned that other teachers in their school were reluctant to get on board with the Enviroschools programme, which 
affected the programme's ability to be successful.

"We need to be looking at this from a whole school perspective not just having one person driving the push and that systems need to be implemented from all angles."

Changing students' mind-sets was also a challenge at some schools where students were not part of an enviro-group. These students felt they did not need to contribute to environmental activities because they were not part of these groups.

“... putting them into groups kind of restricts everyone feeling involved because they're like "Oh, I'm not a compost kid, I don't have to do it". So we're trying to shift that mind-set that these are the wardens kind of idea and that you guys are doing the job, they're just emptying the bins - you're all part of these groups."

One of the participants felt that the large size of their school was a barrier to achieving the successes that had been hoped for by participating in the Enviroschools programme.

“... one of our biggest challenges is the size of the school. I don't think the Enviroschool system is really built to acknowledge a school of our size. When I talk to other Enviroschool leaders and facilitators they are able to achieve a lot more or experience different successes which just wouldn't be achievable with over 700 children."

One of the external challenges teachers faced were the students who came from different cultural backgrounds where 'Zero Waste' was a new concept.

"We have a huge number of kids at our school and a lot of international families. Um and so getting that message across is not just a language barrier but it's also a cultural barrier as well because a lot of the food that they generally bring into the school is packaged food." 
The location of the school was a challenge for one school as they were a rural school which meant that the council did not collect their recycling. Their situation is explained in the quote below:

"No household down this road gets the recycling picked up. We inquired about that and they said, "Well we could get it picked up if we paid for it" but we kinda thought, "We don't really want to have to pay for it". Currently I take all the recycling to the recycling station in Featherston, which is a bit of a hassle."

Another teacher felt that the external community needed to get involved with the Enviroschools programme in a school in order for it to be effective.

"...the community needs to be on board as well in order to actually make it more valuable for the kids. Because it's still valuable and incredibly valuable but I think definitely having those systems in place and having a whole school buy in is essential to having the impact that it can have."

\subsubsection{Benefits}

The benefits of the Enviroschools programme teachers identified were mostly external to the student and the school, but several of the benefits were internal. Internal benefits included the strength, adaptability to different teaching methods, and students' response to having the Enviroschools programme in their school. These benefits are considered internal because they add something to the school and help the schools to further implement the Enviroschools programme. In terms of strength, this related to the level of support teachers received from the Enviroschools organisation. Teachers mentioned that Enviroschools was a full-strength programme, due to the support from facilitators and resources and activities provided for each theme. This support made it easier to implement the programme in their school. It was noted that the programme itself could easily be fitted into regular teaching, as illustrated by the following quote: 
"I'm a huge believer of the Enviroschools programme and I think that there's just so many things that, so many education things that you can do with it. And it just fits in so naturally within the school I think."

The teachers also noted how engaged the students were with their natural environment as a result of the Enviroschools programme.

\begin{abstract}
"'Cause you can see how engaged the kids are with the world around them! [...] when problems come up they want to try and solve them and it's such a great opportunity, you know, looking at it from an environmental perspective."
\end{abstract}

External benefits focused on the impact that students were having on their community and families through the knowledge gained from the Enviroschools programme. In terms of the impact on the community, activities completed through the Enviroschools programme allowed students to contribute to their local green spaces and see a positive response from community members. One example of this was when a group of students helped to plant a local wetlands area with native plants and as a result received a positive response from their community board:

"We had two children from that [the wetlands project] present what we've done so far to the community board and they got a standing ovation at the end of it. And the community board are saying now, "Hey, we just want to support you guys, we want to give you this, we want to give you that". So the kids have been able to see how much impact they've had."

Teachers also noted their hopes for the benefits of the Enviroschools programme to extend into the children's adulthood.

"But they're talking about it and they're excited by it and I think yeah, yeah. Even though they might not take it home they might be as they grow up, that they take it into their life." 
The impact that the Enviroschools programme had at home linked closely to the theme of 'parental awareness' mentioned in Research Question 1. It was mentioned by several teachers that parents would often come into the school saying how they had changed a household behaviour due to their child's influence. This links strongly to the theme of parental awareness, discussed earlier in this chapter. An example of this is shown below:

“...so I was talking to other parents from that and they said "Oh yeah, we've got our compost bin now, we've never had a compost bin". So it's things like that that you will never see in the school, but those children are now making their parents have a worm farm, or a compost bin. And that means that down the track, as adults, they'll be thinking about those things..."

\section{Summary of Study One}

The results from the qualitative study highlighted that many factors, such as supportive teachers, went into making the Enviroschools programme successful in schools. One of the key themes was the school's vision and whether having a successful Enviroschools programme in their school was part of a school's future vision. Teachers also noted the important role that parents had in making the programme successful. If parents were supportive of the programme, then it was more likely to be perceived as a success. Another key finding was the role that enquiry-based learning played in encouraging action competence in the students by allowing them to take ownership of their learning.

The teachers also noted that the programme had a number of challenges and benefits. Some of the challenges included getting other teachers to be involved with the programme, and others felt that changing the mindset of students was the biggest challenge. When looking at the benefits, two key findings stood out. The first was the impact that the children had at home because of learning about environmental issues at school. Children would often go home and get their parents to change behaviours relating to waste and recycling because it was something that they had learned at school. Another benefit was the impact that the programme had on the wider community. Schools would often contribute to the community by doing activities, such 
as planting trees, which were well received by members of the community and enabled the impact of the Enviroschools programme to be more widespread.

\subsection{Study Two (quantitative): Research Question 1}

How well can the Theory of Planned Behaviour predict children's behaviour intentions? Can environmental concern add to the explanation of behaviour intentions?

To answer this research question, the answer is split up into two sections. One examines the TPB variables on their own and exploring the relationships that each has with behaviour intention. The second section looks at how the NEP Scale is correlated with behaviour intentions and whether it adds anything to the level of explained variance of behaviour intentions, both on its own and when included with the other TPB variables.

\subsubsection{Theory of planned behaviour variables}

A linear regression test revealed that the variables of subjective norms, attitudes, and perceived behaviour control explained $72 \%$ of the variance in Living Landscapes behaviour intentions - the intention to compost food scraps, to help parents to plant trees or vegetables, or to help plant trees in the community. Based on the figures shown in Table 9, one can see that subjective norms had a strong positive relationship with behaviour intentions, with a Pearson's correlation of $r=0.743$. The Pearson's correlation between the attitudes variable and behaviour intentions, and between perceived behavioural control and behaviour intentions also showed strong, positive relationship, with values of $r=0.750$, and $r=0.733$ respectively.

When looking at the standardised regression coefficients, subjective norms and Living Landscapes behaviour intention had a significant, weakly moderate correlation between the two variables, with $\beta=.302(p<.01)$, when the other TPB variables were controlled for. This shows that people who felt more influenced by others had higher intentions to perform gardening behaviours than those who were not influenced by others. The 'attitudes towards behaviour' variable and 'behaviour intention' variable had a standardised coefficient of $\beta=.285(p<.01)$, showing a significant, weak and positive correlation. This result suggests that children with a more positive attitude towards 
Living Landscapes behaviours were more likely to express intentions to perform activities such as helping their parents in the garden. The 'perceived behaviour control' variable and the 'behaviour intentions' Living Landscapes variable had a standardised coefficient of $\beta=.385(p<.01)$, showing a significant, moderate, and positive relationship. This relationship indicates that children who felt limited to perform a Living Landscapes behaviour were less likely to have intentions to perform them. All three of the TPB variables significantly (i.e., significance levels of less than .05) predicted behaviour intentions, showing that the TPB is a suitable model for predicting living landscape behaviour intentions. Table 9 below shows a summary of these results.

Table 9: The results of a Pearson's correlation and regression test for the TPB with Living Landscapes behaviour intentions

\begin{tabular}{|l|l|l|l|l|l|}
\hline Variable & $\begin{array}{l}\text { Pearson's } \boldsymbol{r} \\
\text { Correlation }\end{array}$ & $\begin{array}{l}\text { Standardised } \\
\text { coefficients } \\
\text { (Beta) }\end{array}$ & $\boldsymbol{t}$ value & Significance & $\begin{array}{l}\text { Explained } \\
\text { variance }\end{array}$ \\
\hline $\begin{array}{l}\text { Living Landscapes } \\
\text { subjective norms }\end{array}$ & .743 & .302 & 4.23 & .000 & $72 \%$ \\
\hline $\begin{array}{l}\text { Living Landscapes } \\
\text { attitudes }\end{array}$ & .750 & .285 & 3.88 & .000 & \\
\hline $\begin{array}{l}\text { Living Landscapes } \\
\text { perceived } \\
\text { behavioural } \\
\text { control }\end{array}$ & .733 & .384 & 6.65 & .000 & \\
\hline
\end{tabular}

The same linear regression test was done using waste behaviour intentions as the dependent variable, with the rest of the waste TPB variables as independent variables. The results of this test are displayed in Table 10 below. The Pearson's correlation between subjective norms and waste behaviour intentions, $r=.515$, show a strongly moderate relationship. Attitudes towards the behaviour and behaviour intentions had a correlation of $r=.671$, showing a strong positive relationship. The last variable, 'perceived behaviour control', and 'behaviour intentions' had a Pearson's correlation of $r=.587$, showing a strongly moderate relationship.

When looking at the standardised regression coefficient for 'subjective norms' and 'behaviour intentions' for waste, $\beta=.099(p=.163)$, this shows a non-significant, weak, and positive correlation between the two variables. This indicates that children are not 
influenced by others people when expressing their waste reducing behaviour intentions. The standardised regression coefficient for 'attitudes towards the behaviour' and 'behaviour intentions' for waste had a beta value of $\beta=.473(p<.01)$, showing a strongly moderate, positive relationship, and significant correlation between the two variables. This shows that if children have a positive attitude towards waste then they are more likely to express intentions to perform waste behaviours. The standardised coefficient for perceived behaviour control and waste behaviour intentions was $\beta=.324(p<.01)$, showing a significant, positive, and weakly moderate relationship, when other variables are controlled for. This results shows that those students who felt they had control of their behaviours were more likely to intend to perform waste behaviours. Overall, the TPB variables for waste explained $55.8 \%$ of variance in waste behaviour intentions. These results are summarised in Table 10.

Table 10: The results of a Pearson's correlation and regression test for the TPB with waste behaviour intentions

\begin{tabular}{|l|l|l|l|l|l|}
\hline Variable & $\begin{array}{l}\text { Pearson's } \boldsymbol{r} \\
\text { Correlation }\end{array}$ & $\begin{array}{l}\text { Standardised } \\
\text { coefficients } \\
\text { (Beta) }\end{array}$ & $\boldsymbol{t}$ value & Significance & $\begin{array}{l}\text { Explained } \\
\text { variance }\end{array}$ \\
\hline $\begin{array}{l}\text { Waste subjective } \\
\text { norms }\end{array}$ & .515 & .099 & 1.40 & .163 & $55.8 \%$ \\
\hline Waste attitudes & .671 & .473 & 6.98 & .000 & \\
\hline $\begin{array}{l}\text { Waste perceived } \\
\text { behavioural } \\
\text { control }\end{array}$ & .587 & .324 & 4.83 & .000 & \\
\hline
\end{tabular}

\subsubsection{New Ecological Paradigm Scale versus behaviour intentions}

Environmental concern was measured through the NEP scale, where an average score for each child was calculated, using the 10 questions that made up the scale. This score was used to create a variable and then tested against the two behaviour intentions variables. A low score on the scale indicated that a child is more anthropocentric as opposed to ecocentric.

A linear regression test was done between the NEP scale and Living Landscapes behaviour intentions, using behaviour intentions as the independent variable. The standardised coefficient had a value of $\beta=.212$, showing a weak, positive correlation 
between the two variables. The result was significant, with $p<.01$, and explained variance was $4.5 \%\left(R^{2}=.045\right)$. This means that children with higher levels of environmental concern are more likely to have intentions to perform Living Landscapes behaviours. However, the environmental worldview variable (NEP) did not contribute largely to explaining behaviour intentions for Living Landscapes.

The linear regression test between the NEP scale and waste behaviour intentions had a beta of $\beta=.223(p<.01)$ showing a significant and weak correlation between the NEP scale and waste behaviour intentions. The NEP scale explained $5 \%\left(R^{2}=.050\right)$ of the variance in waste behaviour intentions. This result suggests that children with higher levels of environmental concern expressed stronger intentions to perform waste related behaviours. However, similar to the Living Landscapes regression test, the NEP scale did not contribute to the explanation of variance in waste behaviour intentions.

When a multiple step linear regression test was conducted, the NEP Scale was added to step 2 of the independent variables (with the TPB variables being step 1). For the Living Landscapes behaviour intentions, the TPB variables had an explained variance of $71.8 \%$ $\left(R^{2}=.718\right)$. When the NEP Scale was added, the explained variance rose slightly to $72 \%$ $\left(R^{2}=.720\right)$. This shows that the NEP Scale added a minimal amount when explaining the variance in Living Landscapes behaviour intentions.

A multiple linear regressions test was done, using the waste theme. When testing only the TPB variables, they explained $55.8 \%\left(R^{2}=.558\right)$ of variance in waste behaviour intentions. When the NEP Scale was added to the regression test, the explained variance increased to $57.9 \%\left(R^{2}=.579\right)$. These results show that adding the NEP Scale to the waste related TPB variables explains more of the variance in behaviour intentions than when added to the Living Landscapes TPB variables. However, overall the Living Landscapes behaviour intentions had a higher level of explained variance. This shows that the variables used in this test were better at explaining Living Landscapes behaviour intentions than waste behaviour intentions. 
How do socio-demographic characteristics affect behaviour intentions and each of the TPB variables?

The results of correlation and coefficient tests between socio-demographic characteristics and behaviour intentions are summarised in Table and Table 12 below. The socio-demographic characteristics included the following variables: 'Member of an environmental group', 'Gender', 'Age', and 'Location'. A linear regression test was conducted to compare these variables against both Living Landscapes behaviour intentions and waste behaviour intentions. For Living Landscapes, the sociodemographic characteristics explained $4.8 \%$ of variance in behaviour intentions. For Waste, the socio-demographic variables explained $5.8 \%$ of variance in behaviour intentions. This suggests that factors other than socio-demographics explain the variance in behaviour intentions. The findings shown in Table 11 and Table 12 discussed in more detail in the sections below, along with comparisons of the means of each sociodemographic characteristic with the TPB variables.

Table 11: Socio-demographics characteristics and Living Landscapes behaviour intentions

\begin{tabular}{|l|l|l|l|l|l|}
\hline Variable & $\begin{array}{l}\text { Pearson's } r \\
\text { Correlation }\end{array}$ & $\begin{array}{l}\text { Standardised } \\
\text { coefficients } \\
\text { (Beta) }\end{array}$ & $t$ value & Significance & $\begin{array}{l}\text { Explained } \\
\text { variance }\end{array}$ \\
\hline $\begin{array}{l}\text { Member of an } \\
\text { environmental } \\
\text { group }\end{array}$ & .140 & .159 & 1.96 & .052 & $4.8 \%$ \\
\hline Gender & -.003 & -.020 & -.249 & .804 & \\
\hline Age & .053 & .040 & .498 & .619 & \\
\hline Location & -.149 & -.162 & -1.99 & .049 & \\
\hline
\end{tabular}

Table 12: Socio-demographics characteristics and waste behaviour intentions

\begin{tabular}{|l|l|l|l|l|l|}
\hline Variable & $\begin{array}{l}\text { Pearson's } r \\
\text { Correlation }\end{array}$ & $\begin{array}{l}\text { Standardised } \\
\text { coefficients } \\
\text { (Beta) }\end{array}$ & $t$ value & Significance & $\begin{array}{l}\text { Explained } \\
\text { variance }\end{array}$ \\
\hline $\begin{array}{l}\text { Member of an } \\
\text { environmental } \\
\text { group }\end{array}$ & .096 & .120 & 1.49 & .138 & $5.8 \%$ \\
\hline Gender & -.149 & -.161 & -2.02 & .046 & \\
\hline Age & .087 & .075 & .934 & .352 & \\
\hline Location & -.121 & -.135 & -1.67 & .097 & \\
\hline
\end{tabular}




\subsubsection{Member of an environmental group}

Linear regression testing was used to look at the relationship between students' membership of an environmental group and each of the behaviour intention themes. The living landscape behaviour intentions had a stronger relationship with the environmental group variable, with a Pearson's correlation of $r=.140$ and $\beta=.159$. This differs to the waste behaviour intentions variable, which had a Pearson's correlation of $r=.096$ and $\beta=.120$. This suggests that children who were members of an environmental group expressed a stronger willingness to plant trees and vegetables, rather than pick up rubbish and sort recycling. This was reflected when comparing the differences in means for those who were in an environmental group, with those who were not, as explained below.

\section{Living Landscapes TPB variables}

Each of the Living Landscapes TPB variables were compared with the 'member of environmental group' variable, as shown in Figure 5. A lower score on the y-axis indicates that the children had higher levels of agreement towards the questions for each variable. For the Living Landscape TPB variables, there was only a slight difference between the 'Yes' and 'No' groups. For the subjective norm variable, the difference was 0.27 (Yes $\mu=2.11$, No $\mu=2.36$ ), showing that students who were in an environmental group were more likely to have others influence their behaviour choices. Attitudes towards the behaviour had a difference of 0.27 (Yes $\mu=1.93$, No $\mu=2.20$ ), showing that those who were part of an environmental group had slightly more favourable attitude towards performing the Living Landscapes behaviours. Members of environmental groups also reported less perceived behaviour control than those who were not part of a group, with a difference of 0.14 . This indicates that those in an environmental group felt they had more control over their Living Landscapes behaviours than those not in a group. Lastly, the behaviour intentions had a difference of 0.24 , indicating that participants in an environmental group were more likely to intend to perform Living Landscapes behaviours than those not in a group. 


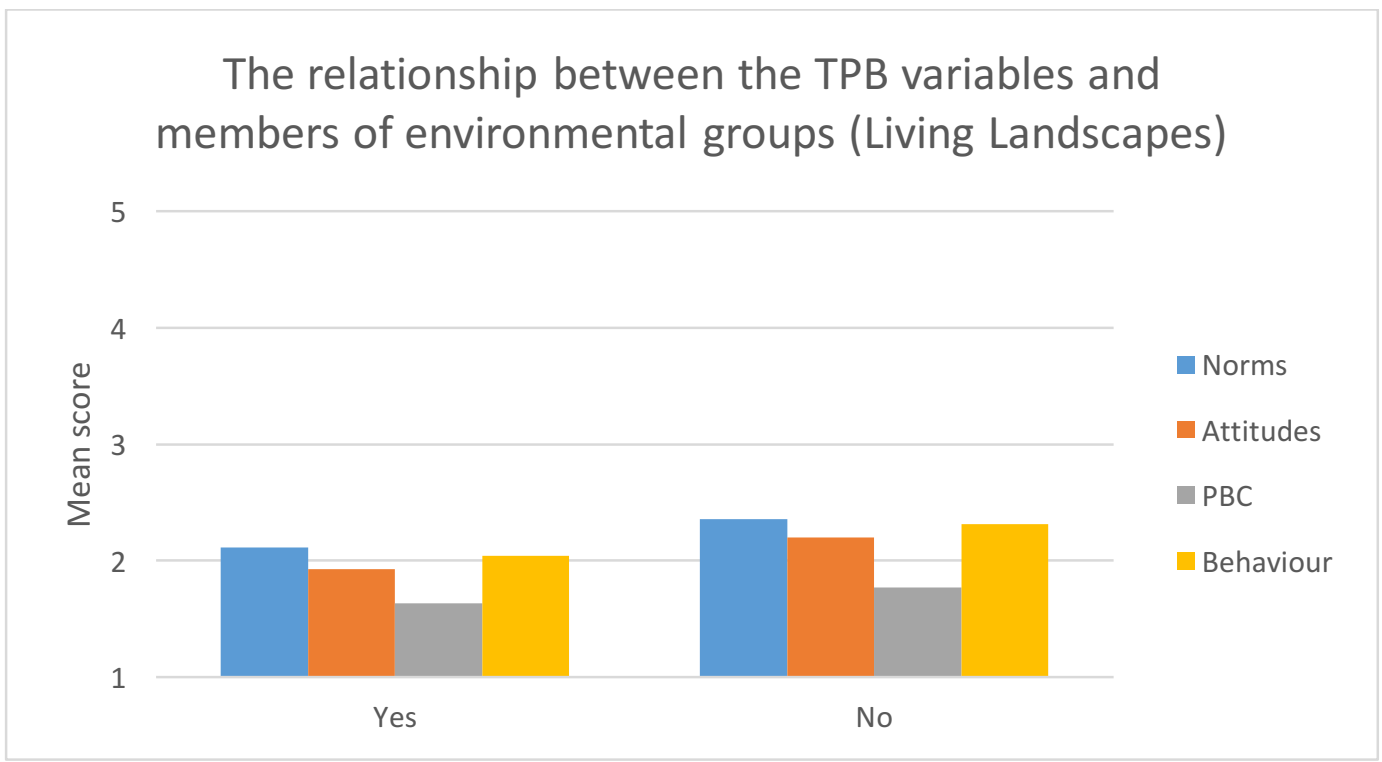

Figure 5: A comparison of the TPB Living Landscapes variables with members of an environmental group

\section{Zero Waste TPB variables}

The TPB variables for waste were compared with the environmental group variable, as shown in Figure 6. Similar to the Living Landscapes theme, it was clear that those children who were not part of an environmental group had slightly higher average score for all of the variables, meaning they disagreed more with the statements that were given in the survey. This suggests that the children who were not part of an environmental organisation tended to have less positive attitudes towards waste behaviours, less control over their behaviours, and were not influenced by others when performing waste behaviours.

The 'subjective norms' variable had a difference in means between members and nonmembers of 0.14 (Yes $\mu=2.44$, No $\mu=2.58$ ). This suggests that members of an environmental group were more likely to think others wanted them to perform waste behaviours. The difference in the means of attitudes towards the behaviour was 0.32 (Yes $\mu=2.16$, No $\mu=2.48$ ), showing that those in environmental groups held a more positive attitude towards waste behaviours than those students who were not members. Perceived behaviour control had a difference of 0.08 (Yes $\mu=1.76$, No $\mu=$ 1.84), showing that both groups felt like they had control over whether they could perform waste behaviours. Lastly, the difference in and behaviour intentions was 0.19 
(Yes $\mu=2$, No $\mu=2.19$ ) which indicates that those in an environmental group were slightly more likely to intend to perform waste behaviours.

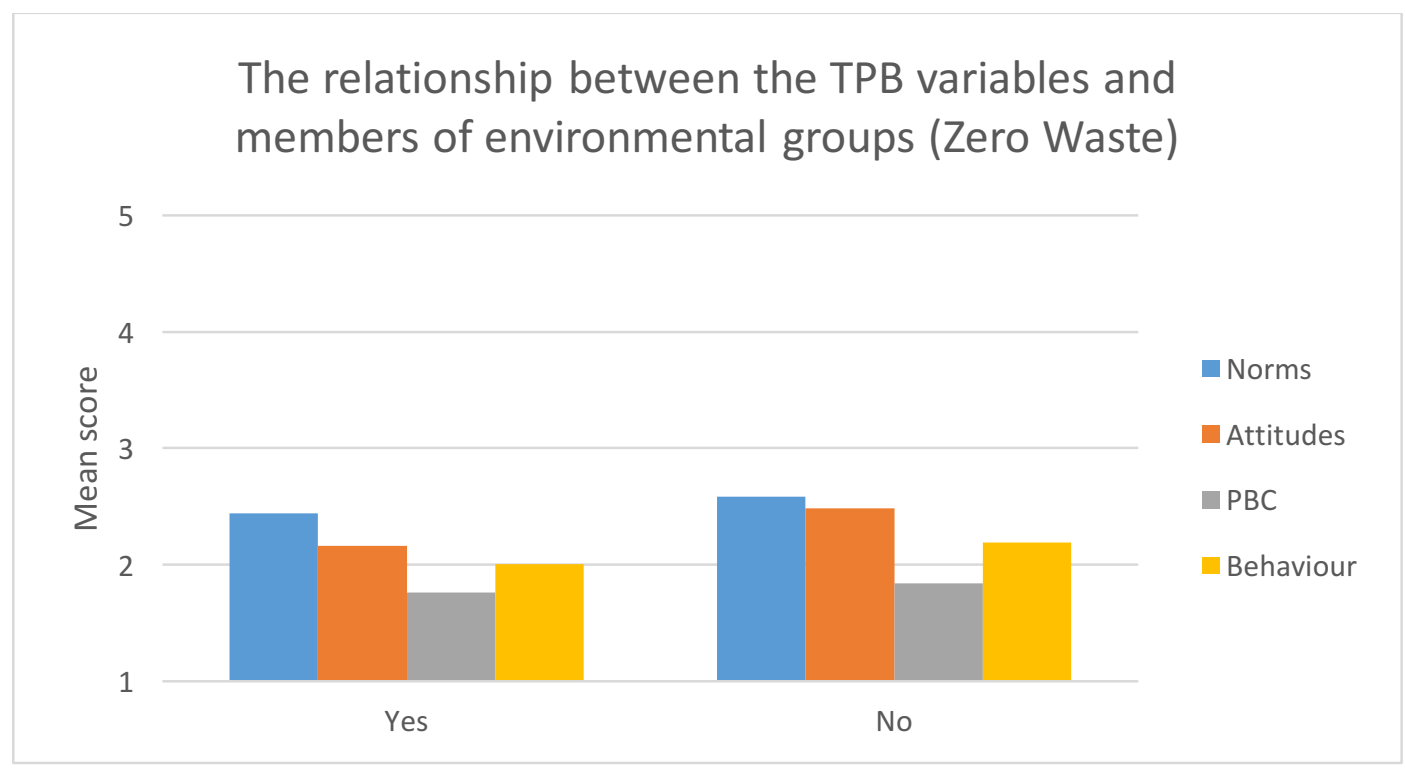

Figure 6: Comparison of TPB waste variables with members of an Environmental group

\subsubsection{Gender}

Gender was the second variable to be included in the socio-demographic regression tests. The Pearson's correlation for gender and Living Landscapes was $r=-.003$, showing a very weak, negative relationship. The standardised coefficient between the variables was $\beta=-.020(p=.804)$, showing that although there was a weak negative relationship, was not a significant finding. For the waste behaviour intentions, the Pearson's correlation was $r=-.149$ and the standardised coefficient was $\beta=-.161(p<.05)$, showing a significant, weak, and negative correlation between the two variables.

\section{Living Landscapes TPB variables}

When comparing each gender with the mean for each TPB variable of Living Landscapes, it was found that females scored lower on all the variables, indicating a higher level of agreement. The following differences in mean, between gender and the TPB variables were found: subjective norms, 0.04 (Male $\mu=2.32$, Female $\mu=2.28$ ); attitudes towards the behaviour, 0.23 (Male $\mu=2.24$, Female $\mu=2.01$ ); perceived behaviour control, 0.09 (Male $\mu=1.84$, Female $\mu=1.93$ ); and behaviour intentions, 0.02 (Male $\mu=2.25$, Female $\mu=2.23$ ). As shown by these figures, and in Figure 7 below there were minimal 
differences in the mean scores of males and females. Overall, the results suggest that both males and females were equally influenced by what others thought when intention to perform Living Landscapes behaviours. Both genders signalled that they felt they had control over their living landscape behaviour intentions as well as being likely to perform these behaviours. The only variable that showed higher levels of difference was the attitudes towards the behaviours, where females showed a more positive attitude overall to the behaviours than other genders.

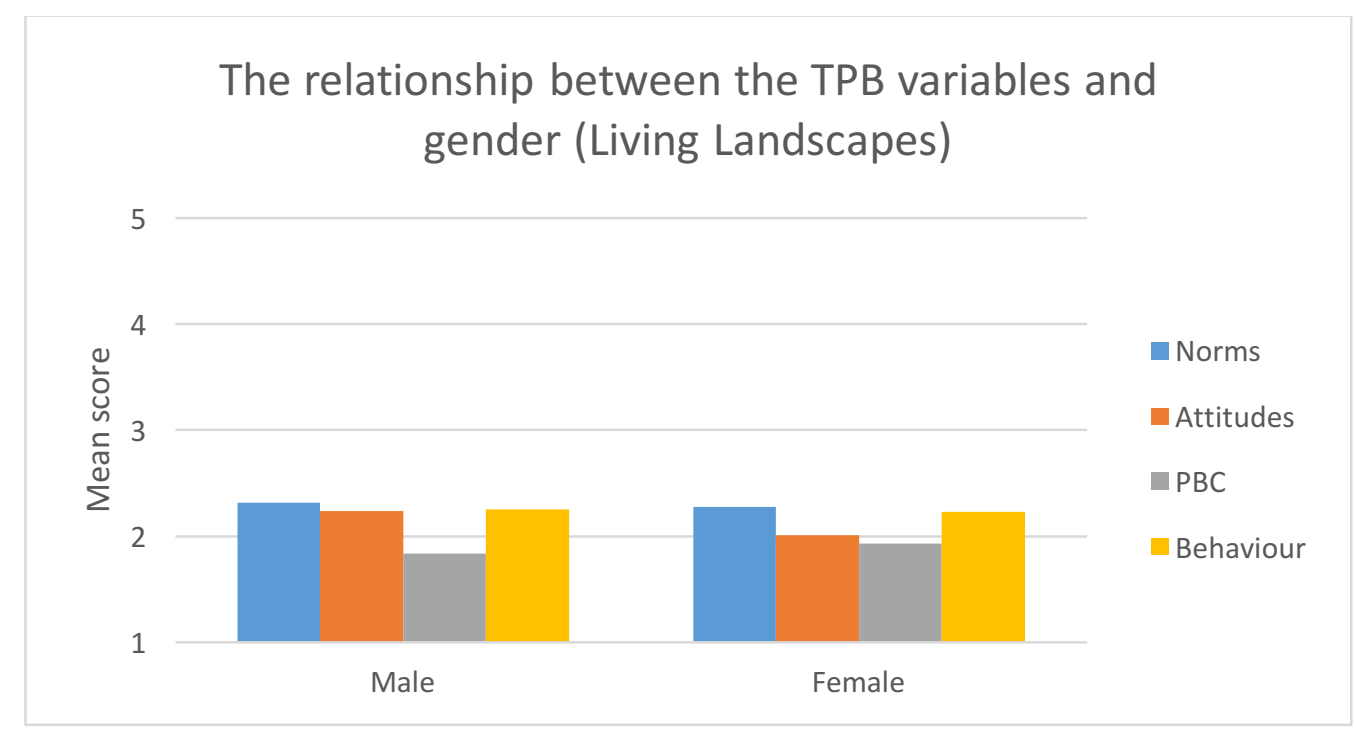

Figure 7: Comparison of TPB Living Landscapes variables with gender

\section{Zero Waste TPB variables}

When comparing the means of each gender with the waste TPB variables, females also had lower scores on all of the TPB variables, indicating higher levels of agreement. The following differences were found between the genders: subjective norms, 0.09 (Male $\mu$ $=2.59$, Female $\mu=2.5$ ); attitudes towards waste behaviours, 0.22 (Male $\mu=2.52$, Female $\mu=2.3$ ), perceived behaviour control, 0.10 (Male $\mu=1.86$, Female $\mu=1.76$ ), and behaviour intentions, 0.27 (Male $\mu=2.28$, Female $\mu=2.01$ ). These results indicate that both males and females were undecided about the influence that others had on their waste behaviours. The same was also shown with attitudes towards waste behaviours, with females showing a slightly more positive attitude. Both genders expressed that they did not feel as though they were limited to perform waste behaviours. As illustrated by the above figures and shown in Figure 8 below, the biggest difference was with behaviour intentions, where females were more likely to intend to perform a behaviour than males. 


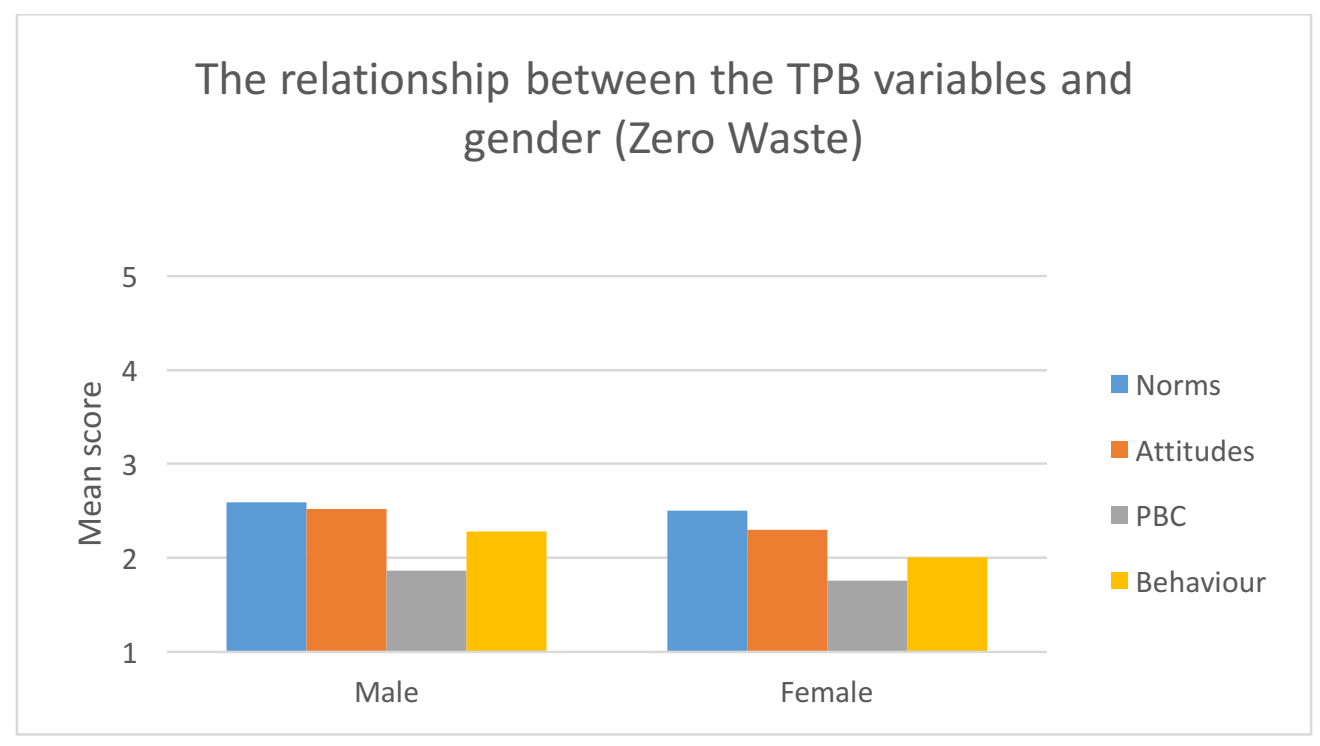

Figure 8: Comparison of the TPB Waste variables with gender

\subsubsection{Age}

When the age variable was added alongside 'environmental group' and 'gender', Pearson's correlation for the Living Landscapes behaviour intentions was $r=0.53$, with the standardised coefficient of behaviour intention and age being $\beta=.040 \quad(p=.619)$. These figures indicated a non-significant, weak and positive correlation between age and Living Landscapes behaviour intention. The same regression test was done using the waste behaviour intentions variable, obtaining the following results: Pearson's correlation, $r=0.87$ and the standardised coefficient was $\beta=.075(p=.352)$. The correlation between waste behaviour intentions and age was also non-significant, weak and positive. However, the correlation between waste behaviour intentions and age was slightly higher than the correlation between the Living Landscapes behaviour intentions and age.

\section{Living Landscapes TPB variables}

When comparing the mean of each Living Landscapes TPB variable for each age group, there appeared to be no major differences between the ages, as shown in Figure 9. When looking at subjective norms, the average scores ranged from $\mu=2.27$ to $\mu=2.92$, with the higher score being that of the 13-year-olds. However, this number is not representative only two 13 -year-olds participated in the survey. The variable of attitudes towards the behaviour had varying scores across the ages, with 12-year-olds having the lowest score of $\mu=1.93$, indicating that they have a more positive attitude 
towards the behaviour than other ages. Until the age of 12 , the level of perceived behavioural control shows an overall negative relationship with Living Landscapes behaviour intentions. This is shown by 9 -year-olds having a score of $\mu=1.76 ; 10$-yearolds of $\mu=1.77 ; 11$-year-olds had $\mu=1.64$; and 12-year-olds $\mu=1.44$. This trend indicates that younger students thought that they had less control over their Living Landscapes behaviour intentions than the older students did. Lastly, there was no apparent trend in the behaviour intentions variable, with the 10 -year-olds being most likely to intend to perform a behaviour $(\mu=2.17)$, and the 13 -year-olds being least likely to perform a behaviour $(\mu=2.83)$, followed by those children aged 11 ( $\mu=2.38)$.

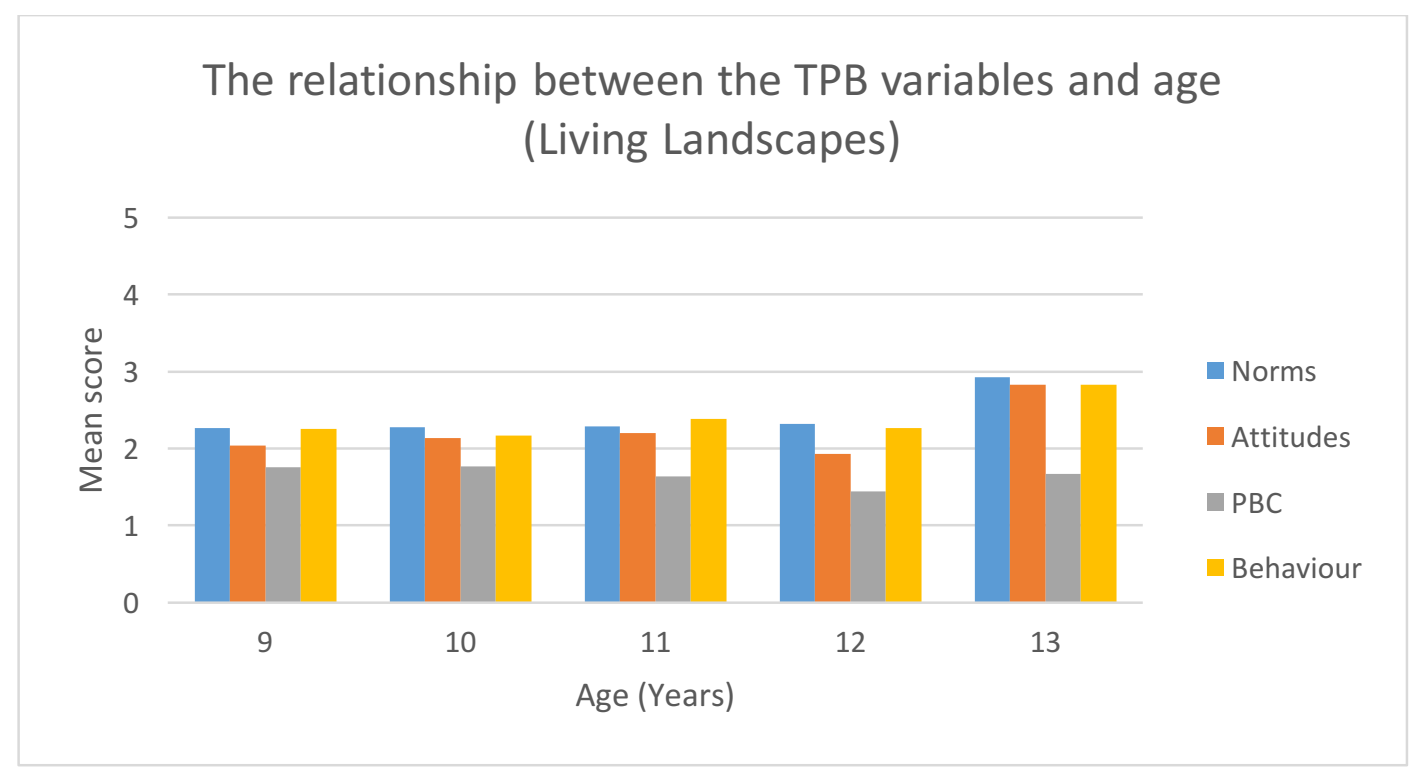

Figure 9: Comparison of the TPB Living Landscape variables with age

\section{Zero Waste TPB variables}

When comparing age to the TPB waste variables, there was minimal difference between the ages, as shown in Figure 10. Subjective norms showed no apparent trend, with the lowest score being children aged 11, showing that they are more influenced by their friends, families, and teachers $(\mu=2.44)$. The age group that indicated to be least influenced by subjective norms were the 13 -year-olds $(\mu=2.83)$, followed by 10 -yearolds $(\mu=2.59)$. When looking at the attitudes towards the behaviour, the score increases from ages 10 to 12 , ranging between $\mu=2.33$ and $\mu=2.45$. This shows that as students get older their attitudes towards waste behaviours become more negative. The 13 and 9-year-olds were outliers, with scores of $\mu=3.25$ and $\mu=2.47$ respectively. 
Perceived behaviour control is at its lowest in the ages of 11 and 12, both with scores of $\mu=1.67$. Those students who felt they had less control over their waste behaviours were in the ages of 10 and 13 , with scores of $\mu=1.92$, and $\mu=1.87$ respectively. Similar to the rest of the waste TPB variables, behaviour intentions showed no apparent trend across the different ages. The age group most likely to intend to perform a behaviour were 11year-olds $(\mu=2.00)$, followed closely by 9 -year-olds $(\mu=2.03)$. Those least likely to intend to perform a behaviour were 13-year-olds with an average score of $\mu=3.16$, followed by 12 -year-olds with an average score of $\mu=2.28$.

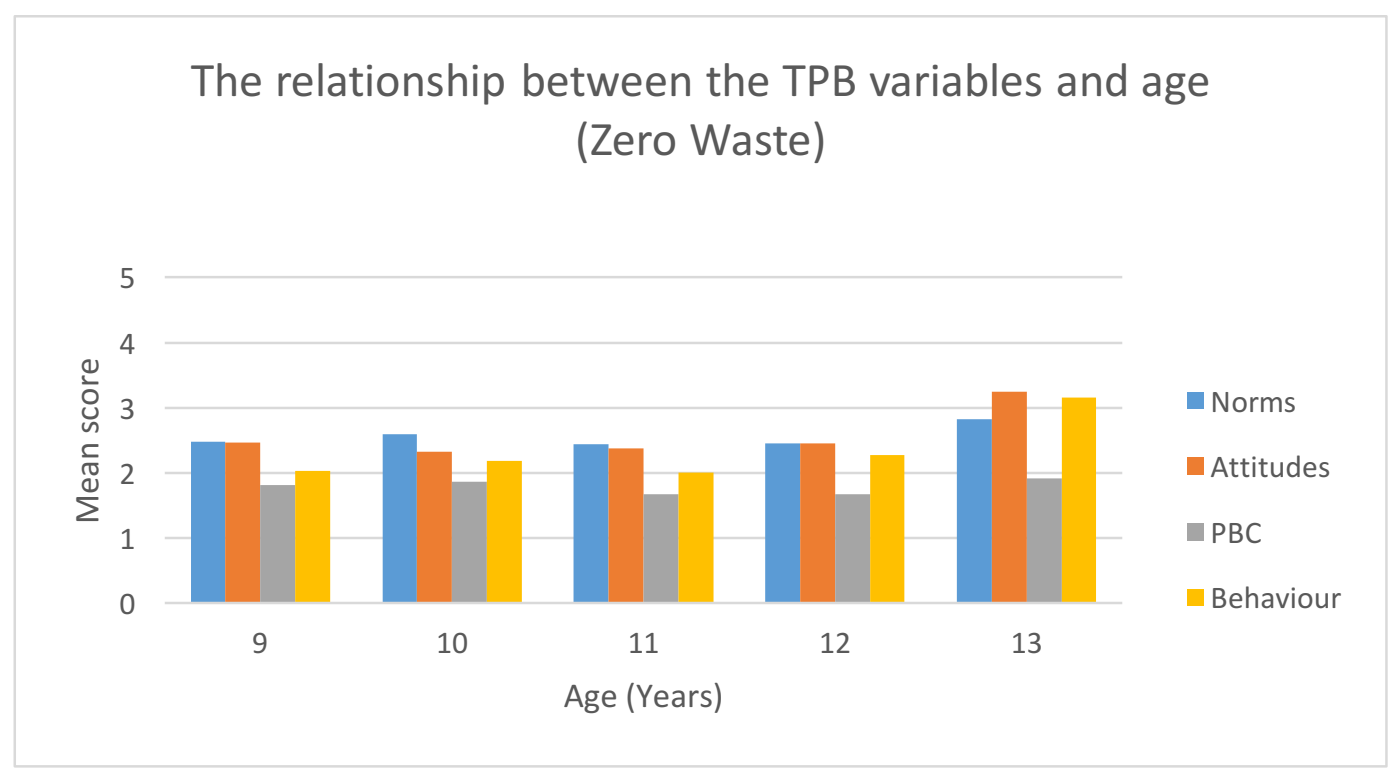

Figure 10: Comparison of the TPB Waste variables with age

\subsubsection{Location}

Location was the last of the socio-demographic variables to be added to the regression tests. Conducting a Pearson's correlation test against Living Landscapes behaviour intentions produced a correlation of $r=-.149$. This result indicated that location had a weak, negative relationship with behaviour intentions for Living Landscapes. The standardised coefficient for location and Living Landscapes behaviour intentions was $\beta=$ $-.162(p<.05)$, showing a significant, weak and negative correlation between the two variables. This correlation suggests that where a person lives has a weak, negative influence over their intentions to perform living landscape behaviours.

When completing the same tests using the waste behaviour intentions variable, Pearson's correlation with the rest of the socio-demographics variables was $r=-.121$, 
showing a negative, weak relationship. The same relationship is shown in the standardised coefficient of waste behaviour intentions and location, with $\beta=-.135$ $(p=.097)$. This suggests that where a person lives negatively influences their intentions to perform waste behaviours. However, as indicated by the p-value, this result is not significant.

\section{Living Landscapes TPB variables}

When comparing the different locations with the mean scores for TPB Living Landscapes variables, the results found that those children living in rural areas had lower scores on all four variables, as shown in Figure 11. This indicates that rural children showed positive attitudes towards Living Landscapes behaviours, were influenced by others, and had stronger living landscape behaviour intentions. For the subjective norms, the location that scored the highest was those who lived in the town $(\mu=2.38)$, suggesting that students living in a town were less likely to be influenced by what others wanted them to do. The 'attitudes towards the behaviour' variable indicated that those children who lived in the city had the highest score $(\mu=2.19)$, showing that they were more likely to have a negative attitude towards performing a living landscape behaviour. When looking at the amount of control that students thought they had over performing a behaviour, the children who lived in a town had the highest score $(\mu=2.02)$. This suggests they felt there were a number of controls limiting them from performing the behaviour. When examining behaviour intentions, the group that was least likely to have the intention to perform a behaviour was those who lived in the city $(\mu=2.34)$. 


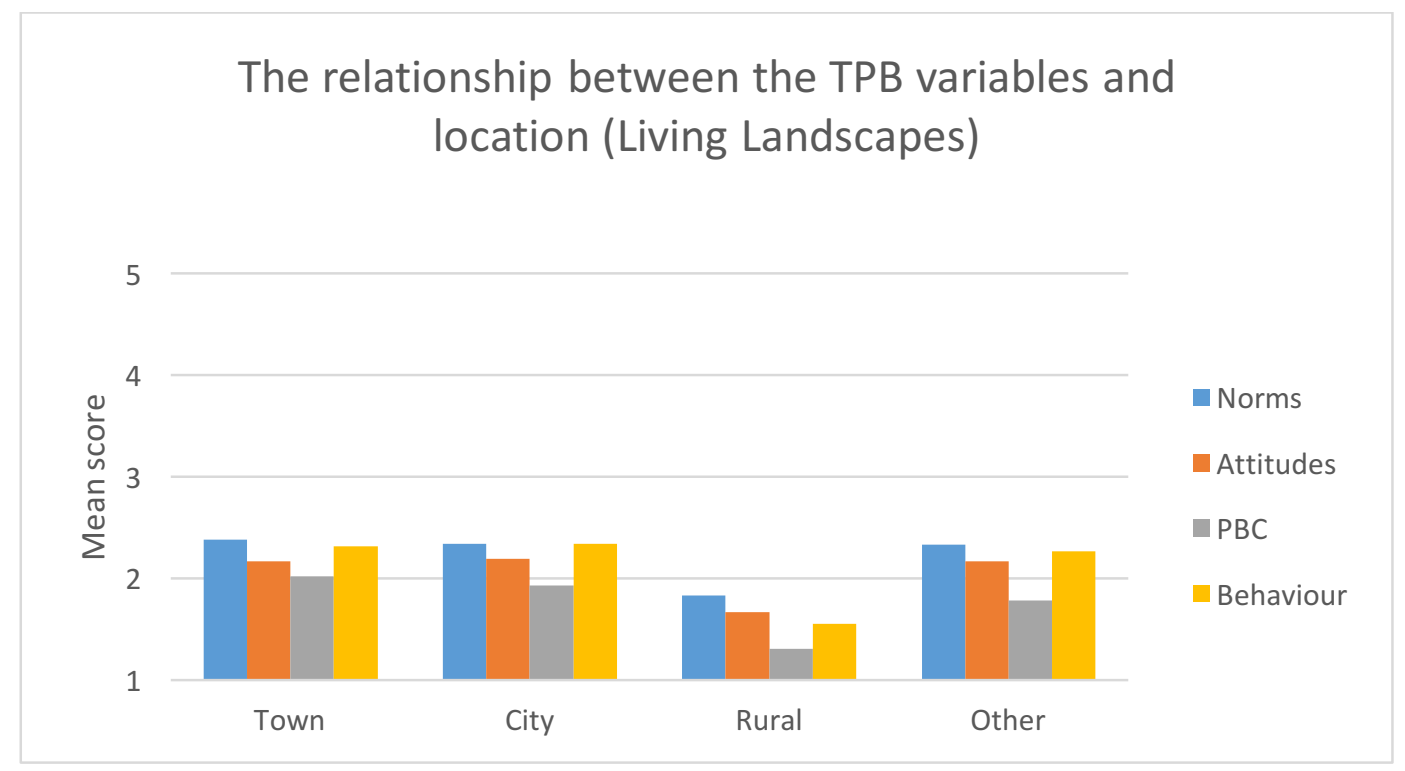

Figure 11: Comparison of the TPB Living Landscape variables with location

\section{Zero Waste TPB variables}

The mean score from each location was then compared to the TPB waste variables, as shown in Figure 12 below. Similar to the Living Landscapes theme, the 'Rural' group had lower scores in almost all of the TPB variables. As shown in the Figure 12, those who were classed as 'Other' (which included a range of answers such as suburbs or different locations depending which parent they were with) had the highest subjective norm scores, with an average of $\mu=2.83$. This suggests that these students were less likely to be influenced by others, compared to those in rural areas, who had the lowest score of $\mu=2.21$. The 'Other' location also had the highest score for attitudes towards waste behaviours ( $\mu=2.63$ ), followed by those in a town, with an average score of $\mu=2.46$. The lowest score was those living in a rural area who had a score of $\mu=2.24$, showing that rural students had a more positive attitude towards waste behaviours.

When looking at perceived behaviour control, the highest scoring was those in the town, with an average score of $\mu=1.95$, showing that these children felt that they had the least control over performing waste related behaviours. The lowest average score for perceived behaviour control was from those who lived in the city, with a score of $\mu=$ 1.70. However, those in rural areas with an average score of $\mu=1.72$ followed this closely. This indicates that these two groups felt they had more control over their waste behaviours. Lastly, when behaviour intentions were examined, the group most likely to 
perform waste behaviours were those living in a rural area, with an average score of $\mu=$ 1.96. The group who were least likely to perform a behaviour were those who lived in a town, with an average score of $\mu=2.29$.

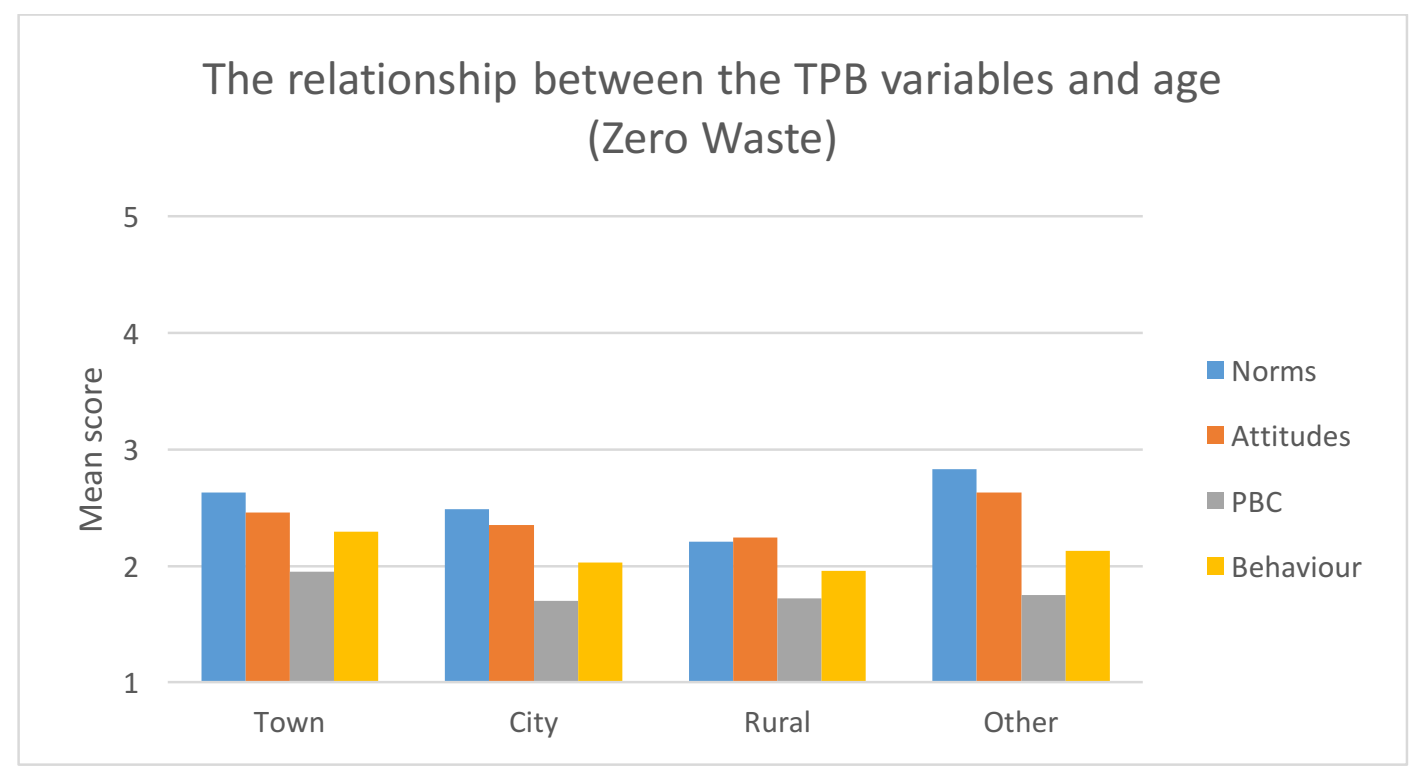

Figure 12: Comparison of the TPB Waste variables and Location

\section{Socio-demographics summary}

Overall, the socio-demographic characteristics had weak, negative relationships with both the Living Landscapes and Zero Waste behaviour intentions. When examining the Living Landscapes behaviour intentions, the socio-demographic variable that had the strongest positive correlation was 'member of an environmental group'. This suggests that students who were members of an environmental group were more willing to perform behaviours that related to gardening. The variable that showed the strongest, negative correlation with Living Landscapes behaviour intentions was location. This shows that those who lived in a town were less likely to engage with these behaviours. Overall, the socio-demographic characteristics used in this test explained $4.8 \%$ of the variance in Living Landscapes behaviour intentions.

When looking at the waste behaviour intentions variable, the strongest positive correlation was also the 'member of an environmental group', indicating that members of environmental groups were more likely to perform waste behaviours. The strongest negative correlation was between waste behaviour intentions and gender. This shows that girls had stronger intentions to perform waste behaviours than boys did. Overall, 
including the socio-demographic variables in the regression test explained $5.8 \%$ of the variance in waste behaviour intentions.

When a multiple linear regression test was done using only the TPB variables, the Living Landscapes behaviour intentions had an explained variance of $72.9 \%\left(R^{2}=.729\right)$. When the socio-demographic characteristics were added, the explained variance increased to $73 \%\left(R^{2}=.730\right)$. This indicates that the socio-demographic characteristics made virtually no difference to the explained variance of Living Landscapes behaviour intentions when the TPB variables were included in the test. Conducting the same test with waste behaviour intentions, the TPB variables for waste showed an explained variance of $55.7 \%\left(R^{2}=.557\right)$. When the socio-demographic variables were added to the test, the explained variance increased to $56.9 \%\left(R^{2}=.569\right)$, indicating that socio-demographics contributed a small amount to the variance in waste behaviour intentions. 


\section{Chapter 5: Discussion}

\subsection{Introduction}

Little research has been done looking into the TPB and EfS programmes in New Zealand, in particular the Enviroschools programme. The findings from this study highlight the importance of having support for EfS from a top-down perspective (the government) through policy, as well as having organisations such as Enviroschools working directly with the community to implement education policy.

The aim of this study was to examine how well the TPB variables predicted the behaviour intentions of children whose schools were part of the Enviroschools programme in the Greater Wellington region. This research also aimed to look at how teachers at these schools implemented this programme and perceived the challenges and benefits of being an Enviroschool. Through this research, the researcher was able to gain a greater understanding into which TPB variables can best predict intentions to engage in behaviours such as planting trees (Living Landscapes) and picking up litter (Zero Waste). The findings explained in the results chapter can be used to provide guidance to the Enviroschools organisation, teachers and education policy regarding which motivators to focus on when trying to change children's behaviour intentions. The results from the qualitative research can help the Enviroschools organisation become aware of both areas that teachers struggle with and areas that the programme excels, thus to improve the content and delivery of the programme as a whole.

This chapter is divided into each study, first discussing the results from the qualitative study and secondly the quantitative study. These results are discussed in the context of similar studies, looking at any differences or similarities and the wider implications of these results in relation to education policy and the Enviroschools programme. This chapter concludes by discussing limitations that were found in the research, recommendations for future research and the concluding comments. 


\subsection{Study One: Implementation and experience of the Enviroschools programme}

\section{from teachers' perspectives}

As mentioned in the results chapter, when teachers were questioned about how the Enviroschools programme worked in their schools, the key themes that arose were: the school's vision, their Enviroschools journey, parental awareness, the integration of EfS, and school environmental activities. When asked about action competence in their teaching, several teachers were unsure about what the term meant, but when provided with a definition and probed for examples of action competence, teachers often referred to enquiry-based learning that was incorporated into their teaching.

The central theme that emerged from the interviews was the vision that schools had for their future. When caring for the environment was a strong part of a school's identity, teachers were more likely to have integrated the Enviroschools programme strongly throughout their teaching. Several schools used their strong environmental identity as a way of creating a point of difference to encourage parents to enrol their children at the school. Teachers assumed that parents would enrol their children in the school to ensure the environmental messages would be part of their education. The vision of the school also played a large role in why schools joined the Enviroschools programme in the first place. Often schools joined up because they felt that the programme fitted naturally within their school already, due to their strong environmental identity. Other schools felt that joining the programme would help them expand on their environmental identity and saw this expansion as part of their future vision. EfS is not a compulsory part of the curriculum, meaning that organisations like Enviroschools rely on schools with a strong environmental vision to sign up to the programme and support this type of education.

The theme of 'parental awareness' was important in determining the success the Enviroschools programme in schools. This theme linked closely with the theme of 'school vision' as parents had a strong role in helping shape the future goals of their child's school. The parental awareness theme arose from the interviews as it addressed the challenges, such as finances or culture, which parents face when trying to act proenvironmentally. It was difficult for many schools to implement a zero waste initiative if 
parents were largely unaware of this issue and gave their children packaged food in their lunches. Perhaps this is a reflection of today's society where people are spending less time preparing their food, choosing to eat foods that are pre-made and/or packaged. $A$ study conducted by Smith, Ng, and Popkin (2013) supports this idea by analysing trends of food preparation and consumption in the USA from 1965 - 1966 to 2007 - 2008. Their study found that between 1965 and 2008 time spent preparing food declined, particularly in households with low-income levels. The authors suggest that the decline was due to a shift towards processed and packaged food requiring little preparation. With this in mind, it is important that schools continue to educate students and their parents about the benefits of growing and preparing their own food in order to reduce consumption of packaged and processed food.

Some teachers felt that some parents were limited financially, and their busy lifestyles made it more difficult to act pro-environmentally. Although socio-economic factors were not examined in the present study, income levels were highlighted by teachers as being a potential limitation for students wanting to reduce the amount of rubbish that comes in their lunchboxes. This may apply to a number of students and poses an issue for schools trying to reduce the waste in their school through the Enviroschools' theme of 'Zero Waste'. Despite teachers believing a family's financial situation impacted on their ability to act pro-environmentally, studies show that those with less money are more likely to act pro-environmentally as a way of saving money (Franzen, 2003). Sociodemographic factors can also be linked to cultural influences where families come from countries where societal norms around waste and environmental issues may be different to New Zealand. Kollmuss and Agyeman (2002) suggest that cultural norms can cause people to act pro-environmentally even if they do not show concern for the environment. If behaviours, such as reducing waste are not part of a family's cultural norms, then they may be less likely to perform the desired behaviours. This links to the quantitative study, which showed that subjective norms strongly influenced Living Landscapes behaviours.

On the other hand, schools with groups of parents who pushed for environmental activities to happen, such as the bike park at Ridgway School, played an important part in making the Enviroschools programme more successful in schools. The literature 
highlights that parents have an important role in their child's education experience and are encouraged to devote their skills and time to activities at their child's school (McNamara et al., 2000; Reay, 2004). Although several parents were willing to volunteer their time and skills towards environmental activities in the present study, often the skillsets of the parents did not match what was needed for the desired activity. The fact that some schools rely on the support of parents and caregivers highlights the issue of accessibility to resources that some schools face. A potential solution would be for the Enviroschools programme to hold classes for parents, teaching them the skills needed for different environmental activities, such as planting and maintaining a vegetable garden. This would allow parents to gain a new skill-set and enable them to bring this knowledge into their child's school and their homes.

Most of the teachers interviewed noted that environmental messages communicated via the children from the Enviroschools programme had an impact on parents. As shown in the results chapter, parents would tell teachers about the changes that had been made at home because of the influence that the Enviroschools programme had on their children. Examples were given of students getting their family to start composting and separating their rubbish into recycling. Parents also noted how their children would stop them from getting plastic bags in the supermarket because of the impact that they have on the environment. This shows that students were going home and sharing the knowledge that they had learned at school through the Enviroschools programme with their parents.

Although the relationship between children's education and their parents' environmental awareness was not measured in the present study, it was still an interesting observation from the teachers and shows a similar result to the study done by Evans and Gill (1996). This study looked at the impact that children receiving environmental education had on their parent's environmental attitudes in England. Their results indicated that parent's knowledge about recycling used materials did not increase after their children received education about recycling. This shows that children can have an influence on their parents' behaviours but not necessarily their knowledge or awareness about environmental issues. However, the number of parents who recycled paper, tin cans and plastics increased after their children had received such 
education. Another study done by Vaughan et al. (2003) showed that parents in a Costa Rican village increased their conservation knowledge after their children had received education about the topic. It was also found that children receiving this education had an indirect impact on community members who had no connection to children in the programme. The conservation knowledge of these community members also increased, showing the extent that information can spread through educating children. If the education given to students through the Enviroschools programme is having a similar impact on parents, as indicated by the results in the present study then then it indicates that the programme is an effective way to encourage behaviour change at a societal or community level. This is an important finding as it links strongly with the Enviroschools organisation's goal of using their programme to create change within student's families and wider communities (Enviroschools, 2014).

\subsubsection{Education for Sustainability integration in schools}

The ways in which the Enviroschools programme was incorporated into schools impacted students and the community in different ways. As mentioned in the results chapter, teachers who saw the Enviroschools programme as being a success felt that it was because it had been integrated throughout the whole school. Having a "whole school approach" was helped by having supportive Enviroschools facilitators who provided the lead teachers with effective resources, guidance and advice. Another key contributor to a successful integration of the programme was having the support from the other teachers in the school. The teachers who felt they had successfully integrated the Enviroschools programme had strong support from their fellow colleagues. The success of integrating the Enviroschools programme into a school was also dependant on how the environmental messages were being taught; schools who took a strong interest in the environmental knowledge that they were giving their students incorporated the Enviroschools themes and principles into every lesson they taught. They would encourage students to think holistically about environmental issues in terms of their impact on the others, the environment and the school, instead of looking at these issues in isolation. 
Those teachers who saw their Enviroschools programme as not having the desired impact on their school believed that this was because other teachers saw the programme as an extra activity on top of their normal teaching. This meant that those teachers did not emphasise the importance of the programme, nor incorporate it throughout their everyday teaching. A study looking at perspectives teachers have of environmental education/EfS show that teachers felt they did not know enough about environmental issues to be able to teach it to their full capacity (Cutter-Mackenzie \& Smith, 2003). A study done by Spiropoulou et al. (2007) also suggested that teachers were reluctant to be involved in environmental education programmes due to their lack of knowledge on the topic. Cutter-Mackenzie and Smith (2003) highlighted that the majority of the teachers surveyed did not receive environmental education training. This could be a potential explanation as to why a number of teachers in the Enviroschools programme were reluctant to get involved, as they may have identified a lack of knowledge in this area and felt uncomfortable teaching it. It appeared that the lead Enviroschools teachers were provided with resources and support but the same was not done for other teachers in the school.

This issue was often overcome with enquiry-based learning. This type of learning became popular in a number of Western countries and was used as a way to get students more involved in their learning, becoming student-directed rather than teacher-directed (Lee, 2012). Teachers would be given a theme and students would subsequently come up with questions that they would want to find out about the topic. Their learning would be structured around the themes and students would complete 'enquiries' to find out the answers to questions that interested them about that theme. This type of teaching linked closely to the idea of 'action competence' that the Enviroschools programme emphasises in its implementation. The key idea behind action competence was that students were leading the action and taking this action without being influenced by what others were doing (Jensen \& Schnack, 2006).

When applying the four components of action competence (Jensen, 2002) to the Enviroschools programme (knowledge about effects, knowledge about root causes, knowledge about strategies for change, knowledge about alternatives and visions), it was clear teachers had adopted several of these. Teachers often mentioned educating 
students about the effects and causes of environmental issues, through completing enquiries on environmental topics and learning in the outdoors. An example of this was the water enquiry done at Eastern Hutt School, where depending on their age; children would be educated about different aspects of the water cycle and took part in some kind of learning in the outdoors. However, it was difficult to gauge from the interviews whether the other two dimensions of action competence were incorporated into teaching. Teachers did not go into detail on how they provided information about strategies for change or alternative ways of overcoming the environmental issues. This finding highlights a difference in the theory behind how action competence should be encouraged and what actually happens in practice. This may be because teachers are unaware of the four components of action competence or simply because they have not been provided training on how to encourage this capability in students.

The students also played a large part in how well the Enviroschools programme was integrated throughout their schools. Teachers noted that they faced no difficulties with getting students engaged with the programme and most activities. However, most lead teachers struggled to get the students to take responsibility for picking up their rubbish and completing other waste related behaviours. Some teachers felt that this was due to the creation of enviro-groups within the school. Students who were not part of these groups did not feel responsible to complete tasks viewed as being for the enviro-group students, such as emptying the school compost bins. Schools tried to mitigate this by removing the enviro-group from their school so that the whole school was essentially an enviro-group and all students felt included in the activities they did. Another solution was to break down the enviro-group into smaller groups so that more students could be included within them. Encouraging students to feel involved and engaged in the environmental activities their schools were partaking in can help all pupils to feel like they are contributing and making a difference. The surveys conducted in study two showed that those students who were in an environmental group had stronger intentions to performs waste and Living Landscapes behaviours. Therefore, if students feel more involved in these activities, then they may be more likely to perform these behaviours in the future. 
If the integration of the Enviroschools programme was successful in a school, the impacts could be seen throughout the community. Those schools who had an active involvement in their community often felt that their students were more connected to their community and felt as though they could make a difference. Teachers considered this a huge benefit for both the students and their community. It would also often result in an increase in financial support from the community for school activities, such as painting murals and tree planting. Having a connection with the local community could mean that the environmental knowledge and behaviours that students were gaining through the Enviroschools programme were transferred to others in the community, who may not have had that exposure otherwise. The study done by Vaughan et al. (2003) showed that when children received environmental education they were able to raise awareness about environmental issues throughout the community over a period of time. However, teachers noted that without the support from the community, the Enviroschools programme was not as successful as it could be. If the local community was not engaged with what schools were doing, then teachers saw that it was very difficult for students to attain a sense of achievement in their community. One way to encourage community involvement and engagement is to foster collaboration between the school and community groups (Epstein, 2008).

The benefits of the Enviroschools programme also included student engagement and the resulting perceived behaviour change of both the student and their parents. Teachers also mentioned that some of these behaviours might have come from outside the school environment, and hoped that students would maintain these behaviours throughout their lives. In terms of challenges, teachers felt that the cultural background that students came from had a big influence into how important they perceived environmental issues. The student's mind-set also proved a challenge as many students felt that they did not need to take responsibility for issues such as waste. Location and resources were the final two themes that were identified as being a challenge for the lead teachers at the schools. Location, in the sense that where a school was situated, often limited the amount of resources that they had access to as well as the fact that many schools relied on parents volunteering to make the Enviroschools programme successful. 


\subsection{Study Two: Using the TPB to explain behaviour intentions}

The results of the quantitative study suggest that the TPB was able to predict behaviour intentions for both Living Landscapes and waste. However, it was evident that the TPB was better at predicting Living Landscapes behaviour intentions than waste behaviour intentions. This is shown by TPB variables explaining a higher level of variance for Living Landscapes than for waste.

When looking specifically at the relationships between the TPB variables, one of the most interesting findings from the survey was the difference in the standardised regression coefficients between the two themes of behaviour intentions (Living Landscapes and Zero Waste). For Living Landscapes, each of the three TPB variables were predictors of behaviour intentions, when the other TPB variables were controlled for. The strongest predictor for Living Landscapes behaviour intentions was 'perceived behaviour control', showing that if the children perceived there to be fewer barriers to them performing the behaviour, then they were more likely to do it. This may have been the strongest predictor of behaviour intentions because it is a harder behaviour to achieve than the waste behaviour intentions. As the Living Landscapes theme focuses on planting trees in the community and having vegetable gardens both at home and at school, it relies on the students having the space, commitment, and ability to plant at home or in the community. If they live in a location where they are unable to have a garden, such as in an apartment in the city, then they are likely to perceive this as something that they do not have control over and therefore limits their ability to perform these behaviours. The interviews done in city schools showed most of their teaching had a stronger focus on waste than on gardening, meaning that alternative ways of growing an edible garden at home (such as in pot plants) may not have been communicated to the students.

These results differ to that of the waste theme, where only attitudes towards the behaviour and perceived behaviour control predicted behaviour intentions when the other TPB variables were controlled for. The waste subjective norms variable had a very weak relationship with behaviour intentions and the standardised regression coefficient was not significant. This means that other people did not influence students when they 
were considered performing waste behaviours. This may have been because waste behaviours were more ingrained than gardening into the culture of the school and society, meaning students were not influenced by what others thought they should be doing. As mentioned previously, almost all of the schools that were involved in the study had put a strong emphasis on having Zero Waste in their school. Reducing waste was potentially an easy behaviour for schools to target - as opposed to deeper environmental problems such as climate change (Robertson \& Krugly-Smolska, 1997). Schools may also be limited by the themes that Enviroschools offers - as there are only five - and therefore select the themes they feel most comfortable with. The TPB variable that best predicted behaviour intentions for waste was attitudes towards the behaviour, which had a moderate positive relationship between the two variables. This shows that if children have a positive attitude towards intending to perform a waste related behaviour, then they are more likely to do it. Therefore, in order to influence children's waste behaviour intentions, educators should focus on changing students' attitudes towards waste behaviours'.

Looking at previous studies that use the TPB, the results from the Living Landscapes behaviour intentions are confirmed with perceived behavioural control being the strongest predictor for behaviour intentions. Perceived behavioural control was also the strongest predictor for behaviour intentions in the TPB studies done by Murtagh et al. (2012), looking at active travel behaviour intentions; Kaiser et al. (2005), looking at conservation behaviour intentions; and Hewitt and Stephens (2007), looking at healthy eating behaviour. However, attitudes towards the behaviour was the strongest predictor for waste behaviour intentions, which was a finding not confirmed by the studies examined in the literature review. Perceived behaviour control may not have been as strong of a predictor for Zero Waste behaviour intentions as it was for Living Landscapes, because it is an easy behaviour to perform, that does not require much effort to do (pick up rubbish or recycle) nor does it require many resources (compared with gardening).

Environmental concern, measured through the NEP scale, was not shown to add a great deal to the overall explained variance of behaviour intentions. The NEP scale added more to the explained variance of waste behaviour intentions, rather than Living 
Landscapes behaviour intentions. This differs to previous studies using the adapted version of the NEP scale to measure environmental concern in children. Firstly, a study done with children in Spanish summer camps showed a stronger relationship with the NEP Scale for children than the present study (Collado et al., 2013). Their results showed that being exposed to nature altered the worldviews of the students who attended. $A$ similar study conducted in China showed similar results but used version of the NEP scale for children that contained 15 items, instead of the 10 used in the present study $(\mathrm{Wu}, 2012)$. As the present study did not look at the effects of the Enviroschools programme on students before and after, it is difficult to compare with the Spanish study. However, in both the Spanish study and the present study the regression coefficient scores showed similar weak, positive relationships between the NEP scale and behaviour intentions.

When comparing socio-demographic characteristics with behaviour intentions, the variables of 'member of an environmental organisation', 'gender', 'age', and 'location' did not contribute significantly to the explained variance of behaviour intentions. The only socio-demographic variable that had a significant relationship with waste was that between gender and waste behaviour intentions, which had a weak, negative relationship. This shows that girls had stronger intentions to perform waste related behaviours such as picking up litter, than males did. For Living Landscapes, the only sociodemographic variable that had a significant relationship with behaviour intentions was location. This relationship was weak and negative which shows that students living in rural areas and areas classed as 'other', were more likely to intend to perform living landscape behaviours than those living in towns or cities. Overall, the sociodemographic features did not add much to the explained variance of behaviour intentions for waste and Living Landscapes, showing that other factors had a stronger influence on behaviour intentions.

\subsection{Limitations}

The present study had a number of limitations. Firstly, when a reliability test was completed on the NEP scale, it proved to have a relatively low Cronbach's alpha, casting doubt on its validity as a measure of environmental concern. This was an unusual result 
given that this scale had been used in previous research with students of a similar age group and had shown good reliability scores. A similar study had relatively high levels of explained variance (36\%) using a version of the NEP scale that had 15 items (eight items assessing the ecological view, and seven assessing an anthropocentric view) and three dimensions (Van Petegem \& Blieck, 2006). This shows that including the extra five items into the NEP scale used in the present study may have made it more reliable. It is also worth noting that in the study by Van Petegem and Blieck (2006), the age group used for their study was slightly older than that used in the present study. This may have meant that the students had a better understanding of the 15 statements as they had higher levels of comprehension.

The low reliability score of the present study meant that the average NEP score for students had to be interpreted with caution. Therefore, it was difficult to compare levels of environmental concern with the TPB and behaviour intentions knowing that the results for environmental concern may not have represented what the children truly thought, due to potentially misunderstanding the wording of the statements. The understanding of this scale was a concern at the beginning of the study, as mentioned in the methodology chapter, therefore a pilot test was done to ensure that students would understand all of the items in the scale. This pilot resulted in one of the scale items having a definition included because the children did not know what the 'Laws of nature' meant. It may be that surveyed students did not fully understand the statements, or that different students interpreted the statements differently. The statements may have also needed an update to make them relevant to today's children, as the children's version of the NEP Scale was first formed over 10 years ago (Manoli et al., 2007).

The students may have needed more clarification about some of the terms used in the NEP scale and, even though they may have asked teachers to explain a statement, they may still have been unsure about what they were being asked. One way to overcome this may have been for each of the 10 NEP statements to be read aloud to the students as was done in the study by Collado et al. (2013). This would have meant if any clarification around a statement was needed the researcher or teacher would have been able to explain the statement to all of the participants, rather than just one. Another 
change that could have been made would have been to use a version of the NEP Scale that contained 15 items instead of the 10 items that were used in the present study. The studies that used the NEP Scale for children containing 15 items had good reliability scores, showing that the five extra items may have improved the overall reliability of the scale (Van Petegem \& Blieck, 2006).

Another limitation of the present study was the recruitment of participants, which delayed data collection. At the beginning of the research, the study was limited to two schools from the Wairarapa and two from Wellington city in order to get an equal representation of rural and urban students. However, after the first school was surveyed it became evident that more schools would need to be recruited due to a lack of participants returning parental consent forms. A concerted effort was made to encourage the return of parental consent forms, such as sending reminders to the teachers in charge about the importance of the consent forms, however this did not significantly increase participant recruitment. A further three schools were recruited to gain more participants, taking the total number of schools involved to seven, which resulted in a sample size of 155 students. In order to avoid the low return rate of consent forms in the future, an incentive, such as a prize, would have been used to get students to return their consent forms. Incentives have shown to be an effective way of getting people to perform a desired behaviour (Schultz, 2014). However, as the problem was discovered after the survey of the first school had been distributed and completed; incentives could not be used in the present study, as they would have needed to be used in all of the schools to make sure the sample was unbiased.

\subsection{Uses and recommendations for future research}

This research produced findings that can be used in a range of ways. The findings of the qualitative study can offer insight to policy makers and the Enviroschools organisation about the different ways that the programme is implemented in schools. The benefits teachers perceived as arising from the Enviroschools programme can be used to influence education policy and the way that EfS is framed within the curriculum. Benefits such as the influence on parents and creating community engagement could be a good way to create a societal behaviour change by having the Enviroschools programme (or 
similar education programme) compulsory in schools. In terms of the challenges, these can be used by the Enviroschools organisation to improve the experiences had by lead teachers. For example, support from other teachers appeared to be an issue for a number of lead teachers. One way to overcome this could be to provide all teachers in an Enviroschool with information and knowledge about the environmental issues that they are meant to be teaching. If the programme were better integrated into the curriculum, then teachers would have more time allocated to teaching it, rather than it just being an extra activity to add on if they have the interest or time. This information would also help support the argument to have EfS as a compulsory part of the curriculum to allow more time to be spent on teaching the topic and incorporating it into other parts of the curriculum. The challenges could also be used to identify any current gaps that the Enviroschools programme has and allow the organisation to address them through another means.

Action competence or the 'action learning cycle' is another area within the Enviroschools programme that could be improved on. Many teachers were unclear about what 'action competence' was and, provided that it is a concept that Enviroschools emphasises in their programme, more information should be given to teachers about what it is and how to promote it in their classroom. Action competence is argued by researchers to be one of the few ways that information provision can lead to behaviour change (Jensen, 2002). Therefore, it is important that teachers are using this method of enabling students to act pro-environmentally in their teaching. Enquirybased learning was identified as a way that schools can encourage action competence through taking a similar process to allow students to make the decisions. If action competence was portrayed to teachers as being similar to enquiry-based learning, then they would already have an understanding of how to encourage it and can apply it to environmental teaching/learning.

A recommendation for future research would be to interview teachers whose school was part of the Enviroschools programme but who are not the lead Enviroschools teachers. Doing this would allow for a range of opinions about the programme to be heard and discussed. These teachers may give offer a greater understanding into the reasons behind the perceived lack of support given to the lead Enviroschools teachers. 
Interviewing these teachers could also give insight into the kind of resources and support they need to make the programme more of a success in schools.

Another recommendation would be to look more closely at the impact that students have on their parent's behaviours because of the Enviroschools programme. Several of the teachers interviewed mentioned the influence that children have on their parents by, raising awareness and changing their behaviours. A future study could measure the impact that students had on their parents by looking at a school that was just beginning its Enviroschools journey and survey the parents before and after students went through an Enviroschools theme such as Zero Waste. Doing this would enable the researcher to see if parents had gained more knowledge or had changed their waste related behaviours as a result of their child receiving the education. If there was shown to be a change in behaviour, then this could be used as evidence of the benefits of including EfS in schools in education policy.

The findings from the quantitative study offer good insight into which factors educators may want to focus on when trying to change waste and gardening related behaviours in their students. When designing the resources for each of the themes, the variables that are most likely to influence behaviour should be taken into consideration. For instance, when focusing on education surrounding waste, educators could focus on changing attitudes towards waste related behaviours so that students view them in a more positive light. Enviroschools could frame their resources to focus on attitudes rather than subjective norms, as subjective norms were unrelated to waste reduction intentions. When trying to change behaviours relating to Living Landscapes, the educators could focus mostly on perceived behaviour control - as this was the strongest predictor of intentions. This could be done by breaking down some of the barriers that students think they have when trying to perform a behaviour and offer simple solutions to overcome any perceived issues e.g. urban gardening techniques. Attitudes and subjective norms were also related to Living Landscapes behaviour intentions. This suggests that programmes could focus on targeting all three TPB variables to increase student's Living Landscapes behaviour intentions, but with a stronger influence on perceived behavioural control. It is important that educators understand the drivers of 
students' behaviours, as they are not universal, which was displayed in the present study.

Recommendations arising from the quantitative study would be to look at more behaviour such as water conservation and energy use, as they are also emphasised in the Enviroschools programme. Doing this would allow give insight into whether the TPB variables have the same strength at predicting these behaviour intentions as they did for waste and Living Landscapes. Measuring actual behaviours of the students would also help to examine how well the TPB can predict behaviour intentions. This would need be done as an observation before and after the education took place to see if any changes to the behaviour had been made (for example, less littering in schools).

Further research could also be done by comparing schools who are part of the Enviroschools programme with those who are not. The same survey would be used but with the version of the NEP scale that has 15 items, instead of 10, with the premise that it would be more reliable. An older age group should be used in the study, perhaps students in years 6 to 8 , to ensure they understand all of the questions asked in the survey. Doing this would allow one to see the effect that the Enviroschools programme has on students by comparing results with students who were not part of the programme. If this research showed that students whose school was part of the Enviroschools programme were more likely to perform a behaviour than those schools who were not, then it would be good evidence for education policy, as it would promote the Enviroschools programme as being effective at changing behaviours. If this research showed the Enviroschools programme was not effective at changing students' behaviours then other EfS options would need to be looked into.

\subsection{Conclusion}

Climate change is a complex issue not currently being addressed effectively within New Zealand's education system. Promoting EfS in New Zealand primary schools is vital given that children today will face the consequences of climate change. The results from the study one offer support for the work that the Enviroschools programme does in schools by highlighting the multitude of benefits teachers see arising from having their students 
involved in the programme. The Enviroschools organisation and policy makers can use the challenges identified by teachers to improve how the programme works in schools. To address the challenge of the lack of awareness from parents about environmental issues, information sessions could be arranged to allow parents to develop an understanding of how the Enviroschools programme works in their child's school. It is important that children feel empowered to take environmental action and the interviews showed that children were able to achieve this through enquiry-based learning with an environmental theme.

\footnotetext{
"So it's things like that that you will never see in the school, but those children are now making their parents have a worm farm, or a compost bin. And that means that down the track, as adults, they'll be thinking about those things."
}

For me, this quote from a teacher at Eastern Hutt Primary School encapsulates how the Enviroschools programme successfully prepares children for a future of environmental uncertainty. Encouraging students to adopt pro-environmental behaviours early in their lives may allow them to become engrained habits for the rest of their lives and the Enviroschools programme appears to be succeeding in fostering these behaviours. The results of the quantitative study (study two) reflects other TPB research with children around the world, indicating that behaviour intentions can be predicted through TPB variables. This study suggests that together, perceived behavioural control, subjective norms, and attitudes can predict children's waste and gardening behaviour intentions. When looking at improving waste behaviour intentions and encouraging enduring behaviour change, EfS programmes and schools should place emphasis on influencing children's attitudes so that they have a more positive attitude towards recycling and picking up litter. When educators are trying to influence gardening behaviours, they should focus on making children feel more in control of their ability to have an edible garden at home, in order to increase their perceived behavioural control.

This research provides invaluable evidence to support the effectiveness of the TPB to predict waste and gardening behaviour intentions of children in Aotearoa New Zealand. By including the NEP scale as a variable of the TPB, the study concludes that environmental concern does not contribute to explaining behaviour intentions of 
children. This finding does not support what the majority of other studies using the NEP Scale for children have found but does offer insight into the effectiveness of the scale when applied in a New Zealand context.

The Enviroschools programme can use these findings to create resources tailored to perceived behavioural control for the Living Landscapes theme, and changing attitudes towards waste behaviours for the Zero Waste theme. They can also use the findings to address challenges that teachers faced when implementing the Enviroschools programme. Policy makers in New Zealand can use the findings to support making EfS compulsory in the national curriculum. The present study has highlighted the important role that the Enviroschools programme has in providing EfS in New Zealand schools. It is vital that the Enviroschools programme is acknowledged for the work that they do by promoting the importance of EfS in the national curriculum.

"'Cause for them to have an idea and actually take action is amazing, and it empowers them so much. And that's what's great about Green-Gold or Enviroschools ... is that it's all about empowering those kids to make change. And I think, traditionally, schools have been very like, talking at the kids, whereas now they can give us so much and they can actually lead a lot of the things." 


\section{References}

Aguilar-Luzón, M. d. C., García-Martínez, J. M. Á., Calvo-Salguero, A., \& Salinas, J. M. (2012). Comparative Study Between the Theory of Planned Behavior and the Value-Belief-Norm Model Regarding the Environment, on Spanish Housewives' Recycling Behavior. Journal of Applied Social Psychology, 42(11), 2797-2833. doi:10.1111/j.1559-1816.2012.00962.x

Ajzen, I. (1991). The theory of planned behavior. Organizational Behavior and Human Decision Processes, 50(2), 179-211. doi:10.1016/0749-5978(91)90020-T

Ajzen, I. (2011). The theory of planned behaviour: reactions and reflections. Psychol Health, 26(9), 1113-1127. doi:10.1080/08870446.2011.613995

Alp, E., Ertepinar, H., Tekkaya, C., \& Yilmaz, A. (2006). A Statistical Analysis of Children's Environmental Knowledge and Attitudes in Turkey. International Research in Geographical and Environmental Education, 15(3), 210-223. doi:10.2167/irgee193.0

Armitage, C., J., \& Conner, M. (2001). Efficacy of the Theory of Planned Behaviour: A meta-analytic review. British Journal of Social Psychology, 40, 471-499.

Bamberg, S., Ajzen, I., \& Schmidt, P. (2003). Choice of Travel Mode in the Theory of Planned Behavior: The Roles of Past Behavior, Habit, and Reasoned Action. Basic and Applied Social Psychology, 25(3), 175-187. doi:10.1207/s15324834basp2503_01

Barraza, L., \& Walford, R. A. (2002). Environmental Education: A comparison between English and Mexican school children. Environmental Education Research, 8(2), 171-186. doi:10.1080/13504620220128239

Barriball, K. L., \& While, A. (1994). Collecting data using a semi-structured interview: a discussion paper. Journal of Advanced Nursing, 19, 328-335.

Boeve-de Pauw, J., Donche, V., \& Van Petegem, P. (2011). Adolescents' environmental worldview and personality: An explorative study. Journal of Environmental Psychology, 31(2), 109-117. doi:10.1016/j.jenvp.2010.05.003

Bourke, B. (2014). Positionality: Reflecting on the Research Process. The Qualitative Report, 19(33), 1-9.

Boyes, E., \& Stanisstreet, M. (2012). Environmental Education for Behaviour Change: Which actions should be targeted? International Journal of Science Education, 34(10), 1591-1614. doi:10.1080/09500693.2011.584079

Bradshaw, M., \& Stratford, E. (2010). Qualitative Research Design and Rigour. In I. Hay (Ed.), Qualitative Research Methods in Human Geography (pp. 70-80). Ontario, Canada: Oxford University Press.

Braun, V., \& Clarke, V. (2006). Using thematic analysis in psychology. Qualitative Research in Psychology, 3(2), 77-101. doi:10.1191/1478088706qp063oa

Bryman, A., \& Cramer, D. (2011). Quantitative Data Analysis with IBM SPSS 17, 18 \& 19: A Guide for Social Scientists. East Sussex, UK: Routledge.

Chan, K. K. W. (1996). Environmental attitudes and behaviour of secondary school students in Hong Kong. The Environmentalist, 16(4), 297-306. doi:10.1007/bf02239656

Chawla, L., \& Cushing, D. F. (2007). Education for strategic environmental behavior. Environmental Education Research, 13(4), 437-452. doi:10.1080/13504620701581539

Chu, S. K. W., Tse, S. K., \& Chow, K. (2011). Using collaborative teaching and inquiry project-based learning to help primary school students develop information 
literacy and information skills. Library \& Information Science Research, 33(2), 132-143. doi:10.1016/j.lisr.2010.07.017

Collado, S., Staats, H., \& Corraliza, J. A. (2013). Experiencing nature in children's summer camps: Affective, cognitive and behavioural consequences. Journal of Environmental Psychology, 33, 37-44. doi:10.1016/j.jenvp.2012.08.002

Creswell, J. (2014). Research Design: Qualitative, Quantitative, and Mixed Methods Approaches (4 ed.). United States of America: SAGE Publications.

Cutter-Mackenzie, A., \& Smith, R. (2003). Ecological literacy: the 'missing paradigm' in environmental education (part one). Environmental Education Research, 9(4), 497-524. doi:10.1080/1350462032000126131

De Groot, J., \& Steg, L. (2007). General Beliefs and the Theory of Planned Behavior: The Role of Environmental Concerns in the TPB. Journal of Applied Social Psychology, 37(8), 1817-1836.

Dowling, R. (2010). Power, Subjectivity, and Ethics in Qualitative Research. In I. Hay (Ed.), Qualitative Research Methods in Human Geography (pp. 26-39). Ontario, Canada: Oxford University Press.

Dunlap, R. (2008). The New Environmental Paradigm Scale: From Marginality to Worldwide Use. The Journal of Environmental Education, 40(1), 3-18. doi:10.3200/joee.40.1.3-18

Dunlap, R., Van Liere, K., Mertig, A., \& Jones, R. (2000). Measuring Endorsement of the New Ecological Paradigm: A Revised NEP Scale. Journal of Social Issues, 56(3), 425-442.

Dunn, K. (2010). Interviewing. In I. Hay (Ed.), Qualitative Research Methods in Human Geography (pp. 101-138). Ontario, Canada: Oxford University Press.

Eames, C., Cowie, B., \& Bolstad, R. (2008). An evaluation of characteristics of environmental education practice in New Zealand schools. Environmental Education Research, 14(1), 35-51. doi:10.1080/13504620701843343

Eames, C., Roberts, J., Cooper, G., \& Hipkins, R. (2010). Education for sustainability in New Zealand schools: An evaluation of three professional development programmes. New Zealand: NZCER.

Enviroschools. (2014). Enviroschools: fostering a generation of people who instinctively think and act sustainably. Retrieved from http://www.enviroschools.org.nz/our_organisation/how-itworks/0 2017 ES one-pager.pdf

Enviroschools. (2017a). The History of Enviroschools. Retrieved from http://www.enviroschools.org.nz/about us/our history

Enviroschools. (2017b). Living Landscapes Learning Guide. Living Landscapes. Enviroschools.

Enviroschools. (2018). I Tōu Ake Rohe: In Your Region. Retrieved from http://www.enviroschools.org.nz/in your region/map

Enviroschools Wellington. (2013). Enviroschools and Te Aho Tū Roa: Wellington Region - Te Upoko o Te Ika Snapshot 2013. Wellington: Enviroschools.

Epstein, J. (2008). Improving Family and Community Involvement in Secondary Schools. Education Digest, 73(6), 9-12.

Evans, S. M., \& Gill, M. E. (1996). Schoolchildren as educators: The indirect influence of environmental education in schools on parents' attitudes towards the environment. Journal of Biological Education (Society of Biology), 30(4), 243.

Franzen, A. (2003). Environmental Attitudes in International Comparison: An Analysis of the ISSP Surveys 1993 and 2000. Social Science Quarterly, 84(2), 297-308. 
Gifford, R. (2014). Environmental psychology matters. Annu Rev Psychol, 65, 541-579. doi:10.1146/annurev-psych-010213-115048

Gifford, R., \& Nilsson, A. (2014). Personal and social factors that influence proenvironmental concern and behaviour: A review. International Journal of Psychology, 49(3), 141-157.

Gotch, C., \& Hall, T. (2004). Understanding nature-related behaviors among children through a theory of reasoned action approach. Environmental Education Research, 10(2), 157-177. doi:10.1080/13504620242000198159

Gratton, L., Povey, R., \& Clark-Carter, D. (2007). Promoting children's fruit and vegetable consumption: interventions using the Theory of Planned Behaviour as a framework. The British Journal of Health Psychology, 12, 639-650. doi:10.1348/135910706X171504

Grodzinska-Jurczak, M., Bartosiewicz, A., Twardowska, A., \& Ballantyne, R. (2003). Evaluating the Impact of a School Waste Education Programme upon Students', Parents' and Teachers' Environmental Knowledge, Attitudes and Behaviour. International Research in Geographical and Environmental Education, 12(2), 106-122. doi:10.1080/10382040308667521

Grossoehme, D. H. (2014). Overview of qualitative research. J Health Care Chaplain, 20(3), 109-122. doi:10.1080/08854726.2014.925660

Hawcroft, L. J., \& Milfont, T. L. (2010). The use (and abuse) of the new environmental paradigm scale over the last 30 years: A meta-analysis. Journal of Environmental Psychology, 30(2), 143-158. doi:10.1016/j.jenvp.2009.10.003

Hewitt, A. M., \& Stephens, C. (2007). Healthy eating among 10 - 13-year-old New Zealand children: understanding choice using the Theory of Planned Behaviour and the role of parental influence. Psychology, Health \& Medicine, 12(5), 526535. doi:10.1080/13548500601164396

IPCC. (2015). Climate Change 2014: Synthesis Report. Switzerland: Intergovernmental Panel on Climate Change.

Jensen, B. B. (2002). Knowledge, Action and Pro-environmental Behaviour. Environmental Education Research, 8(3), 325-334. doi:10.1080/13504620220145474

Jensen, B. B., \& Schnack, K. (2006). The action competence approach in environmental education. Environmental Education Research, 12(3-4), 471-486. doi:10.1080/13504620600943053

Johnson, R. B., Onwuegbuzie, A. J., \& Turner, L. A. (2007). Towards a Definition of Mixed Methods Research. Journal of Mixed Methods Research, 1(2), 112-133. doi:10.1177/1558689806298224

Kaiser, F., G, Hübner, G., \& Bogner, F., X. (2005). Contrasting the Theory of Planned Behavior With the Value-Belief-Norm Model in Explaining Conservation Behavior. Journal of Applied Social Psychology, 35(10), 2150-2170.

Karpudewan, M., \& Keong, C. C. (2013). Pro-Environmental Concern Among Primary School Students. Jurnal Teknologi, 63(2), 1-6.

Kemmis, S., \& Mutton, R. (2012). Education for sustainability (EfS): practice and practice architectures. Environmental Education Research, 18(2), 187-207. doi:10.1080/13504622.2011.596929

Kollmuss, A., \& Agyeman, J. (2002). Mind the Gap: Why do people act environmentally and what are the barriers to pro-environmental behavior? Environmental Education Research, 8(3), 239-260. doi:10.1080/13504620220145401 
Kopnina, H. (2011). Applying the New Ecological Paradigm Scale in the Case of Environmental Education: Qualitative Analysis of the Ecological Worldview of Dutch Children. In Factis Pax, 5(3), 374-388.

Lee, V. S. (2012). What is inquiry-guided learning? New Directions for Teaching and Learning, 2012(129), 5-14. doi:10.1002/tl.20002

Leeming, F. C., \& Dwyer, W. O. (1995). Children's environmental attitude and knowledge scale: Construction and validation. Journal of Environmental Education, 26(3), 22.

Legault, L., \& Pelletier, L. G. (2000). Impact of an Environmental Education Program on Students' and Parents' Attitudes, Motivation, and Behaviours. Canadian Journal of Behavioural Science, 32(4), 243-250.

Lopez-Mosquera, N., \& Sanchez, M. (2012). Theory of Planned Behavior and the ValueBelief-Norm Theory explaining willingness to pay for a suburban park. J Environ Manage, 113, 251-262. doi:10.1016/j.jenvman.2012.08.029

Manoli, C. C., Johnson, B., \& Dunlap, R. E. (2007). Assessing Children's Environmental Worldviews: Modifying and Validating the New Ecological Paradigm Scale for Use With Children. The Journal of Environmental Education, 38(4), 3-13. doi:10.3200/joee.38.4.3-13

McNamara, O., Hustler, D., Stronach, I., Rodrigo, M., Beresford, E., \& Botcherby, S. (2000). Room to Manoeuvre: Mobilising the 'Active Partner' in Home-School Relations. British Educational Research Journal, 26(4), 473-489.

Ministry for the Environment. (1998). Learning to Care for Our Environment: A national strategy for environmental education. Wellington: Ministry for the Environment.

Ministry of Education. (2007). The New Zealand Curriculum. Wellington: Learning Media Limited.

Morgan, D. L. (2016). Paradigms Lost and Pragmatism Regained. Journal of Mixed Methods Research, 1(1), 48-76. doi:10.1177/2345678906292462

Murtagh, S., Rowe, D., A, Elliot, M., A, McMinn, D., \& Nelson, N. (2012). Predicting active school travel: The role of planned behavior and habit strength. International Journal of Behavioral Nutrition and Physical Activity, 9(1), 65.

Osbaldiston, R., \& Schott, J. P. (2012). Environmental Sustainability and Behavioral Science: Meta-Analysis of Proenvironmental Behavior Experiments. Environment and Behavior, 42(2), 257-299.

Parliamentary Commissioner for the Environment. (2004). See Change: Learning and education for sustainability. Wellington: Parliamentary Commissioner for the Environment.

Parliamentary Commissioner for the Environment. (2007). Outcome evaluation. See Change: Learning and education for sustainability. Wellington: Parliamentary Commissioner for the Environment.

Punch, K. (2013). Introduction to Social Research: Quantitative and Qualititative Approaches. London, UK: SAGE Publications.

Reay, D. (2004). Education and cultural capital: the implications of changing trends in education policies. Cultural Trends, 13(2), 73-86. doi:10.1080/0954896042000267161

Reid, H., Alam, M., Berger, R., Cannon, T., Huq, S., \& Milligan, A. (2009). CommunityBased Adaptation to Climate Change. In H. Ashley, N. Kenton, \& A. Milligan (Eds.), Participatory learning and action: Community-based adaptation to climate change. UK: Russell Press. 
Reisinger, A., Kitching, R., Chiew, F., Hughes, L., Newton, P., Schuster, S., . . Whetton, P. (2014). Australasia. In B. Fitzharris \& D. Karoly (Eds.), Climate Change 2014: Impacts, Adaptation, and Vulnerability. Part B: Regional Aspects.

Contribution of Working Group II to the Fifth Assessment Report of the Intergovernmental Panel on Climate

Change (pp. 1371-1430). Cambridge, United Kingdom: Cambridge University Press.

Rickinson, M. (2001). Learners and Learning in Environmental Education: A critical review of the evidence. Environmental Education Research, 7(3), 207-320. doi:10.1080/13504620120065230

Robertson, C., \& Krugly-Smolska, E. (1997). Gaps between Advocated Practices and Teaching Realities in Environmental Education. Environmental Education Research, 3(3), 311-326.

Schultz, P. W. (2014). Strategies for Promoting Proenvironmental Behavior Lots of Tools but Few Instructions. European Psychologist, 19(2), 107-117. doi:10.1027/1016-9040/a000163

Smith, L., Ng, S. W., \& Popkin, B. (2013). Trends in US home food preparation and consumption: analysis of national nutrition surveys and time use studies from 1965-1966 to 2007-2008. Nutritional Journal, 12(45), 2-10.

Spiropoulou, D., Antonakaki, T., Kontaxaki, S., \& Bouras, S. (2007). Primary Teachers' Literacy and Attitudes on Education for Sustainable Development. Journal of Science Education and Technology, 16(5), 443-450. doi:10.1007/s10956-0079061-7

Steg, L., van den Berg, A. E., \& de Groot, J. I. M. (2012). Environmental Psychology. Hoboken: Wiley.

Steg, L., \& Vlek, C. (2009). Encouraging pro-environmental behaviour: An integrative review and research agenda. Journal of Environmental Psychology, 29(3), 309317. doi:10.1016/j.jenvp.2008.10.004

Stern, M., Powell, R., \& Ardoin, N. (2008). What Difference Does it Make? Assessing Outcomes From Participation in a Residential Environmental Education Program. The Journal of Environmental Education, 39(4), 31-43.

Stern, P. C., Dietz, T., Abel, T., D., Guagnano, G., A, \& Kalof, L. (1999). A Value-BeliefNorm Theory of Support for Social Movements: The Case of Environmentalism. Human Ecology Review, 6(2), 81-97.

Streiner, D. L. (2003). Starting at the beginning: an introduction to coefficient alpha and internal consistency. Journal of Personality Assessment, 80(1), 99-103. doi:10.1207/S15327752JPA8001_18

Summers, M., Corney, G., \& Childs, A. N. N. (2003). Teaching Sustainable Development in Primary Schools: An empirical study of issues for teachers. Environmental Education Research, 9(3), 327-346. doi:10.1080/13504620303458

Tilbury, D., Stevenson, R. B., Fien, J., \& Schreuder, D. (Eds.). (2002). Education and Sustainability: Responding to the Global Challenge. Gland, Switzerland and Cambridge, UK: IUCN.

Toimata Foundation (Producer). (2017a, 24-03-2018). Enviroschools Theme areas. Retrieved from http://www.enviroschools.org.nz/members area/themeareas/ES Theme Areas - Introduction 2017 web2.pdf

Toimata Foundation. (2017b). Zero Waste. New Zealand: Enviroschools Foundation. Townrow, C. S., Laurence, N., Blythe, C., Long, J., \& Harré, N. (2016). The Maui's Dolphin Challenge: Lessons From a School-Based Litter Reduction Project. 
Australian Journal of Environmental Education, 32(3), 288-308.

doi:10.1017/aee.2016.27

Urwin, K., \& Jordan, A. (2008). Does public policy support or undermine climate change adaptation? Exploring policy interplay across different scales of governance. Global Environmental Change, 18(1), 180-191. doi:10.1016/j.gloenvcha.2007.08.002

van Aalst, M. K., Cannon, T., \& Burton, I. (2008). Community level adaptation to climate change: The potential role of participatory community risk assessment. Global Environmental Change, 18(1), 165-179. doi:10.1016/j.gloenvcha.2007.06.002

Van Petegem, P., \& Blieck, A. (2006). The environmental worldview of children: a cross-cultural perspective. Environmental Education Research, 12(5), 625-635. doi:10.1080/13504620601053662

Vaughan, C., Gack, J., Solorazano, H., \& Ray, R. (2003). The Effect of Environmental Education on Schoolchildren, Their Parents, and Community Members: A Study of Intergenerational and Intercommunity Learning. The Journal of Environmental Education, 34(3), 12-21. doi:10.1080/00958960309603489

Wu, L. (2012). Exploring the New Ecological Paradigm Scale for Gauging Children's Environmental Attitudes in China. The Journal of Environmental Education, 43(2), 107-120. doi:10.1080/00958964.2011.616554

Zelezny, L. C. (1999). Educational Interventions That Improve Environmental Behaviors: A Meta-Analysis. The Journal of Environmental Education, 31(1), 5-14. doi:10.1080/00958969909598627 
Appendix A - sample survey

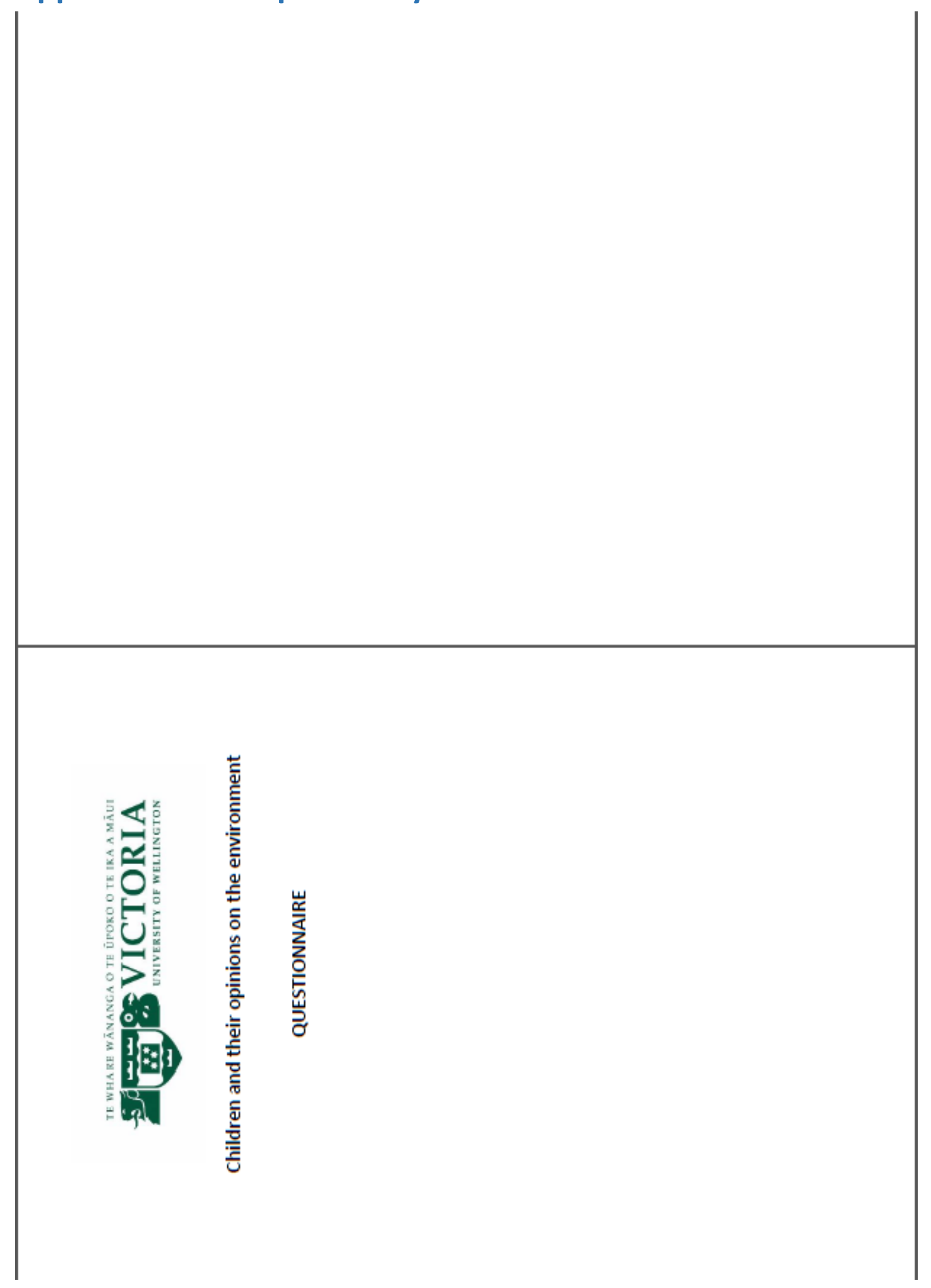




\begin{tabular}{|c|c|c|c|c|c|c|c|c|c|c|c|}
\hline 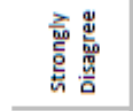 & in & in & & \multirow{4}{*}{ 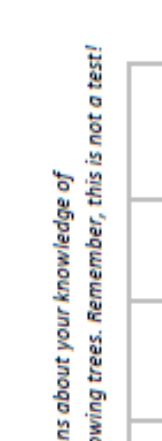 } & \multirow[b]{2}{*}{ 容 } & \multirow[b]{2}{*}{$\square$} & \multirow[b]{2}{*}{$\square$} & \multirow[b]{2}{*}{$\square$} & \multirow[b]{2}{*}{$\square$} & \multirow[b]{2}{*}{$\square$} & \multirow[b]{2}{*}{$\square$} \\
\hline 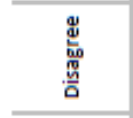 & $\nabla$ & $\theta$ & & & & & & & & & \\
\hline 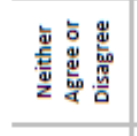 & 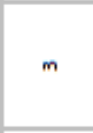 & $m$ & & & 愛 & $\square$ & $\square$ & $\square$ & $\square$ & $\square$ & $\square$ \\
\hline 幽 & $N$ & $N$ & \multirow{4}{*}{ 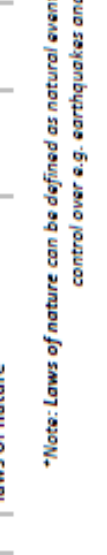 } & & 岂 & 口 & $\square$ & $\square$ & $\square$ & $\square$ & $\square$ \\
\hline 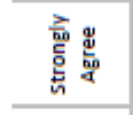 & $r$ & - & & \multirow{3}{*}{ 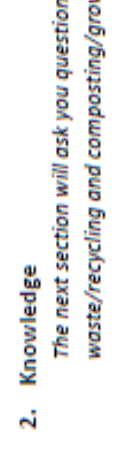 } & 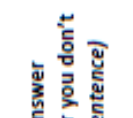 & 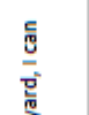 & 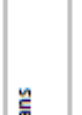 & 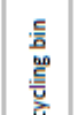 & 离 & 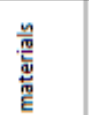 & 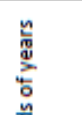 \\
\hline \multirow[t]{2}{*}{ 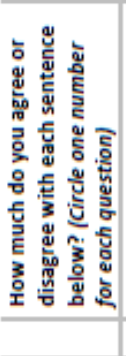 } & 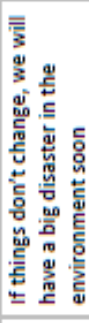 & 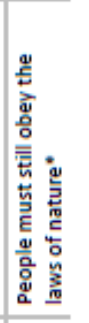 & & & 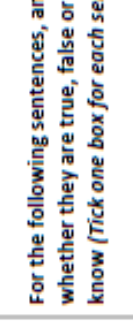 & 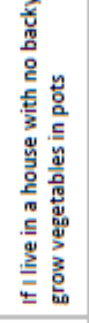 & 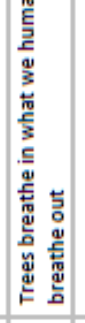 & 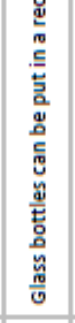 & 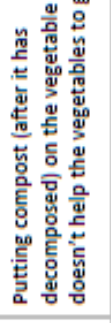 & 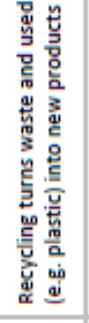 & 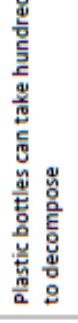 \\
\hline & - & - & & & & $\pi$ & ค & $u$ & ס & ข & \\
\hline
\end{tabular}

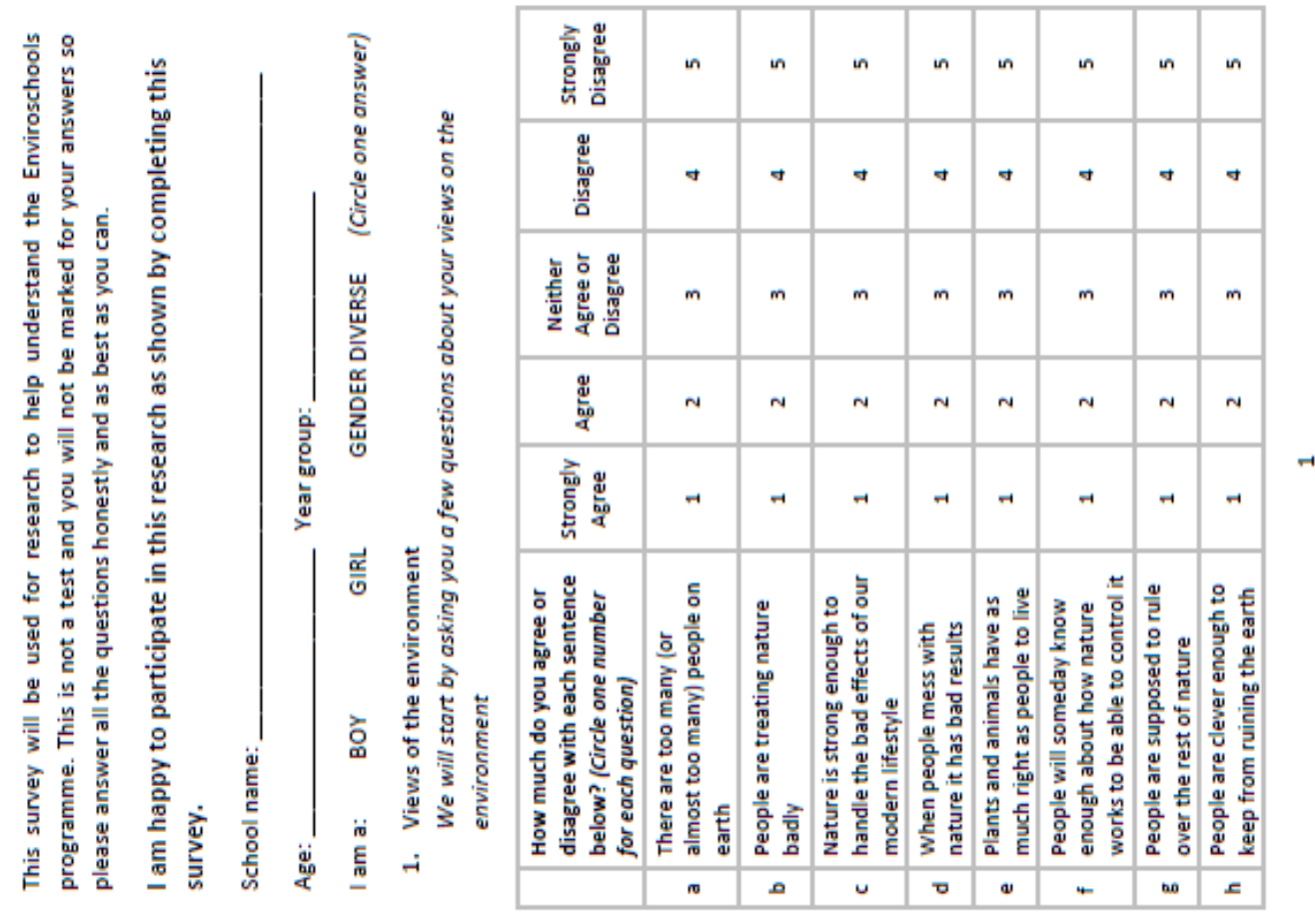




\begin{tabular}{|c|c|c|c|c|c|c|c|c|c|c|c|}
\hline 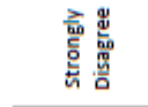 & in & in & in & in & in & in & in & in & in & in & in \\
\hline 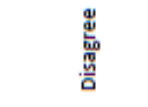 & $\vec{\sigma}$ & $\theta$ & $\sigma$ & $\theta$ & $\nabla$ & $\nabla$ & $\nabla$ & ब & $\nabla$ & $\nabla$ & 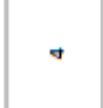 \\
\hline 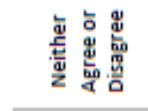 & $m$ & $m$ & $m$ & $m$ & $m$ & $m$ & $m$ & $m$ & $m$ & $m$ & $m$ \\
\hline 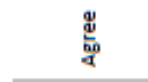 & $N$ & $N$ & $N$ & $\sim$ & N & $N$ & $N$ & $N$ & $N$ & $N$ & $N$ \\
\hline 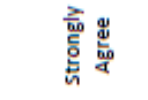 & 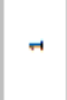 & $r$ & $r$ & 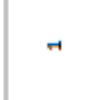 & $r$ & 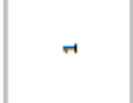 & $r$ & $H$ & $r$ & 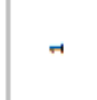 & H \\
\hline 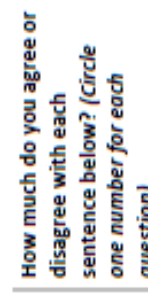 & 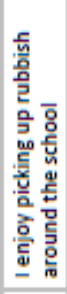 & 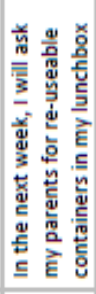 & 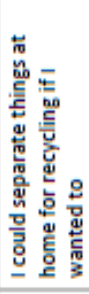 & 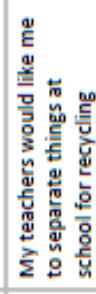 & 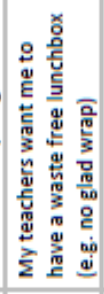 & 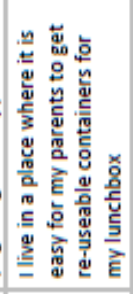 & 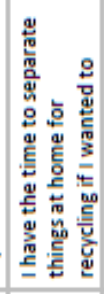 & 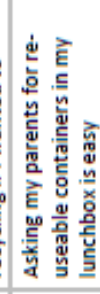 & 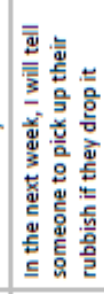 & 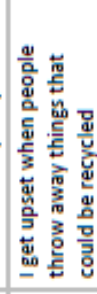 & 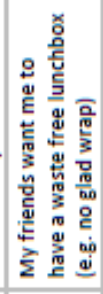 \\
\hline & $\approx$ & - & $E$ & e & 。 & a & $\sigma$ & 2 & $n$ & ـ & $=$ \\
\hline
\end{tabular}

\begin{tabular}{|c|c|c|c|c|c|c|c|c|c|c|}
\hline 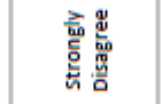 & in & in & in & in & in & in & in & in & in & in \\
\hline 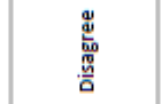 & न & न & $\nabla$ & ग & 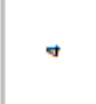 & व & ब & व & व & $\nabla$ \\
\hline 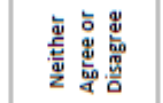 & $\mathrm{m}$ & $\mathrm{m}$ & $\mathrm{m}$ & $\mathrm{m}$ & $\mathrm{m}$ & $\mathrm{m}$ & $\mathrm{m}$ & $\mathrm{m}$ & $\mathrm{m}$ & $\mathrm{m}$ \\
\hline 产 & $N$ & N & $\sim$ & N & N & N & N & $N$ & $N$ & $N$ \\
\hline 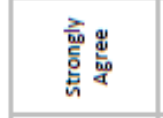 & 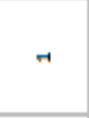 & H & $\vec{H}$ & H & H & H & $r$ & $H$ & r & H \\
\hline 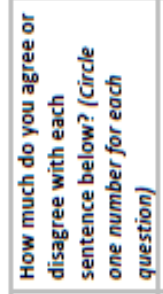 & 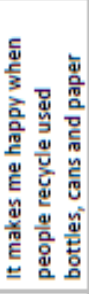 & 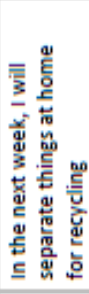 & 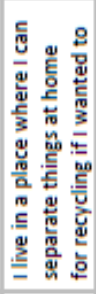 & 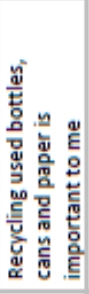 & 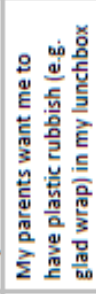 & 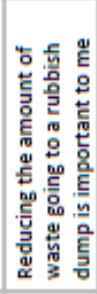 & 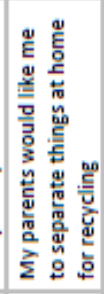 & 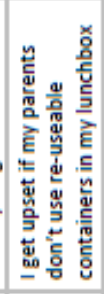 & 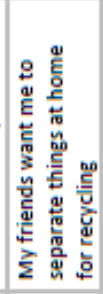 & 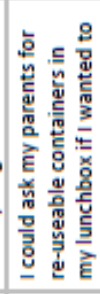 \\
\hline & $\pi$ & ـ & $u$ & ס & a & 4 & $\infty$ & $=$ & - & - \\
\hline
\end{tabular}




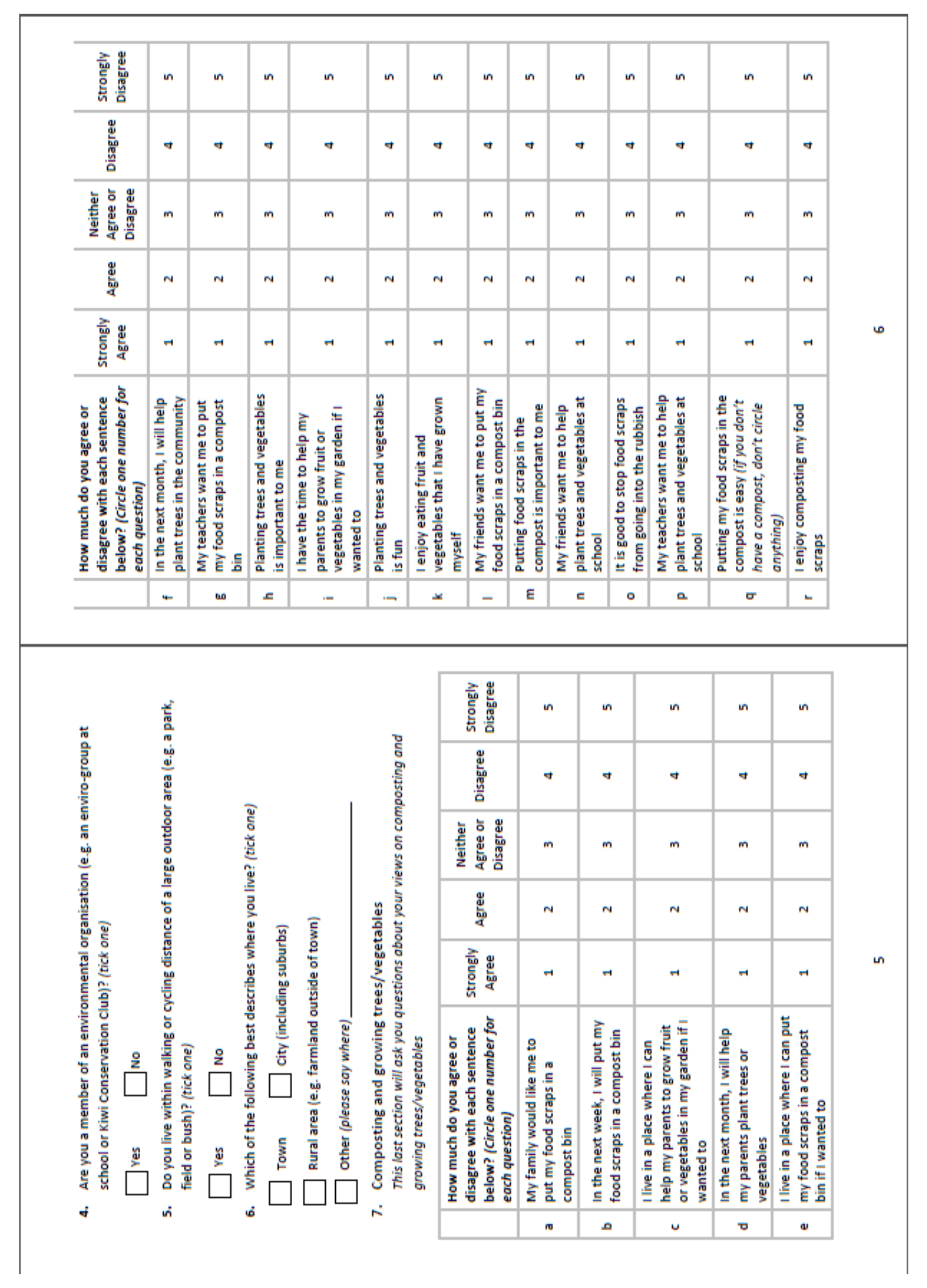




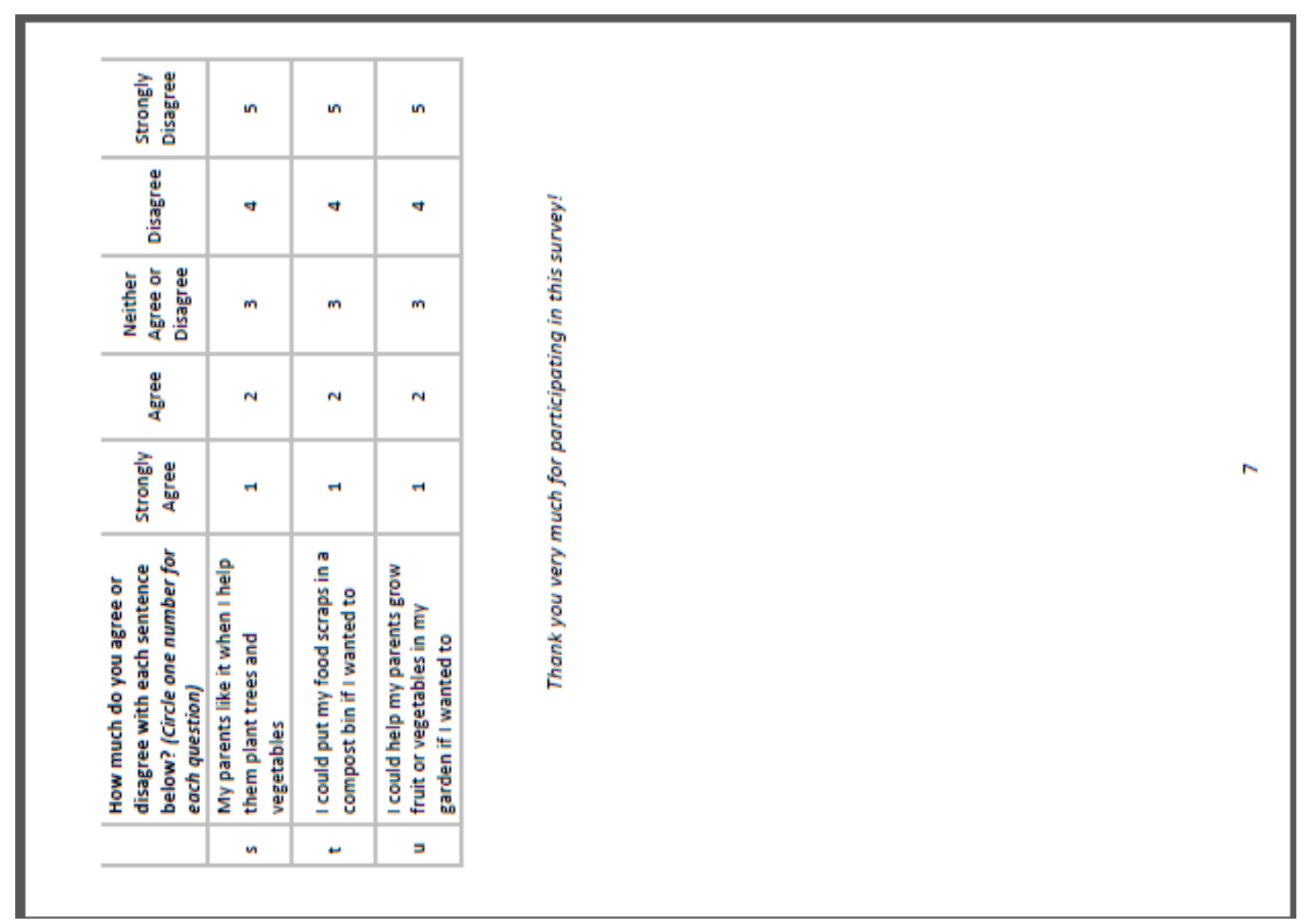




\section{Appendix B - Ethics Approval}

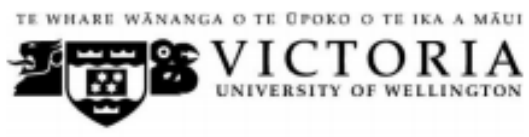

MEMORANDUM

Phone 0-4-4635205

Email Averil.coxheadevuw.ac.nz.

\begin{tabular}{l|l}
\hline TO & Ria Goble \\
\hline COPY TO & Wokje Abrahamse \\
\hline FROM & Dr Averil Coxhead, Acting Convener, Human Ethics Committee \\
\hline DATE & 26 May 2017 \\
\hline PAGES & 1 \\
\hline & $\begin{array}{l}\text { Ethics Approval: 24521 } \\
\text { SUR relationship between environmental attitudes and behaviour } \\
\text { intentions among children: a study of the Enviroschools } \\
\text { programme }\end{array}$ \\
\hline
\end{tabular}

Thank you for your application for ethical approval, which has now been considered by the Standing Committee of the Human Ethics Committee.

Your application has been approved from the above date and this approval continues until 1 March 2018. If your data collection is not completed by this date you should apply to the Human Ethics Committee for an extension to this approval.

Best wishes with the research.

Averil Coxhead,

Acting Convener, Victoria University Human Ethics Committee 


\section{Appendix C}

1. Information sheet for interview participants

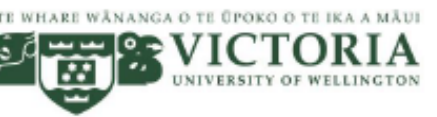

The relationship between environmental attitudes and behaviour intentions among children: a study of the Enviroschools programme

\section{INFORMATION SHEET FOR PARTICIPANTS}

Thank you for your interest in this project. Please read this information before deciding whether or not to take part. If you decide to participate, thank you. If you decide not to take part, thank you for considering my request.

\section{Who am I?}

My name is Ria Goble and I am a Masters student in Environmental Studies at Victoria University of Wellington. This research project is work towards my thesis.

\section{What is the aim of the project?}

This project aims to examine how children in the Enviroschools programme perceive the barriers, influences and attitudes towards particular environmental behaviours and their intentions to perform these behaviours. This study will also look at children's overall environmental concern. Alongside this, I am looking at different ways the Enviroschools programme is taught at four primary schools in the Wellington region. In summary, this study aims to understand the Enviroschools programme, its successes and if there is room for improvement. This study may be published, presented at conferences or by Enviroschools on their website.

The Victoria University of Wellington Human Ethics Committee has approved this research.

How can you help?

If you agree to take part, I will interview you at your school. I will ask you questions about your experiences with the Enviroschools programme. The interview will take approximately 30 minutes. I will record the interview and write it up later. You can stop the interview at any time, without giving a reason. You can withdraw from the study by contacting me at any point before the $30^{\text {th }}$ September 2017 . If you withdraw, the information you provided will be destroyed or returned to you.

What will happen to the information you give?

You will not be named in the final report but your school will be named (provided you have the authority to agree to this on behalf of the school).

Only my supervisors and I will read the notes or transcript of the interview. The interview transcripts, summaries and any recordings will be kept securely and destroyed a year after the research ends. 
What will the project produce?

The information from my research will be used to produce my Masters thesis.

If you accept this invitation, what are your rights as a research participant?

You do not have to accept this invitation if you don't want to. If you do decide to participate, you have the right to:

- choose not to answer any question;

- ask for the recorder to be turned off at any time during the interview;

- withdraw from the study before 30-Sept-2017;

- ask any questions about the study at any time;

- receive a copy of your interview recording;

- read over and comment on a written summary of your interview;

- be able to read any reports of this research by emailing the researcher to request a copy.

If you have any questions or problems, who can you contact?

If you have any questions, either now or in the future, please feel free to contact either:

Student:

Name: Ria Goble

University email address:

ria.goble@vuw.ac.nz
Supervisor:

Name: Dr. Wokje Abrahamse

Role: Senior Lecturer

School: Geography, Environment and Earth Sciences

Phone: 044635217

wokje.abrahamse@vuw.ac.nz

\section{Human Ethics Committee information}

If you have any concerns about the ethical conduct of the research you may contact the Victoria University HEC Convener: Associate Professor Susan Corbett. Email susan.corbett@vuw.ac.nz or telephone +64-4-4635480. 


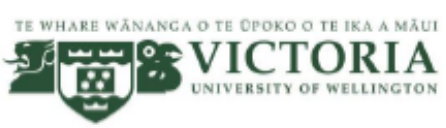

The relationship between environmental attitudes and behaviour intentions among children: a study of the Enviroschools programme

\section{CONSENT TO INTERVIEW}

This consent form will be held for 1 year.

Researcher: Ria Goble, School of Geography, Environment and Earth Sciences, Victoria University of Wellington

- I have read the Information Sheet and the project has been explained to me. My questions have been answered to my satisfaction. I understand that I can ask further questions at any time.

- I agree to take part in an audio recorded interview.

I understand that:

- Imay withdraw from this study at any point before 30-Sep-2017, without giving any reason, and any information that I have provided will be returned to me or destroyed.

- The information I have provided will be destroyed 1 year after the research is finished.

- Any information I provide will be kept confidential to the researcher and the supervisor. I understand that the results will be used for a Masters report and a summary of the results may be used in academic reports and/or presented at conferences.

- I consent to information or opinions which I have given being attributed to my school in any reports on this research

Yes $\square$ No

- I would like a copy of the transcript of my interview:

Yes $\square$ No $\square$

- I would like a summary of my interview:

Yes $\square$ No $\square$

- I would like to receive a copy of the final report and have added my email Yes $\square$ No $\square$ address below.

Signature of participant:

Name of participant:

Date:

Email address: 


\section{Appendix D}

1. Information sheet for parents/legal guardians

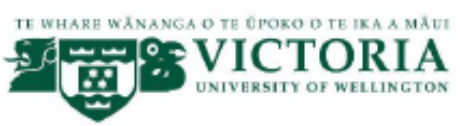

The relationship between environmental attitudes and behaviour intentions among children: a study of the Enviroschools programme

\section{INFORMATION SHEET FOR PARENTS OR LEGAL GUARDIAN OF CHILD PARTICIPANT}

Researcher: Ria Goble, School of Geography, Environment and Earth Sciences, Victoria University of Wellington

\section{About this project}

I am a Masters student in Environmental Studies at Victoria University of Wellington. As part of this degree, I am undertaking a research project leading to a thesis. This project aims to examine how children in the Enviroschools programme perceive the barriers, influences and attitudes towards particular environmental behaviours and their intentions to perform these behaviours. This study will also look at children's overall environmental concern. Alongside this, I am looking at different ways the Enviroschools programme is taught at four primary schools in the Wellington region. This study may be published, presented at conferences or by Enviroschools on their website.

This research project has received approval from the Victoria University Human Ethics Committee, Ethics Approval: 24521.

What is involved?

I am inviting children participants, ages 9-13, as well selected teachers who are involved in the Enviroschools environmental education programme, to take part in this research. Surveys completed by the children, designed to take approximately 15 minutes to complete will form the basis of my research project. This will be supplemented by interviews of teachers who have a leading role in implementing the Enviroschools programme.

- As part of a class exercise, your child's teacher will administer the surveys in the classroom and your child's teacher will collect the surveys upon completion. Your child will be asked if they would like to participate in the survey, and will be giving their consent by completing the survey. Examples of the survey questions are:

1. Planting trees and vegetables in the garden is fun (Agree - Disagree)

2. In the next week, I will put my food scraps in a compost bin (Agree Disagree)

- Surveys will not ask for your child's name, making them anonymous

- Completed surveys will be kept in a locked filing cabinet, and will be destroyed one year after completion. 
If you have any questions or problems, who can you contact?

If you have any questions, either now or in the future, please feel free to contact either:

Student:

Name: Ria Goble

University email address:

ria.goble@vuw.ac.nz
Supervisor:

Name: Dr. Wokje Abrahamse

Role: Senior Lecturer

School: Geography, Environment and Earth

Sciences

Phone: 044635217

wokje.abrahamse@vuw.ac.nz

Human Ethics Committee information

If you have any concerns about the ethical conduct of the research, you may contact the

Victoria University HEC Convener: Associate Professor Susan Corbett. Email

susan.corbett@vuw.ac.nz or telephone +64-4-4635480. 


\section{The relationship between environmental attitudes and behaviour intentions among children: a study of the Enviroschools programme}

\section{PARTICIPANT (STUDENT'S) INFORMATION SHEET}

Kia ora!

I would like to tell you about my University study that's about children like you and their actions and worries about the environment. I am curious to hear your opinion because it is important for organisations like Enviroschools to know if children like you (who are part of their programme) intend to take action to help the environment (like planting trees)

I am asking children from the Wellington region (aged 9-13) and some of your teachers to be part of this research A survey, lasting about 15 minutes will form this study. You will be asked to do a survey during class time. It is completely your choice to be part of this research. All you have to do is tell your teacher or me on the day of the survey that you don't want to be part of it and we won't ask you any questions.

By completing the survey, you will be giving your consent. Your survey answers will be kept private, even from your teachers! I won't even ask your name. For these reasons, it will not be possible to connect you with this study.

This study may be published, presented at conferences or by Enviroschools on their website.

If you would like to ask me any questions at all then please have your parents email me anytime. There is more information about this study in the 'Parent or legal guardian information sheet'. If they have not received a paper copy of this from your teacher, I will happily send you one in the mail.

Thank you so much for reading this. I look forward to seeing you soon at school.

Ria Goble - Victoria University of Wellington

Email: ria.goble@vuw.ac.nz 


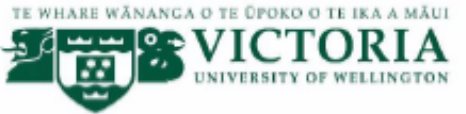

\section{The relationship between environmental attitudes and behaviour intentions among children: a study of the Enviroschools programme}

\section{INFORMATION SHEET FOR PRINCIPALS/TEACHERS}

Thank you for your interest in this project. Please read this information before deciding whether or not your school/class wants to take part. If you decide to participate, thank you. If you decide not to take part, thank you for considering my request.

Who am I?

My name is Ria Goble and I am a Masters student in Environmental Studies at Victoria University of Wellington. This research project is work towards my thesis.

What is the aim of the project?

This project aims to examine how children in the Enviroschools programme perceive the barriers, influences and attitudes towards particular environmental behaviours and their intentions to perform these behaviours. This study will also look at children's overall environmental concern. Alongside this, I am looking at different ways the Enviroschools programme is taught at four primary schools in the Wellington region. In summary, this study aims to understand the Enviroschools programme, its successes and if there is room for improvement. This study may be published, presented at conferences or by Enviroschools on their website.

The Victoria University of Wellington Human Ethics Committee has approved this research, Ethics Approval: 24521

How can you help?

If you agree to take part, I will be asking year 5 to 8 students at your school to partake in a survey. Questions will be asked relating to their attitudes, behaviour intentions, perceived control, influences and environmental concern. The survey will be done in class time, taking approximately 15 minutes. Students will have the choice of opting out of doing the survey and consent will be gained from their parents. By completing the survey, students will be giving their consent.

What will happen to the information you give?

The information that the students give will be confidential. The survey will not ask for student's names so that their identity will not be disclosed in any reports, presentations, or public documentation. The completed surveys will remain in a locked filing cabinet and will be destroyed one year after the research has finished. 
What will the project produce?

The information from my research will be used in my Masters thesis.

If you have any questions or problems, who can you contact?

If you have any questions, either now or in the future, please feel free to contact either:

Student:

Name: Ria Goble

University email address:

ria.goble@vuw.ac.nz

\section{Supervisor:}

Name: Dr. Wokje Abrahamse

Role: Senior Lecturer

School: Geography, Environment and Earth Sciences

Phone: 044635217

wokje.abrahamse@vuw.ac.nz

\section{Human Ethics Committee information}

If you have any concerns about the ethical conduct of the research you may contact the Victoria University HEC Convener: Associate Professor Susan Corbett. Email susan.corbett@vuw.ac.nz or telephone $+64-4-4635480$. 


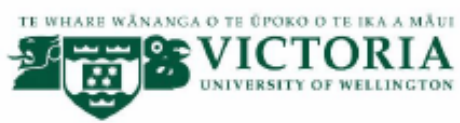

\section{The relationship between environmental attitudes and behaviour intentions among children: a study of the Enviroschools programme}

\section{CONSENT FORM}

Researcher: Ria Goble, School of Geography, Environment and Earth Sciences, Victoria University of Wellington

My child and I have been given and understand the explanation of this research project. We have had an opportunity to ask questions and have them answered to our satisfaction via the contact information provided on the information sheet. I understand that by signing this consent form I am giving my child permission to participate in this research under the condition that on the day of the survey they too agree with participating in the research.

My child and I understand that any information they provide will be kept confidential to the researcher, the supervisor, and the Enviroschools programme staff. This study may be published, presented at conferences or by Enviroschools on their website. We understand that the published results will not use my child's name, and that the results of the study will not be attributed to them in any way that will identify them. We understand that the primary material such as the original survey will be kept safe, locked in a filing drawer.

Your child's teacher will be provided with a copy of the class results of the research when it is completed, however, please tick this box if you would like to receive a personal summary of the class results.

If you have indicated that you would like to be sent this document, please provide your contact details below. If you do not have an email address or would prefer a posted copy, please input your postal address instead.

Email address:

I fully understand the information presented on this document. I agree to my child's participation in this research consisting of a survey on the condition that they too give their consent to participating in this research on the day.

Signature of parent or legal guardian:

Date: 
The relationship between environmental attitudes and behaviour intentions among children: a study of the Enviroschools programme

Dear Sir / Madam,

\section{CONSENT FORM}

My name is Ria Goble and I am an Environmental Studies Masters student from Victoria University of Wellington. As part of my Master's degree, I am undertaking a research project examining the relationship between environmental attitudes and behaviour intentions among children. I will be trying to identify ways in which the environmental education programme, Enviroschools, is successful in fostering these attitudes and intentions in children.

Results from the class survey as well as one or two interviews with teachers (conducted by me) will be the foundation of this study. Any of the information that the students or teachers provide will be confidential. Teachers or student's names will not obtained and therefore no results of the study can be attributed to the teacher/student in any way that will identify them.

In accordance with the Victoria University Human Ethics Committee, I request confirmation from you, the teacher that your class is willing to participate in this study. Separate information and consent forms will be given to students and parents.

More information on this study is available on the information sheet, or you can contact me via email.

Kind regards,

Ria Goble

Email: ria.goble@vuw.ac.nz

\section{PLEASE SIGN HERE}

As a teacher of this school, I consent for Miss Ria Goble to conduct her research with willing students in my classroom.

School Name Date

Teacher's Name

Teacher's Signature 


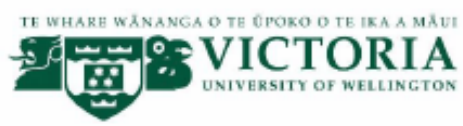

The relationship between environmental attitudes and behaviour intentions among children: a study of the Enviroschools programme

\section{CONSENT FORM}

\section{Dear Sir / Madam,}

My name is Ria Goble and I am an Environmental Studies Masters student from Victoria University of Wellington. As part of my Master's degree, I am undertaking a research project examining the relationship between environmental attitudes and behaviour intentions among children. I will be trying to identify ways in which the environmental education programme, Enviroschools, is successful in fostering these attitudes and intentions in children.

Results from the class survey as well as one or two interviews with teachers (conducted by me) will be the foundation of this study. Any of the information that the students or teachers provide will be confidential. Teachers or student's names will not obtained and therefore no results of the study can be attributed to the teacher or student in any way that will identify them.

In accordance with the Victoria University Human Ethics Committee, I request confirmation from you, the Principal or acting Director that the school is willing to participate in this study. Separate information and consent forms will be given to teachers, students and parents.

More information on this study is available on the information sheet, or you can contact me via email.

Kind regards,

Ria Goble

Enail: ria.goble@vuw.ac.nz

\section{PLEASE SIGN HERE}

As Principal of this school, I consent for Miss Ria Goble to conduct her research with the willing participants of the students of this school.

School Name

Date

Principal Name

Principal Signature 